Florida International University FIU Digital Commons

FIU Electronic Theses and Dissertations

University Graduate School

11-13-2015

\title{
The Linguistic Market of Codeswitching in U.S. Latino Literature
}

Marilyn Zeledon

Florida International University, marilynzeledon@comcast.net

DOI: 10.25148 /etd.FIDC000191

Follow this and additional works at: https://digitalcommons.fiu.edu/etd

Part of the Ethnic Studies Commons, Latina/o Studies Commons, and the Literature in English, North America, Ethnic and Cultural Minority Commons

\section{Recommended Citation}

Zeledon, Marilyn, "The Linguistic Market of Codeswitching in U.S. Latino Literature" (2015). FIU Electronic Theses and Dissertations. 2295.

https://digitalcommons.fiu.edu/etd/2295

This work is brought to you for free and open access by the University Graduate School at FIU Digital Commons. It has been accepted for inclusion in FIU Electronic Theses and Dissertations by an authorized administrator of FIU Digital Commons. For more information, please contact dcc@fiu.edu. 
FLORIDA INTERNATIONAL UNIVERSITY

Miami, Florida

\section{THE LINGUISTIC MARKET OF CODESWITCHING IN}

\section{U.S. LATINO LITERATURE}

A dissertation submitted in partial fulfillment of

the requirements for the degree of

DOCTOR OF PHILOSOPHY

in

SPANISH

by

Marilyn Zeledón

2015 
To: Dean John Stack

School of International and Public Affairs

This dissertation, written by Marilyn Zeledón, and entitled The Linguistic Market of Codeswitching in U.S. Latino Literature, having been approved in respect to style and intellectual content, is referred to you for judgment.

We have read this dissertation and recommend that it be approved.

$\begin{array}{r}\hline \text { Asunción Gómez } \\ \hline \text { Phillip Carter } \\ \hline \text { Erik Camayd-Freixas, Co-Major Professor }\end{array}$

Date of Defense: November 13, 2015

The dissertation of Marilyn Zeledón is approved.

$\begin{array}{r}\text { Dean John Stack } \\ \text { School of International and Public Affairs } \\ \hline \begin{array}{r}\text { Dean Lakshmi N. Reddi } \\ \text { University Graduate School }\end{array}\end{array}$

Florida International University, 2015 


\section{DEDICATION}

I dedicate this thesis to my husband Diego for his constant words of support and encouragement. Thank you for your patience. I couldn't have done it without you. I also

dedicate this thesis to my children Álvaro and Juan Diego; you were the source of my inspiration. 


\section{ACKNOWLEDGMENT}

I would like to thank the members of my committee for their continued guidance during this project. I am particularly grateful to my Major Professor for his firm direction and for his confidence in my ability to complete this project. I am also very grateful to all the members of the Department of Modern Languages for their support, and for the opportunity to develop and teach courses as a Teaching Assistant. 


\title{
ABSTRACT OF THE DISSERTATION \\ THE LINGUISTIC MARKET OF CODESWITCHING \\ IN U.S. LATINO LITERATURE
}

\author{
By \\ Marilyn Zeledón \\ Florida International University, 2015 \\ Miami, Florida \\ Professor Erik Camayd-Freixas, Co-Major Professor \\ Professor Melissa Baralt, Co-Major Professor
}

This dissertation is a multidisciplinary study that brings together the fields of literature, sociolinguistics, and cultural studies in order to understand the motivation and meaning of English-Spanish codeswitching or language alternation in Latino literature produced in the United States. Codeswitching was first introduced in Latino literature around the time of the Chicano Movement in the 1970s and has been used as a distinctive feature of Latino literary works to this day. By doing a close linguistic analysis of narratives by four different authors belonging to the largest Latino communities in the country (Chicano, Puerto Ricans, Dominican Americans, and Cuban Americans), this study examines whether codeswitching is used as a mere decorative element to add ethnic flavor, performs a mimetic role of oral codeswitching, or responds to a political strategy.

To reach representative conclusions, the political, social, cultural, and linguistic backgrounds of each community are studied in order to establish commonalities or differences in the experiences of these immigrant communities in the United States and how these experiences inform their writing. Considering the negative views held by 
speakers of both English and Spanish regarding the use of oral codeswitching, the need to study its use in literature is compelling. To that end, I have adopted social, and sociolinguistic theories to identify whether codeswitching operates as linguistic and symbolic capital in Latino literature, which authors may profit from to advance a Latino agenda.

This work concludes that how codeswitching is used in Latino literature and the goals it ultimately achieves—if any—hinge on the positioning of the authors vis-à-vis hegemonic English monolingualism and their own experience as members of the Latino community to which they belong. Thus, the role of codeswitching may indeed be solely ornamental or ethnic or it may be a political one; that of expanding the space in which Latinos are allowed to operate.

The narratives studied include Rudolfo Anaya's Bless Me Ultima (1972), Esmeralda Santiago’s When I was Puerto Rican (1993), Cristina García’s Dreaming in Cuban (1992), and Junot Díaz’s The Brief Wondrous Life of Oscar Wao (2007). 
TABLE OF CONTENTS

CHAPTER

PAGE

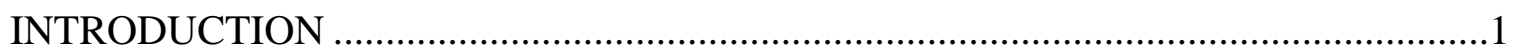

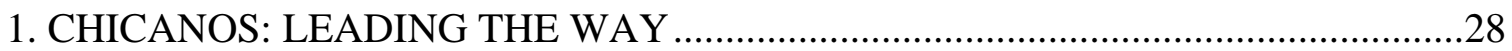

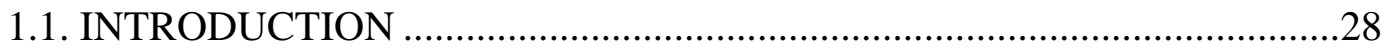

1.2. HISTORICAL OVERVIEW OF CHICANO LITERATURE.. ......................29

1.3. MEXICAN IMMIGRANTS, MEXICAN AMERICANS, AND CHICANOS .33

1.4. THE CHICANO RENAISSANCE ..............................................................36

1.5. CHICANO LITERATURE AS A POLITICAL ARM OF

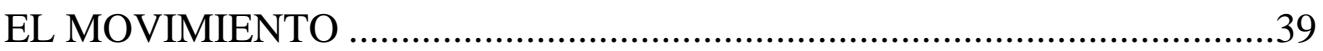

1.6. BLESS ME ULTIMA AND ITS PUBLICATION BY QUINTO SOL .........42

1.7. SUMMARY AND THEMES OF BLESS ME ULTIMA …….......................44

1.8. CODESWITCHING IN BLESS ME ULTIMA ………................................47

1.9. TYPOLOGY AND CLASSIFICATION OF CODESWITCHING IN

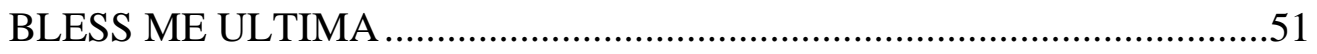

1.10. CODESWITCHING AS A LITERARY DEVICE IN BLESS ME

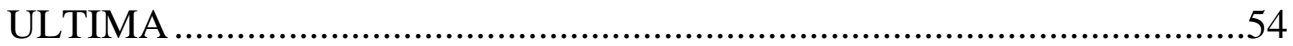

1.11. CODESWITCHING AS AN ELEMENT OF POWER IN BLESS ME ULTIMA

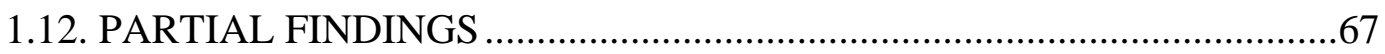

2. NUYORICANS: NEITHER HERE NOR THERE ………......................................70

2.1. INTRODUCTION .........................................................................

2.2. PUERTO RICANS, BORICUAS, NUYORICANS: HISTORICAL

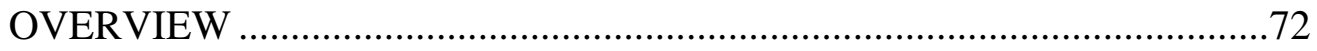

2.3. THE LANGUAGE OF NEW YORK PUERTO RICANS..............................79

2.4. HISTORICAL OVERVIEW OF NUYORICAN LITERATURE...................83

2.5. CODESWITCHING IN NUYORICAN LITERATURE ..............................88

2.6. WHEN I WAS PUERTO RICAN: SUMMARY AND THEMES ..................91

2.7. CODESWITCHING IN WHEN I WAS PUERTO RICAN ............................96

2.8. TYPOLOGY AND CLASSIFICATION OF CODESWITCHING IN WHEN I WAS PUERTO RICAN …….......................................................104

2.9. CODESWITCHING AS A LITERARY DEVICE IN WHEN I WAS

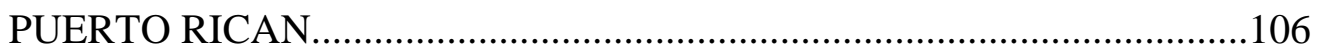

2.10. PARTIAL FINDINGS ..........................................................................109

3. THE CUBAN CONDITION: IMMIGRATION OR EXILE.........................................114

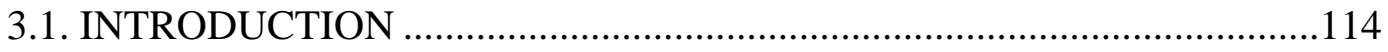

3.2. EXILE, DIASPORA, OR IMMIGRATION? ……………………….........116

3.3. THE LANGUAGE OF CUBAN AMERICANS ..........................................122

3.4. CUBAN-AMERICAN LITERATURE ......................................................126 
3.5. CODESWITCHING IN CUBAN-AMERICAN LITERATURE

3.6. SUMMARY AND THEMES OF DREAMING IN CUBAN .137

3.7. CODESWITCHING IN DREAMING IN CUBAN .141

3.8. TYPOLOGY AND CLASSIFICATION OF CODESWITCHING IN DREAMING IN CUBAN.

4. DOMINICAN AMERICANS: UN PIE AQUÍ Y EL OTRO ALLÁ .........................156

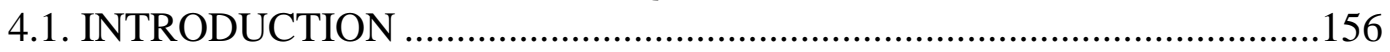

4.2. IMMIGRATION OF DOMINICANS TO THE UNITED STATES ............158

4.3. RACE AND IDENTITY OF DOMINICAN AMERICANS .......................162

4.4. THE LANGUAGE OF DOMINICAN AMERICANS ...............................169

4.5.DOMINICAN-AMERICAN LITERATURE ..............................................173

4.6. SUMMARY AND THEMES OF THE BRIEF WONDROUS LIFE OF

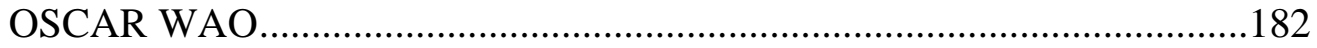

4.7. CODESWITCHING IN THE BRIEF WONDROUS LIFE OF OSCAR WAO

4.8. TYPOLOGY AND CLASSIFICATION OF CODESWITCHING IN THE BRIEF WONDROUS LIFE OF OSCAR WAO.

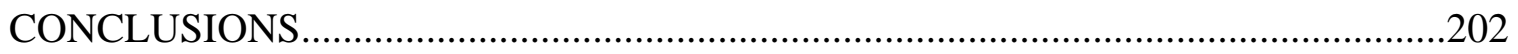

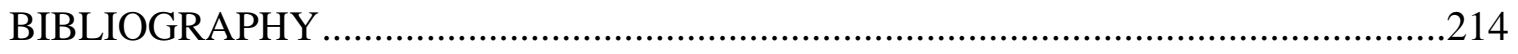

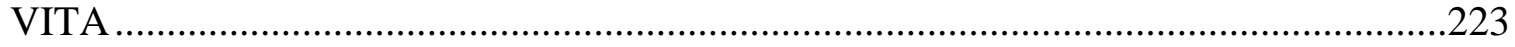




\section{INTRODUCTION}

Codeswitching or the alternation between English and Spanish within the same text has become the preferred writing mode for Latino writers in the United States. This research examines selected works by four major Latino authors: Rudolfo Anaya, Junot Díaz, Cristina García, and Esmeralda Santiago, who engage in different levels of codeswitching in their literary production. By following the works of these authors, this dissertation wishes to explore how, when, why, and by whom codeswitching is used in Latino literature and whether this writing practice has any political significance for a Latino agenda. The texts selected for this research are all prose fiction written between 1972 and 2007 and published in the United States.

The use of English-Spanish codeswitching in oral form is characteristic of many members of the Latino community in the United States in their daily oral communication. John Gumperz, one of the leading experts and first theorists of codeswitching defines the phenomenon as "the juxtaposition within the same speech exchange of passages of speech belonging to two different grammatical systems or subsystems” (59). Later studies have turned to a more social approach from the field of sociolinguistics that views codeswitching in context and vested with symbolic value (Myers-Scotton, Heller, Milroy and Muysken, Woolard), a notion this dissertation wishes to adopt, as opposed to a formal or structural approach—why rather than how codeswitching takes place. Also, these sociolinguistic approaches hinge on the notions of language use as capital (power), previously developed by Pierre Bourdieu, in the realm of cultural studies.

Despite its widespread use in oral communication, codeswitching is far less common in written form, especially in literature. Codeswitching-referred to by many in 
a derogatory manner as Spanglish or Tex-Mex-is not often used in formal written communication due to the permanency of the text and its negative associations and high stigmatization as a sub-standard language. In other words, engaging in codeswitching at the oral level is more permissible because of the spontaneity of the speech act which may justify its use; whereas writing is considered a more formal and premeditated medium. Despite this agreed-upon social norm, Latino writers are increasingly engaging in codeswitching in their literary productions - a fact that deserves a long overdue study and is the goal of this dissertation.

Codeswitching has seldom been studied from the perspective of literature (Azevedo 1991, Bürki 2003, Callahan 2002, 2004, Gumperz 1998, Keller 1979, Lipski 1982, Mendieta-Lombardo and Cintrón 1995, Nuessel 2000, Rudin 1996, Valdés Fallis 1977). There have been some studies of English-Spanish codeswitching in Chicano poetry and theater, but these fall short when applied to narratives given the distinct natures of these genres. Theater allegedly reproduces actual speech and poetry has always enjoyed linguistic licenses not only in alternating languages but also in flouting grammar rules; both of which fall outside the scope of the present study.

Although the authors chosen for this study may or may not be fully bilingual, their literary production is not considered bilingual in the sense that they do not use the two languages in equal proportions. Bilingual literature does exist not only in contact zones and in contemporary literature, but also has existed in other places and times. ${ }^{1}$ However, bilingual literature falls outside the scope of this research as it is considered to

${ }^{1}$ Other authors who have used bilingualism in literature include Franz Kafka, James Joyce, T.S. Elliot, José María Arguedas, Julio Cortázar, Ernest Hemingway, among other writers. Codeswitching has also been practiced in literature in other language combinations such as Russian, Flemish and Dutch literature. 
be regulated by different motivations. Some L2 (a second language) competence is required to successfully codeswitch in writing, but given its premeditation, it is uncertain how much. For oral codeswitching, a higher level of bilingualism is required. It is possible to conclude that all authors under research do have some degree of bilingualism that allows them to codeswitch. Their level of bilingualism is uncertain from the texts but also irrelevant, as the individual analysis will show.

\section{AIM AND CONTRIBUTIONS OF THIS STUDY}

This study brings together the fields of sociolinguistics, literature, and cultural studies by examining the types and uses of codeswitching in U.S.-based Latino literature. From the sociolinguistic analytical view, it reviews the different approaches to codeswitching in a formal sense, the varying degrees to which this mode is used, and the typology of codeswitching by each author. From a literary viewpoint, this study analyzes the use of codeswitching as a medium of composition in these works for the creation of characters, and as a rhetorical device for the creation of plot, theme, voice, language of intimacy, comical effect, and other literary functions, including its aesthetic role. Finally, from a cultural and social perspective, this research examines how or whether the works of these and other Latino codeswitchers have contributed to the affirmation of the Latino community, to the legitimization of its literature, or to its consolidation as a political and ethnic force, and — by extension— to a greater presence and tolerance of Spanish in the United States. Thus, this study will follow an interdisciplinary approach to exploring the use of codeswitching as a literary and pragmatic device. Bringing these fields together will provide a larger picture of the current state of affairs of Latino literature in the United States, and the role of codeswitching, if any. This combination of fields presents 
the challenge of requiring two distinct approaches to the same works: a literary one following a humanistic approach, and a linguistic one, following a cognitive/technical approach. The former will rely on traditional literary, critical analysis and theory, while the latter will rely on statistical and empirical sociolinguistic analyses that can provide quantitative data, which can then be translated into meaningful conclusions as to the use of codeswitching.

The contributions of this research to the current study of Latino literature in the United States are, among others, the identification of how codeswitching is used in Latino literature; what has been the impact of such use on the readership; and how instrumental it has been in the legitimization of Latino literature for the advancement of a Latino agenda. Other answers sought by this research include: Is there a pattern or has there been a progressive escalation in the use of codeswitching in Latino literature? Linguistically, what types of codeswitching take place in these texts? How, why, when and by whom is it used? Is it merely a mimetic representation of oral speech? Is codeswitching spontaneous or is it deliberately implanted in Latino literature? Is it unavoidable in such culture-filled literature? What is gained or lost, if anything, by the use of codeswitching in Latino literature? Is there a political agenda tied to codeswitching? Is Latino literature one of opposition to mainstream literature? How does it impact the issue of identity of the members of the Latino community? How is codeswitching viewed by Anglos or other Hispanics/Latinos (monolingual or bilingual readers)? What is the role of the publishing industry in the advancement of Latino literature in the United States? Is Latino literature mostly produced for/read by Latino readers? 


\section{AUTHORS AND WORKS INCLUDED IN THIS STUDY}

Before attempting to tackle these questions, it becomes essential to establish the relationship_-if any_among the writers selected for this research, and what binds them together considering their diverse national backgrounds. Although they could all be classified as Latino writers under a general label, more specifically, Anaya is Chicano, Santiago is Nuyorican, Díaz is Dominican American, and García is Cuban American. This distinction is paramount as each national group can be identified with its own agenda in addition to the distinct history of each of the national groups represented by these authors, and their relationship vis-à-vis the United States. It is expected that this sampling can provide a meaningful picture of the current status of Latino literature in the United States as they represent not only different geographical regions in the country but also some of the largest Latino communities. The works also span thirty-five years, which allows for a diachronic analysis of codeswitching.

One particular narrative by each author has been selected: Rudolfo Anaya’s Bless Me Ultima (1972), Esmeralda Santiago’s When I Was Puerto Rican (1993), Cristina García’s Dreaming in Cuban (1992), and Junot Díaz’s The Brief Wondrous Life of Oscar Wao (2007). The works selected are among the best-known Latino narratives and have become must-reads for any study of Latino literature.

\section{ORGANIZATION AND METHODOLOGY OF THIS STUDY}

In order to meet the goal outlined above, the present dissertation is organized as follows: In this introduction, I begin with an explanation of the key concepts, terminology, and theories underpinning this study regarding codeswitching. Then, I provide a background and some history on the use of codeswitching in Latino literature. 
Following this introduction, a chapter is devoted to a novel by each of the authors, to end with a conclusion.

Before turning to the study of the narratives, each chapter will explore the historical background of each national group represented by each author in order to understand the motivations for immigration of that community and thus have the necessary context before exploring the literary works. Then, the linguistic situation of each community will be addressed in order to explore whether there are differences in the codeswitching practices of each group and the reasons for such difference to see if they are mirrored in their literature. Each chapter will provide a summary of the literature produced by each group in order to situate the particular literary work in the context of Latino literature in the United States. Then, more specifically, each chapter will closely analyze, classify, and quantify the codeswitching tokens according to linguistic categories in order to have an objective and quantitative tool that can be used to make comparisons among the texts and draw conclusions about the significance of codeswitching for each novel.

\section{CHICANO, HISPANIC OR LATINO}

Given that the topic of this research is the literature produced by members of the ethnic group commonly referred to as Hispanic or Latino and Chicano, the clarification of such labels is a must. The debate of whether there is a difference between Hispanic and Latino is a heated one but I have sided with the term Latino because of its greater inclusiveness, and will be using it in this study. For example, as explained by Suzanne Oboler, the term Latino is to some an ethnic designator, which began to emerge among grassroot sectors of the population and was coined as a progressive alternative to the 
state-imposed bureaucratic label Hispanic (viii), which denotes more acceptability. However, it is unclear from the research whether the term is accepted by all the members of the community. Also, there seems to be a regional difference in the perception of these labels across the United States probably due to individual experiences and identities: Hispanic on the East Coast and Latino on the West Coast. Even if these terms have been imposed on this community by the media, the government, and other Americans, they are not categorically rejected either. For Ilan Stavans, the term Hispanic "became a commodity in government documents and the media. It describes people on the basis of their cultural and verbal heritage," whereas Latino "has become the option, a sign of rebellion, the choice of intellectuals and artists, because it emerges from within this ethnic group and because its etymology simultaneously denounces Anglo and Iberian oppression” (25). Gloria Anzaldúa, a Chicana writer, refers to the label of Hispanic as "a term designated by the U.S. government to make it easier to handle us on paper” (119). If asked, most Latinos will first identify themselves by their country of origin and secondly as Latinos (Caminero 2), whether they are blacks, mestizos or mulattos. In any case, it is clear that the choice of Hispanic or Latino is rather an imposition than a choice. It is only upon entering U.S. territory that these labels become relevant or are first heard by the now members of such community, hence the reluctance to adopt either one.

In the United States, people are customarily asked for their ethnicity or racial identity on government, work, or school forms in which the category of Hispanic or Latino is equated to that of African Americans, Native Americans or White, among other racial categories. The U.S. Census Bureau has been using the term Hispanic as an ethnic classification since 1980. Despite its attempts to refrain from labeling it as a race, it is 
treated and perceived as "an effectively homogenized minority population comparable to African Americans” (Burrows 33). Latinos have learned—and continue to learn—to live with such a classification method. However inaccurate these terms are and despite the disagreements, the term Latino does seem to represent closely enough all persons of a Latin American background or ancestry, regardless of their permanence in the United States, their immigration status, their place of birth, or the degree to which they speak Spanish. The four authors selected for the present research project fit in this classification.

This research argues that the notion of a Latino ethnicity or identity is an artificial one, imposed on Latin American immigrants and their descendants. By definition, ethnicity is "belonging and being perceived by others as belonging to an ethnic group" (Sollors xiii). Ethnicity is now commonly identified as a social construct, or in terms of Benedict Anderson: "an imagined community," and I would add, a gradual construct, from the inside and outside, by members of the community themselves and by others. When they first arrive in the United States most immigrants do not automatically insert themselves in their ethnic community. It is a gradual process fueled by feelings of alienation as they attempt vainly to enter the mainstream or as they fail to assimilate when facing inequalities and discrimination. Hence, the immigrant community is forced to invent, promote, and reinforce a space in which it can operate: an ethnicity. This ethnicity transcends skin color, dialectal variation of their language, country of origin, etc., among other national identifiers. Thus, despite the diversity in countries of origin, Latino ethnicity is fueled by, among other elements, the cultural production attributed to such group, including literature. Not every immigrant or immigrant-descendent wishes to 
become part of such group. The degree to which they actually embrace their ethnicity varies greatly, depending on their desire-and success—in assimilating into the host culture. Sollors claims that "assimilation is the foe of ethnicity" (xiv). Ethnicity, as opposed to the concept of nation, does not rely on flags or anthems, but on a set of elements that are common to all who wish to partake in it. Sollors further argues that ethnicity "may be shared far beyond the boundaries within which it is claimed. It marks an acquired modern sense of belonging that replaces visible, concrete communities whose kinship symbolism ethnicity may yet mobilize in order to appear more natural” (xiv). It is these feelings of being caught between two cultures and two languages that have fostered the production of Latino literature-what Sollor labels "collective fictions"-which are the focus of this dissertation.

The term Chicano is not free from controversy either. By Chicanos it is meant the people from the American South West of Mexican descent, whose ancestors inhabited the region before the Mexican-American War of 1846-1848, when it was Mexican territory. It is unclear whether the term Chicano is extended to—or embraced by—other Mexican Americans or Mexicans who have immigrated later to the United States. Juan BruceNovoa, a renowned Chicano scholar, defines it succinctly to include all Mexicans living permanently in the United States (73). It does not tell us anything about identity, however. For Sonja Burrows, Chicano is a term that in addition to commonly describing native-born U.S. citizens of Mexican ancestry, is a "positive self-identifying social construction” (38), but this was not always the case.

The origin of the term Chicano is uncertain. Some critics claim it is a shortened version of "Mexicano" as spoken in its original Nahualt. The first uses of the term are 
also unclear. Pejorative at first, and used to refer to recently arrived or poor Mexican immigrants, it became widely spread as a self-identifier during the 1960s Mexican activism movement, which ran parallel to—and was strongly influenced by—the Black Civil Rights struggle of the time. According to Novoa, the Chicano movement "attempted to imitate the pattern of community unity through racial identity and opposition to the predominantly white social structure Blacks were successfully presenting to the country" (126). Since then, the term Chicano has acquired political connotations, to the degree that one of its great exponents, Sabine Ulibarrí, once denied being a Chicano because of the political charge attributed to Chicanismo (Duke Dos Santos and De La Fuente 28). The Chicano movement of the 1960s "embodied the effort to overturn the dire conditions existing within the Chicano communities during the postwar period” (Stavans 8).

In 1965, through the National Farm Workers Association, César Chávez led Chicanos to labor strike advocating resistance to discrimination and better working conditions. This farmworkers' group later became the Chicano civil-rights movement, which gave the term Chicano its political connotations. Hence there is a distinction from that of Latinos, which is a less politically-charged term, not because the conditions do not warrant a movement of opposition for Latinos but because of the different times in which they have developed, and the less homogenized nature of Latinos (i.e., coming from different countries). Both Chicanos and other Latinos have had to (or are trying to) regain the space that ancestors of these communities occupied centuries ago. This study will be using the term Latino to refer to all individuals of Latin American descent regardless of the country of origin and length of permanence in the United States. 


\section{THEORETICAL APPROACHES TO CODESWITCHING}

This study follows a descriptive (as opposed to a prescriptive) approach to codeswitching, understanding such phenomenon as a natural consequence of speech by individuals living in border regions or contact zones, where "languages are in contact in the sense they are adjacent in their speakers' mental lexicon and can impinge on each other in production" (Myers-Scotton, Contact 5). Its use in narrative reflects a generalized use in speech characteristic of people living in two cultural realities. In addition to this mimetic use that constitutes the "excuse" to insert codeswitching in literature, I side with those theorists who argue that codeswitching is a linguistic strategy (Gumperz, Myers-Scotton, Callahan) deliberately used by authors with several other purposes, but more specifically with Monica Heller's view that codeswitching is also a political strategy. To study the use of codeswitching, this research seeks to combine both a technical or structural framework from sociolinguistics, and a pragmatic and social point of view from the field of cultural studies, and more specifically the theories of Pierre Bourdieu, which shall ground the study socially. The conclusions drawn from the linguistic analysis will be transferred to the literary and cultural spheres for a broader and farther-reaching understanding of the sociopolitical implications of codeswitching.

At this point, it is necessary to further refine the definition of codeswitching offered above that will be used in this study, as not every language alternation found in these narratives constitutes codeswitching in a strictly technical sense. In fact, some of the language alternation practiced by many Latino authors can be easily dismissed as codeswitching by some theorists, and be classified as simply word loan or borrowing. Hence, it is important to distinguish among these terms, including "language mixing." 
For Gumperz, "Borrowing can be defined as the introduction of single words or short, frozen, idiomatic phrases from one variety into the other" (66), borrowing does not make any assumptions about the bilingual nature of the speaker or the context in which he/she is writing. In other words, borrowing can occur outside contact zones, and it is mostly lexical items, whereas codeswitching "relies on the meaningful juxtaposition of what speakers must consciously or subconsciously process as strings formed according to the internal rules of two distinct grammatical systems” (Gumperz 66). Another term, language mixing, "implies the creation of an entirely new entity and the disappearance of both constituents” (Myers-Scotton, Contact 3), suggesting that it is not systematically organized, as codeswitching is. This distinction is important; in many instances, the switches in the narratives do fall into the category of word loan or language mixing.

Distinguishing word borrowing from codeswitching is challenging even for experts, since phonological factors may play a role, which are not obvious in writing. It is not frequent to find indications in the text of how codeswitched material is pronounced. Just as there is disagreement among linguists regarding the boundary between word borrowing and codeswitching, the required extension of the phrase to be classified as one or the other is not clear either. However, for the purposes of this study, word borrowing, language mixing, and codeswitching, although distinct, can have the same literary and political effect. Therefore, an exact distinction or characterization is not absolutely essential. Word loan, if pervasive, can also represent a political stance or footing (i.e., positioning of an individual in an interaction) as codeswitching. A typological analysis will reveal if that is the case. This research is trying to establish the value of the use of 
codeswitching by Latino authors, not whether their use of foreign content fits the strict definition of codeswitching.

Following the classification offered by Myers-Sotton, one of the most important distinctions that will be made in the analysis of the texts is whether the switches that consist of lexical items represent "core" or "cultural” borrowings. The former is a switch that includes a lexical item for which there is a perfectly equivalent English term, and the latter is a switch that includes a lexical item that refers to a cultural object or concept for which the author has no other linguistic sign to use in the matrix language. ${ }^{2}$ In the context of Latino literature, cultural borrowings are the most acceptable form of codeswitching, even for English monolinguals, as it is obvious to the reader that the author does not have a choice due to the inexistence of an equivalent term. Thus, this distinction will be essential to understand the role of codeswitching in the texts.

Since this research will focus on written codeswitching, it is important to establish how it differs from oral codeswitching. The oral codeswitcher engages in codeswitching with a bilingual interlocutor or one he/she knows will understand his/her bilingual or codeswitching utterance. It would be unlikely for an individual to initiate a conversation using codeswitching without knowing whether his/her interlocutor would be able to understand. That would be against the "cooperative principle” proposed by Grice, which requires the speaker to “execute his performance with reasonable dispatch” (Wardhaugh 290) in order to guarantee understanding. In writing, however, the codeswitcher does not know his/her audience or the degree to which readers will be able to understand the

\footnotetext{
${ }^{2}$ The "matrix" or dominant language (English) language provides the grammatical structure of the bilingual utterance and an "embedded" language (Spanish) supplies the content morphemes.
} 
codeswitched text. Furthermore, there is an inherent permanency associated with writing. Therefore, the audacious choice of the author to use codeswitching must respond to other factors, such as social and political ones: "Unlike verbal code switching, textual code switching, while still a process of bilingual language alternation, consciously aims at achieving a specific effect” (Burrows 92). According to Gumperz, bilinguals “do not use code switching before they know something about the listener's background and attitudes. To do otherwise, would be to risk serious misunderstandings" (68), which signals the intentionality of codeswitching in writing and to the multiple meanings of bilingual texts.

The texts under study, whose matrix language is English, exhibit different levels of codeswitching: from the sporadic use of isolated words to whole paragraphs of Spanish content. Codeswitching, originally thought of as random practice, has been determined to be grammatically governed. Shana Poplack states that "the basis for this conviction is the empirical observation that bilinguals tend to switch intra-sententially at certain (morpho)syntactic boundaries and not at others” (1). Codeswitching is classified as inter-sentential (alternation of languages between sentences); intra-sentential (alternation within the sentence); and tag switching (using a tag in the other language at the end or beginning of the sentence). Experts focus on intra-sentential codeswitching, where it is seen really at work. For some theorists, inter-sentential and tag switching do not represent real codeswitching. Much of the Spanish switches in the works under study appears in the form of inter-sentential and tag switching. As stated above, the precise classification of codeswitching is not essential for this discussion. For the purposes of this research, any language alternation will be counted as codeswitching. 
The premeditation and intentionality of codeswitching in writing, particularly in published works, are obvious, and do not seem to be "a reflection of internal, subconscious mechanisms of bilingual expression” (Lipski, Spanish-English 192) as oral codeswitching is. Therefore, whether the authors engage in codeswitching themselves in their daily lives is irrelevant, as it is unlikely that their literary production be a reflection of their own oral speech. Hence, the use of codeswitching must respond to other motivations, which this study wishes to unveil. In the chapters that follow, a more detailed analysis of the typology of codeswitching in each on the literary works will reveal the extent to which codeswitching responds to filling cultural gaps, serves as a decorative or exotic use of language, as "stylistic embroidery" (in terms of Valdés-Fallis), is used for "foregrounding," or represents the actual speech of Latino speakers. ${ }^{3}$ I argue that it does all of the above but it may vary by author.

This study does not make a judgment as to the adequacy of codeswitching, but it does assume that Spanish is in a diglossic relationship with English in the United States; that is, Spanish and English are not on an equal footing. English is legitimized and supported by the state and its institutions, and it is the dominant code, whereas Spanish is the language of a minority, often relegated to household use, subordinate to English, and enjoying considerably less or no institutional support, even though it is spoken by over 35 million people in the United States and was spoken in present U.S. territory centuries before English was.

\footnotetext{
${ }^{3}$ Foregrounding is a literary strategy to use text to call the reader's attention to how something is said vs. what is said.
} 
Diglossia "refers to the rather strict and complementary allocation of the [linguistic] varieties in a community’s repertoire to different domains” (Myers-Scotton, Contact 49). Professional writing falls in the formal domain in which English is expected. Callahan notes that "since languages do not exist apart from their speakers, it follows that speakers of less-valued codes will lack the privileges associated with competence in the language of higher prestige” (139). Thus, the use of Spanish in these narratives is even more meaningful, particularly if we consider that when codeswitching was first used in literature or poetry (around 1959) the Hispanic population was much smaller. As a result, authors have used different methods to make sure that their texts can be understood by the English monolingual reader. Ernst Rudin, in his study of Spanish in the Chicano novel cites three methods to make Spanish accessible: providing a literal translation, a non-literal translation, and contextual translation (124). Whether or not the author provides translation, contextualization or glossing for the Spanish content will reveal what his/her stance on the use of codeswitching is.

\section{CODESWITCHING AS SYMBOLIC VALUE}

An underlying premise of this dissertation is that language does not merely communicate and when it is not communicating it must be performing something else; such is the case when using codeswitching in literature in a monolingual context. That “something else," I argue —in addition to performing a role as a symbol of group identity and solidarity—is conquering territory; a political move exploited by some Latino authors. The degree to which they can codeswitch, I argue, depends on their status in the “linguistic market” (Bourdieu’s term). Anyone can codeswitch socially with peers (i.e., other bilinguals) at the oral level, but not everyone can afford to codeswitch in writing; 
thus equating language use to power. The intensity of codeswitching in writing is directly proportional to the "linguistic capital" (or power) of the author. As we will see below, literary works in which codeswitching is present are not exclusively read by a bilingual readership. The higher the author's status or recognition is (i.e., linguistic capital), the more drastic and radical his/her codeswitching is. This approach of codeswitching as "performative" (J.L. Austin's term) is in line with Pierre Bourdieu's notions of a linguistic market according to which: "There is a linguistic market whenever someone produces an utterance for receivers capable of assessing it, evaluating it and setting a price on it” (Sociology 79). Bourdieu's theories in the cultural and social realm are in the background of more sociolinguistic ones (Carol Myers-Scotton, Monica Heller), which I wish to adopt to explain the codeswitching as used in the narratives in question. Also borrowing Bourdieu's marketplace metaphor, Heller claims that: "Code-switching becomes available as a resource for the exercise of, or resistance to, power by virtue of its place in the repertoires of individual speakers, on the one hand, and of its position with respect to other forms of language practices in circulation, on the other" (Code-switching 159).

Despite the several diverging approaches to codeswitching, it has long been accepted that it is a communication strategy used to convey meaning, to establish complicity or solidarity between the speakers (or between writer/narrator and reader), or used as a "contextualization cue” as originally proposed by Gumperz (1982), which can very well be applied to written codeswitching. Myers-Scotton sees the use of codeswitching "as a way to optimize rewards," and as a negotiation of power. However, "there is no guarantee that switching codes accomplishes a speaker’s goals" (Contact 46), 
as the intention of the speaker (writer) might not have the expected result on the hearer (or reader). In the same line, Bourdieu claims that language "is not only an instrument of communication or even knowledge, but also an instrument of power” (The Economics 648), as language does not exist in isolation but in relation to its context. He further defines this linguistic market by saying that "Every interaction, every linguistic communication, even between two people, two friends, boy and girl, all linguistic interactions, are in a sense micro-markets which always remain dominated by the overall structures” (Sociology 80). Carla Jonsson also defines codeswitching as a "resource to resist power and/or exercise power” (212).

Codeswitching can be viewed, used, and perceived as a means to empower readers (and obviously, writers) of Latino literature, to expand the territory gained by Latinos as a political and cultural force, and to challenge the hegemony of the English language, or the "English only" movement. ${ }^{4}$ Authors have an implicit censorship on the code they write in, if they wish to succeed as writers in mainstream America, which requires them to write in the standard code (i.e., English). Writers, as well as educators, have been vested with a tacit authority to preserve and protect the language of the market in which they operate. Writers, and literary works in general, are used as sources of reference for language correctness as they are considered to be "grammar-abiding" individuals. The political stance of writers who engage in codeswitching in their literary production cannot be emphasized enough. Myers-Scotton writes that a "marked” choice

\footnotetext{
${ }^{4}$ As of the date of this publication, the English-only legislation has been adopted by 31 states, according to the movement's website: www.us-english.org.
} 
"when unmarked choices exist (as they do in conventionalized exchanges) rocks the social boat” (Self-enhancing 202).

The theory behind this is the markedness model—considered the most influential and most fully developed model to explain the motivations of codeswitching-developed by Carol Myers-Scotton, which will be used to explain the value of codeswitching in the linguistic market. The markedness model argues that all speakers have a "markedness metric," an innate internalized model which enables them to recognize that all code choices are more or less "unmarked" or "marked." "Unmarked" is used to mean that the choice of a particular linguistic variety is expected as the medium for a talk exchange, given the norms of the society regarding the salience of specific situational factors present [...]. "Marked" choices are at the other end of the continuum; they are not usual, and in some sense they are disidentifications with what is expected. (Social Motivations 151)

The markedness model is also based on the assumption of a set of rights and obligations (RO) between participants in a given interaction type (Myers-Scotton, Social Motivations 84). Such ROs are derived from what is customary in the community, but they are not the same for every interaction. Codeswitching might be the "unmarked" (expected) choice for certain Latino communities, but not for the larger readership of their literature. There is no doubt that codeswitching is viewed as a "marked" (unexpected) choice and "speakers also know the consequences of making marked or unexpected choices” (Myers-Scotton, Social Motivations 75). I have adopted MyersScotton's markedness model because it implies premeditation in the use of 
codeswitching, as opposed to other theories that may analyze codeswitching as a spontaneous utterance and only in connection to its immediate consequences. In the case of written codeswitching, premeditation and intention are less debatable, and its consequences are further-reaching.

It will be evident from the analysis of the works in the following chapters that codeswitching is at times unjustified, meaning that an accurate English word or sentence could have been used (“core borrowings”). The role such borrowings perform goes beyond communication. Bourdieu claims that utterances are rarely exclusively used as a pure instrument of communication. These utterances perform, what he calls "symbolic profit” (Language 67). Borrowing the terminology from economics, Bourdieu claims that there are hierarchies among speakers in the "market" (space in which speech acts take place). Those ranked higher in the hierarchy possess "linguistic capital," which they are able to exploit given their advantageous position. As anticipated by Myers-Scotton: "Certain groups of speakers, such as those who have statusful positions, are predicted to make more marked choices than other groups" (Self-enhacing 200). The authors in this study possess varying amounts of linguistic capital according to their particular conditions at the time of their writing. How much codeswitching their linguistic capital can "purchase” will be addressed individually in each chapter.

While some may claim that the role of codeswitching is merely decorative, which this research does not deny, the implications of codeswitching outside the text are more compelling than that. The use of codeswitching as an exotic element falls within the text, at the surface level only. It is indeed performing a decorative function at a superficial level. The monolingual reader may even find that certain uses of codeswitching are 
necessary, but when they are not, the political intention of the text is clear. As mentioned earlier, codeswitching is regarded by most non-experts as a deficient command of the language, which is not likely to reflect the author's own language or mode of communication, or one he/she would want to project for him/herself. If codeswitching is considered substandard, why should an author wish to make this feature salient in his/her writing? In connection to codeswitching in Chicano culture, Gumperz explains how attitudes toward codeswitching may change as political ideologies change. He refers specifically to California and the Southwest where pocho or caló served as a pejorative term for the Spanish of local Chicanos, "but with the awakening of ethnic consciousness and the growing pride in local folk traditions, these speech styles and the code switching they imply have become symbolic of Chicano ethnic values” (63). This implies that codeswitching may be accepted or tolerated when it is read as representing ethnic values.

By daring to codeswitch in their narratives, Some Latino authors are in a privileged position to advance the interests of a Latino agenda given their acquired status in the literary milieu; they possess "linguistic capital" which they are exploiting in their productions. In the chapters that follow we will ascertain whether this is the case for each author. Thus, codeswitching is being used as “symbolic capital.” By writing in an unexpected, marked or disdained code, authors can turn their choice of code into an asset. Callahan argues that "an author who uses Spanish/English codeswitching in the United States may not obtain financial gain, but may attain social and professional recognition for what is seen as an artistic innovation” (140). Some of these authors have taken up the challenge to adopt a code of communication that is rejected by mainstream publishers, English-only advocates, and even Spanish speakers with purist ideas about language, who 
would disapprove. However, as Myers-Scotton states: "users of marked choices will be those with status sufficiently high to allow them to take chances, and those so positioned that the possibility of achieving such status is real" (Social Motivations 141). This view is also supported by Callahan, who sees speakers as entrepreneurs and the sociolinguistic environment as a marketplace, and language exchanges as transactions, in which the "language user gets something in return: attention, money or power" (141). In addition to this personal gain, there is a benefit for the community as well. The author's choice of language, in addition to its implications, make it evident that codeswitching goes beyond its use as an instrument of communication, as it could even be considered an obstruction to communication with—or even a distancing from—a monolingual readership. "Access to the code used must not be universal; if it is, the user has no asset to exploit" (Callahan 141), hence my argument as to the value and intentionality of codeswitching.

The use of codeswitching in narratives seems to have entered the mainstream literary market and to have been accepted by readers, as the popularity of some of these authors demonstrates. They manage to still accommodate the monolingual English speaker at the same time that they invite and write about experiences that are appealing to Chicanos and Latinos. It is uncertain whether this trend will continue (i.e., more codeswitching or Spanish content in literature written in English). However, when compared to the first productions of Latino literature, there seems to be a gradual increment in codeswitching content where there was none before. This dissertation wishes to explore whether the above continues to be the case. 


\section{CODESWITCHING AS A LITERARY DEVICE}

Codeswitching has also been intensively used in Latino poetry and theater, which fall outside the scope of this study. Bilingual writing, such as that found in poetry, responds to a more spontaneous language hybridity than that found in narratives. In poetry, the bilingual voice is - presumably — that of the poet. It reflects his/her personal writing style, not that of a community. Bilingual writing responds more to the impossibility of the writer to choose one of the languages due to his/her bilingual nature and upbringing. Furthermore, using codeswitching in poetry for “decorative” purposes or because "it sounds better" bears more relevance due to the aesthetic dimension of poetry. Codeswitching, such as that found in the works subject to this research, is more premeditated and thus worthy of study. Fictional narratives provide a better medium to mirror the speech of a community given the multiplicity of voices they can present: heteroglossia, in Bakhtin’s terms.

Other Latino authors have engaged in an even more dynamic codeswitching-or language alternation - to the point of producing bilingual texts, such as Gloria Anzaldúa’s Borderlands/La Frontera, in which the bilingual and bicultural condition of the writer is explicitly the subject matter of her writing: "Because we speak with tongues of fire we are culturally crucified. Racially, culturally and linguistically somos huérfanos-we speak an orphan tongue” (80). Anzaldúa needs both codes to attempt to describe her experience living on the Borderlands. She does not create fiction; she is the narrator herself. Her bilingualism is a reflection of who she is. This is not the case in the narratives in this research, in which the bilingual/bicultural experience can be that of a fictional character or narrator, which may or may not reflect that of the author. 
In addition to premeditation and intentionality, what justifies codeswitching from a literary perspective—or at the level of the text—is the theme of the narratives. Callahan identifies three conditions, which warrant the use of codeswitching: The setting in which Spanish is the usual language; the characters, or narrator, are speakers of Spanish (or English/Spanish codeswitching); and the thematic content centers on social, political or cultural issues germane to the Latino community (36). The analysis of who engages in codeswitching and their purpose for it will reveal whether codeswitching in these novels is artificial or authentic - terms used by Callahan to the classification of written codeswitching. According to her,

for written codeswitching to be authentic it must be identical to the types of codeswitching heard in everyday speech, characters in whose dialogue it appears must represent members of a speech community in which codeswitching would be an unmarked mode of discourse, as the speech situation in which they codeswitch must be representative of one in which they would do so in real life. (99)

Then, there is the issue of the narrator, whose voice, it is assumed, would be one of a Latino. Callahan observes: "Codeswitching in the main narrative could be said to be an extension of this: the author's own sociolinguistic background predicts his or her use of codeswitching” (90). The expectation is that both, characters and narrator would engage in an authentic codeswitching as it is heard in everyday speech. Artificial codeswitching would be one that would not be likely to be heard in everyday speech, and which appears to be unnatural, forced, decorative, or one that "may not reflect a 
conversational exchange in which codeswitching could be attributed to a sociopragmatic function” (Callahan 100).

This research will also analyze the treatment of codeswitching within the text; that is, whether it is marked with a typographical distinction, such as a different typeface; or a translation/explanation/glossary is provided. The use of any of these techniques will help us discern how the author presents codeswitching to his/her audience. The classification in syntactical categories (single lexical items such as nouns, adjectives, verbs, adverbs, prepositions, conjunctions, and interjections, phrases or clauses) will also be crucial to understanding the motivation for codeswitching. The author's approach to codeswitching in each novel will also be useful in understanding what the effect on the reader might be and the assumptions made by the author as to who his/her audience is: the monolingual or bilingual reader, other members of the Latino community or Anglo readers.

\section{HISTORY OF CODESWITCHING IN LATINO LITERATURE}

The origins of codeswitching in Latino literature and those of Latino literature itself are the same; meaning that codeswitching has been used all along since the first works of Latino literature were published. Pocho, a bildungsroman by Chicano author José Antonio Villarreal, published in 1959, engages in codeswitching to some degree. He is considered the first Chicano writer to publish after the Treaty of Guadalupe Hidalgo was signed in 1848. There seems to be an enormous gap between these two dates. As explained by Luis Leal, it is impossible to believe that Chicano literature did not exist during this time. Rather, he claims, "American critics and literary historians neglected Chicano literature” (1). Still, Chicano literature was the first to lead the way before the rest of Latino literature followed a few years later. Other authors that came before, but 
were not yet called Chicano authors, include María Amparo Ruíz de Burton in 1885 with The Squatter and the Don. She is considered by some critics to be the first female Chicano author, but she did not engage in codeswitching. Then, more recent authors, including Victor Villaseñor, Aristeo Brito, Miguel Méndez, Tomas Rivera, Rudolfo Anaya, Ana Castillo, Sandra Cisneros, Gloria Anzaldúa, and Cherry Moraga increasingly engaged in different levels of codeswitching as they produced works. The literary production by Chicanos includes essay, short story, poetry, theater, and novel.

Codeswitching not only requires the intention to insert Spanish content into the text, but also the subject matter must justify it. Such is the case of I am Joaquín by Rodolfo "Corky" Gonzales, 1967, considered one of the leaders of the Chicano Movement, along with César Chávez. In I am Joaquín, Gonzales epitomizes the struggle of Chicanos: "Yo soy Joaquín, / perdido en un mundo de confusión: / I am Joaquín, lost in a world of confusion, / caught up in the whirl of a gringo society, / confused by the rules, scorned by attitudes, / suppressed by manipulation, and destroyed by modern society” (Herencia 195). This epic poem is considered one of the most inspiring pieces of literature of the Chicano Movement.

Codeswitching is also prevalent in Chicano plays, which go back to El Teatro Campesino, a group of farmworkers led by Luis Valdez in 1965 in California. Codeswitching is a frequent occurrence in Chicano theater as it is the language of the characters without going through the filter of a narrator, or "a symbolic representation of Chicano usage” (Jonnson 20). Thus, codeswitching in Chicano theater is highly mimetic. Although some of the premises posited for narratives can apply to theater, the absence of a narrator gives the plays a more limited, and predictable, use of codeswitching. 
Codeswitching has always been present in the narratives of Latino-descent authors. We should be reminded that the Hispanic presence in the United States dates to the 1500s, many years before English settlers arrived. As far as language is concerned, Spanish was spoken in parts of the current U.S. territory before English ever was, including present day Florida and the Southwest, initially claimed by Spanish explorers led by Ponce de León and Hernando de Soto, respectively. It is ironic then to see that 500 years later Latino groups experience the condition of otherness to which they have been relegated by the hegemonic culture when their ancestors and their language were here first. In Burrows’s words: “The deletion of Latino history from the national story means the negation of roots, of presence, and of agency for those omitted” (44). Burrows talks about the "in-betweenness" of the Latino experience as a group that is "both desired and debased by U.S. society, which simultaneously needs and dehumanizes them” (42). It is this "in-betweenness" that is shared by all Latinos, which is reflected in their literature. The codeswitching employed in Latino literature is in some cases an attempt to reclaim and restore the space that was once theirs. 


\section{CHAPTER 1}

\section{CHICANOS: LEADING THE WAY}

Deslenguadas. Somos los del español deficiente. We are your linguistic nightmare, your linguistic aberration, your linguistic mestizaje, the subject of your burla. Because we speak with tongues of fire we are culturally crucified. Racially and linguistically somos huérfanos-we speak an orphan tongue.

Linguistic Terrorism-Gloria Anzaldúa

\subsection{INTRODUCTION}

The phenomenon of codeswitching in contemporary U.S. Latino literature cannot be addressed without first laying out the groundwork advanced by Chicano writers in the early 1970s, which gave rise to an entire strand of literature known as Chicano literature. ${ }^{5}$ It is safe to say that English-Spanish codeswitching had very seldom been used in literature in the United States before being adopted by Chicano writers as their distinctive writing feature. Hence, tracing such origins becomes essential to view the diachronic evolution of codeswitching, which is one of the goals of this study. However, it should be clear that codeswitching is not characteristic of every Chicano literary work. Chicano literature may be wholly in English, wholly in Spanish, or mostly in English using codeswitching or vice versa; nor is codeswitching exclusively used by Chicanos, as this study will show. However, for the purposes of this chapter, I will refer to Chicano works and authors who engage in codeswitching.

\footnotetext{
${ }^{5}$ The term Chicano has a long and uncertain etymological history. It is believed to be the shortened version of Mexicano, in its Nahuatl pronunciation. It has come to identify—and will be used as such for the purposes of this study - the people of Mexican descent who live and have lived in the current U.S. Southwest territory, formerly belonging to Mexico, which includes the states presently known as Colorado, Arizona, California, Utah, Nevada, Wyoming, and New Mexico since their annexation by the United States in 1848.
} 
Rudolfo Anaya's Bless Me Ultima (1972) is the epitome of Chicano Literature, frequently used as a model to refer to such period-and to its accompanying movement—and it is widely recognized as such. ${ }^{6}$ Therefore, I have chosen it to begin the study of codeswitching in Latino literature, as it provides a perfect example of the early incursions in codeswitching by bilingual or bicultural writers. Several other novels from the period can be compared to Bless Me Ultima, if not in content, in form, particularly in connection to the use of codeswitching. The background surrounding the publication of Bless Me Ultima will also be addressed given its special circumstances, which were crucial for the development of other Chicano novels that would follow.

In the following sections, this study will attempt to dissect, from a literary and sociolinguistic perspective, the technicalities of codeswitching in Bless Me Ultima, which can lead to extra-literary and extra-linguistic conclusions regarding the current status of Latino literature, and by extension, the Latino community as a whole, and its linguistic situation. However, reviewing the history of Chicano literature and the origins of the movement itself are essential to provide context.

\subsection{HISTORICAL OVERVIEW OF CHICANO LITERATURE}

As with any periodization, it is not an easy task to establish the origins of Chicano literature with certainty. Different scholars place its beginnings at different times depending on the view adopted (i.e., historical, political, geographical or cultural). A first approach traces the origins of Chicano literature as early as the 1500s, with the arrival of Spanish explorers and missionaries in the American Southwest to include colonial

\footnotetext{
${ }^{6}$ Although this study considers that Latino literature includes Chicano literature, it will be dealt with separately in this chapter due to its enormous contributions before Latino literature came to exist.
} 
literature written by explorers, chroniclers and priests, even though the term Chicano was unknown at the time. This classification would include works such as The Account by Alvar Núñez Cabeza de Vaca, and that of several missionaries, including Fray Marcos de Niza in 1539, Fray Francisco de Escobar in 1603, and Fray Alonso de Benavides in 1630, among many other chroniclers of the time. ${ }^{7}$ This approach represents a geographical classification that includes all literary works ever written on the territory now known as the American Southwest (formerly the North of Mexico), both before and after the independence of Mexico from the Spanish Crown. However, to label the literary production from such time as Chicano literature would be anachronistic given that the term Chicano did not carry the historical or political implications it acquired later. At best, this period could be described as pre-Chicano, as suggested by prominent Chicano scholar, Luis Leal.

A second group of scholars identify the origins of this literature with the end of the Mexican-American War or the signing of the Treaty of Guadalupe Hidalgo, alleging that the struggles of the inhabitants of this region began with that event, and connecting the term Chicano to the experience of Mexicans as a "colony" of the United States, which situates the Chicano experience under a post-colonial oppressive discourse. For Francisco Lomelí this is a "historical beginning" (105), that assumes a transformation in the lives of Chicanos claiming a new chapter in the historiography of literature. ${ }^{8}$ However, despite being rightfully termed, the literature produced in this period is scarce, lost or ignored.

\footnotetext{
${ }^{7}$ The Account (Relaciones) was published in 1542 in Zamora, Spain but since it was inspired by events that took place in what is now the American Southwest, it is sometimes included in U.S. literature anthologies.

${ }^{8}$ Signed in 1848, the Treaty of Guadalupe Hidalgo ended the Mexican-American War of 1846-1848, and provided for the United States to pay US\$15 million to Mexico for the current states of New Mexico, Arizona, Nevada, Utah, and parts of Wyoming and Colorado.
} 
Furthermore, it is assumed that any works from this period would have been written in Spanish, which was the language spoken in the region at the time by the formerly Mexican inhabitants of the region. This explains their exclusion from the U.S. literary canon and the little interest in preserving them. Following another classification, Nicholas Kanellos terms this period as "native literature" in his Anthology of Hispanic Literature of the United States, and includes several anonymous works such as The Comanches, and some ballads (Gregorio Cortés, Little Indian Ballad), which are characteristic of the time, but scarce nonetheless. ${ }^{9,} 10$

The reason to mark the year 1848 as the birth of Chicanos as a community—and that of its literature-other than for obvious historical reason is that such year transformed the lives of Chicanos. The inhabitants of the now American Southwest found themselves part of a new nation, that spoke a different language, and in some cases, were removed from their land, which had belonged to their families for generations. The Treaty of Guadalupe Hidalgo offered the former Mexican citizens the right to obtain U.S. citizenship, to maintain their property, and to preserve their religion, but violations of such offers became commonplace. Many lost their land, suffered discrimination, or were persecuted by the authorities.

Because of the political implications of the term Chicano, the roots of their movement can be traced back to this historical date, as posited by most scholars. However, later generations born in this territory would fare better in comparison as they

\footnotetext{
9 The "Ballad of Gregorio Cortez" (1902) narrates a case of unfair accusation between a Texas ranger and Gregorio, a vaquero, which is a prototype of the literature that developed in the region.

${ }^{10}$ Luis Leal places this period between 1848 and 1912, when New Mexico and Arizona achieved statehood.
} 
gradually inserted themselves into American life. As stated by Leal, "by 1912 they had already assimilated the elements of Anglo American culture necessary for them to participate in public life, but at the same time, they were not ready to abandon the cultural legacy of their ancestors” (76). Leal also claims that assimilation into American culture was not complete due to "the arrival of numerous political refugees and thousands of Mexican farmworkers and laborers attracted by the agricultural and industrial boom” (76). Such influx kept nourishing Mexican culture in the United States and led to its revival, which continues to this day. Assimilating into American culture was considered a betrayal. The term "pochos"-coined by Mexican philosopher and minister of Culture José Vasconcelos—-was used pejoratively to refer to those who assimilated. ${ }^{11}$

The year 1959 is signaled by many, including Leal, as the true birth of Chicano literature, with the publication of Pocho, by José Antonio Villarreal, which has been recognized as the first contemporary Chicano novel. If not a historical or geographical beginning, it is a symbolic one. This was the first novel that dealt with the identity struggle of Chicanos. ${ }^{12}$ Also, Villarreal, according to Ilan Stavans "was the first to switch from Spanish to English” (82), although in a very incipient manner. Stavans also adds that "Villarreal opened up a new narrative field by introducing a distinctively MexicanAmerican perspective on identity and cultural conflicts” (83). However, at the time of its publication, its reception was modest, but it was brought to the forefront again in 1971 during the Chicano boom, after being out of print and almost forgotten (Lomelí 95).

\footnotetext{
${ }^{11}$ It later came to designate the way Spanish was spoken in the region.

${ }^{12}$ Pocho tells the story of a Mexican who immigrates to the United States in the aftermath of the Mexican Revolution, and the challenges he faces for survival parallel to his dilemma of adaptation to his new culture, thus creating the archetype of the Mexican immigrant, hence the term pocho.
} 
Hence, for the purposes of this research, this latter period seems to have given way to the mode of writing that has become characteristic of Latino authors, including Chicanos. However, it was only in the mid 1960s that the term acquired the political connotations attributed to it nowadays.

\subsection{MEXICAN IMMIGRANTS, MEXICAN AMERICANS, AND CHICANOS}

Considering that this chapter deals with a Chicano author, it becomes essential to clarify how the term Chicano is different from the terms Mexican, Mexican American (or the hyphenated form Mexican-American), all of which have the same ethnic origin and can be used interchangeably in some instances, depending on how each person wishes to identify him or herself. We can see the conflict in these terms expressed by Chicano scholar, Alfred Arteaga: "I was born in California. . . but my relation to that nation [United States] is problematic. U.S. Anglo-American nationalists define their nation to the exclusion of my people. ... My nation is not Mexico, yet I am ethnically Mexican and racially mestizo" (3-4).

In short, a Mexican immigrant is one who has recently arrived to the United States or has not yet assimilated into the culture. A Mexican American may have been born in the United States or has become a U.S. citizen and has assimilated into the culture. Chicanos are also Mexican Americans, but the term carries political connotations - that Mexican Americans may not wish to adopt—as they are exclusively the descendants of the people that inhabited the Southwest region of the United States that formerly belonged to Mexico. However, there are indications that signal that Mexicans, Mexican Americans and Chicanos may prefer to call themselves Hispanics nowadays, probably in an attempt to distance themselves from the stereotypes carried by 
these terms and hopefully avoid further discrimination. Despite these differences, what binds these groups together is their experience vis-à-vis the United States. For the purposes of this research, the term Chicano has historical, political and geographical connotations, and Chicano literature is that written by authors who prefer to call themselves Chicanos, and wish to be viewed as such (i.e., with all the political implications of the term).

According to Bruce-Novoa, the term Chicano was "chosen by political activists to replace other popular self-denominators, like Mexican, Mexicano, or Mexican American” (226). In the term Mexican American, he sees "disjunction and duality" and argues that "it evokes the traditional U.S. process of assimilation" (Dialogical 226), which is absent in the one-word term Chicano or Mexicano. The term Mexican American may be viewed as a synonym of assimilation at a cost of giving up identification with their ethnic heritage, which is absent in Chicano. Bruce-Novoa explains how the term Chicano "encapsulated dual strategies: while it unified an imagined community interiorly, simultaneously it differentiated the group, not only from the Anglo Americans, but also from the national culture of Mexico" (Dialogical 227). The term Chicano quickly caught on, and came to signify defiance to Anglo culture. It extended to Chicano art, Chicano literature, Chicano studies, Chicano culture, etc.

Although Chicanos did not immigrate to the United States—as it was the border that moved north for them-they were considered second-class citizens even after acquiring U.S. citizenship under the Treaty of Guadalupe Hidalgo. At the same time, Mexicans have been immigrating steadily to the United States since the beginning of the twentieth century as the demand for cheap labor in the United States has required it, and 
have been deported as it has ceased to be in demand. Regarding the immigration of Mexicans at the beginning of the twentieth century, Erik Camayd-Freixas explains that They were in fact crucial to American growth and prosperity. Exempt from the restrictive quotas imposed on other nationalities, they moved back and forth across the border in a self-regulating pattern of circular migration that responded to labor supply and demand. But this delicate equilibrium would soon be shattered. As they grew in number and became visible outside the plantations, particularly in cities beyond the Southwest, they became targets of racial prejudice by the growing nativism of the time, which regarded them as less compatible with American civilization, and therefore more of a threat, than the Eastern Europeans. (153-4)

Although each group has struggled with different issues, it is impossible to deny the elements that bind them. For many scholars, the constant influx of Mexican immigrants to the U.S. Southwest has helped to maintain a strong connection to the ethnic roots of Chicanos by providing them with the cultural elements that are necessary to strengthen their ancestral identity, which could have been otherwise erased from their memory with the passage of time. These factors further reiterate the importance of the connection between Mexicans, Mexican Americans, and Chicanos, and as well as their distinction.

It is easy to understand the desire of Chicanos to have their own identityseparate from that of Mexican immigrants or Mexican Americans-in particular their entitlement to equal treatment and non-discrimination for having been born on U.S. soil. Such were the issues that brought about the Chicano Movement. 


\subsection{THE CHICANO "RENAISSANCE”}

The Civil Rights movement of the 1960s was a major contributor to what has been termed the Chicano Renaissance (thus named in imitation of the Harlem Renaissance); it helped to equate the Chicano struggle to that of Blacks. Blacks were brought to America as slaves against their will, just like Chicanos one day found themselves on the other side of the border without having had a say—as individuals—in the transaction. Back in the 1960s, Chicanos joined Blacks—and even borrowed their rhetoric - in their effort to debunk "the mechanisms in place that had for so long suppressed a sense of ethnicity, having denied minorities a history and a culture” (Lomelí 89). According to Rodolfo Acuña, at the time, Chicanos "occupied the bottom of the education scale. ... were subject to social segregation . . . and their lack of education made it difficult for Chicanos to compete in the job market” (312). This was in addition to being poor and politically underrepresented—all of these laments were grouped under a movement named "La Causa," which encompassed their claims for economic, social, and political changes, and cultural recognition. At that time, Chicanos found in César Chávez a leader that would represent them as he initiated the farm workers' strike in 1965 to boycott grape growers in Delano, California. The strike lasted for 5 years and eventually attracted attention at the national level.

The Chicano Movement created a noise that opened the door to multiple artistic manifestations that had been waiting for such a space. This included literature as well as other cultural expressions. According to Lomelí, "a rightful place in American society was claimed and a new ethos was generated" (90), hence the term Chicano Renaissance, Blossoming or Flourishing, all terms coined back at the outset of the movement. 
One of the most prominent manifestations from this period was the Chicano theater. El Teatro Campesino, founded by Luis Valdez, was used by the movement as a vehicle for the dissemination of Chicano culture. In poetry, it was Rodolfo "Corky" González, who, in his I Am Joaquín poem summarized the struggles of Chicanos, and became, according to Lomelí, “a type of historical manifesto” (91): Yo soy Joaquín, / perdido en un mundo de confusión: / I am Joaquín, lost in a world of confusion, / caught up in the whirl of a gringo society, / confused by the rules, scorned by attitudes, / suppressed by manipulation, and destroyed by modern society” (Herencia 195).

Such were the methods employed by Chicanos to make themselves known to the rest of the country. Chicano literature was not the exception, not that it had not existed before, but it had been largely ignored or forgotten. For Lomelí: “Our literary expression has remained vigorous through oral tradition and folklore, but unfortunately the language barrier has not permitted it to transcend cultural lines. It has never made an impact on Anglo-American literature, subsisting marginally as if it were not a part of the overall American experience (103).”

What did Chicano literature wish to accomplish? Other than the creation of its own space, for Bruce-Novoa, it sought to initiate "a process of historical review carried out through an ideology of nation building which stressed several key points: retrieval of family and ethnic tradition, identification with the working class, [and] struggle against assimilation” (134). Chicano writers from the time were entrusted with such task, which in turn would forge a new space for future writers, and hopefully this time, they would be read at the national level given the new outlets for publishing now owned by or open to Chicanos. 
Now that they had a voice, Chicano writers set out to tell their story, to present their artistic wealth to the world, or at least, to the rest of the country, and to "undo a long history of misconceptions, distortions, and caricatures that misrepresented our way of being” (Lomelí 103). Chicano literature became the canvas on which to express what it is to live in one's own native land as a foreigner and their condition of internal colonialism, or in the words of Arteaga, "autocolonialism" in which the "colonist never goes home" (17). ${ }^{13}$ It was also an opportunity for Chicanos to redefine themselves, to go back and rediscover their roots, which resulted in the appropriation of the Aztlán as their homeland; thought to have been located in the American Southwest. ${ }^{14}$ Bill Ashcroft explains the importance of the Aztlán myth, which was a major contributor to uniting Chicanos and helping fuel their nationalism: "The Aztlán myth proved to be a surprisingly resilient weapon in the Chicano/a political arsenal because it so comprehensively united ethnicity, place and nation” (17). The Aztlán myth was coupled with El Plan Espiritual de Aztlán, which laid out the goals of their movement, and read as a manifesto. ${ }^{15}$ According to Lee Bebout: "Through the Plan, Chicanos were able to remap their place in the Americas, contesting the boundaries that define modern nationstates and carving out a homeland" (3).

\footnotetext{
${ }^{13}$ The idea of colonialism was strongly emphasized at the time of the Chicano movement by Chicano scholars, including Alfred Arteaga, who sees Chicanos as victims of double colonialism, once by the Spanish and then by the Americans.

${ }^{14}$ Aztlán, the mythical land of Chicanos, is believed to have been the original home of the Aztecs who migrated South around the year 1064 after a volcanic eruption in New Mexico. Aztlán means "home of the Aztecs” in Nahualt.

${ }^{15}$ El Plan Espiritual de Aztlán laid out the strategies of the movement and claimed the lineage of Chicanos and pre-Columbian Aztecs, and established the Southwest as home for both groups.
} 
No other writer has expressed the struggle of Chicanos as vividly as Gloria Anzaldúa. For her, life in the "Borderlands" (her term) means “you are neither hispana india negra española / ni gabacha, eres mestizo, mulata, half-breed / caught in the crossfile between camps / while carrying all five races on your back” (194). Fiction writers were doing the same but in their own terms. As argued by Edward Said, literature is "the method the colonized people use to assert their own identity and the existence of their own history” (xiii). Chicano art, in this case literature, was their opportunity to tell their side of the story to the world and to themselves, by reaffirming their connection to the land (i.e. the Southwest), what Bruce Novoa has termed a "geographic rescue operation” (Restrospace 102).

It is essential to review the political and social context of the Southwest existing at the time in which the novel chosen to represent this period was written, in order to foster an understanding of the predicament of Chicanos and what they wished to accomplish with their literature. This study claims that there is a close connection between the style adopted by Chicano writers (i.e., codeswitching) and their political agenda.

\subsection{CHICANO LITERATURE AS A POLITICAL ARM OF EL MOVIMIENTO}

The coincidence of the birth of Chicano literature with the social activism of the Chicano Movement is not fortuitous. Pocho, the novel that is considered to have marked the beginnings of Chicano literature, was published in 1959, just a few years before the Chicano Movement was in full swing. It did not gain recognition until the Chicano Movement began to gain momentum, however. Thus, it is argued that Chicano literature was the cultural arm of the Chicano Movement for the advancement of their political 
ideology and the dissemination of their claims. According to Iris Haslhofer, Chicanos "were longing to construct a separate ethnic identity which stood in opposition to Anglo American hegemony” (11). The conditions were optimal for Chicanos-through their literature - to present their life, their struggles, their identity, and their culture to the world. For decades, Chicanos had felt rejected by the dominant Anglo American system, which led to their feelings of oppression and cultural inferiority. Literature would be their voice. Their resistance would not longer be silent or individual, but collective. Additionally, literature would guarantee the continuity of their ethnicity for future generations and help avoid being absorbed by the hegemonic culture through assimilation. Chicano literature would reinforce Chicano values for generations to come, and that it did.

Chicano narratives denounced, some more openly than others, the complicated historical power relations between Anglos and Chicanos, the hegemony held by the former over the latter, and the marginalization to which Chicanos had been subjected since the annexation of the territory of their ancestors. The marginalized group does not have all the resources at its disposal to legitimate its culture, as the hegemonic group does, which is also "reinforced by politics, jurisdiction, executive power and also by e.g. popular culture products as well as popular ideological ideas that are meant to reproduce the shared values and beliefs of U.S. Anglo American culture” (Haslhofer 17).

The insertion of Spanish words or the use of codeswitching was part of their literary formula, along with certain other elements that populate Chicano narratives. In the words of Bruce-Novoa, he simplifies the style of Chicano writing saying that: "The standard formula for a successful Chicano piece calls for five or six carnales, a dozen 
eses and batos, a sprinkle of Spanish and a well placed "Chinga tu madre" (Retrospace 16); meaning that it is not the Spanish words themselves that are important but the position adopted by the author by refusing to write in the standard code (i.e., the English language) at the risk of being rejected by mainstream literary canons.

Chicano literature is a blend of theme, language, and cultural elements. Some works attempt to validate their past, others refer to the life in el barrio, the experience of otherness, resistance to acculturation or assimilation, language conflict, and identity issues; such are some of the major themes of Chicano literature. ${ }^{16}$ This has been extensively studied and clearly identified. For Gary Keller:

some of the major ones [themes] being social protest against Anglo, or more rarely, Mexican oppression, consciousness-raising of the "naïve" Chicano, usually a migrant worker and/or Mexican newly arrived in the United States, the recuperation of Chicano history ... the creation or recreation of a Chicano mythos (Aztlán, La Raza, Emiliano Zapata, etc.), the emancipation of the Chicana from both Anglo and Hispano male dominance, and the quest for a personal identity within the bicultural Mexican American milieu. (Stratagems 303)

The novel chosen to represent Chicano literature in this study does indeed fall into one of the categories above. Selecting one novel to represent such a prolific literary period was not an easy task, as there were dozens to choose from. Because of its notoriety

\footnotetext{
${ }^{16}$ El barrio, the Spanish word for neighborhood, has come to denote the lower class neighborhoods in large cities such as New York, Chicago, Los Angeles, etc.
} 
and its many features of a Chicano novel-as the next sections will show-Bless $\mathrm{Me}$ Ultima (1972) joined the many voices of Chicanos as a true representative of its art.

\subsection{BLESS ME ULTIMA AND ITS PUBLICATION BY QUINTO SOL}

Bless Me Ultima by Rudolfo Anaya, published in 1972, quickly became the most widely read and critically acclaimed Chicano novel. Its popularity was based on the right combination of all the elements to make it a true representative of Chicano literature: First, it was written by a Chicano, who identified himself as such. Second, the story takes place in the American Southwest, the land of the mythic Aztlán. Third, it incorporates mythical, cultural, and folklore elements, and it addresses one of the topics exploited by Chicano literature: the search for identity. Lastly, it also uses an incipient form of codeswitching. Bless Me Ultima is considered a classic of Chicano literature, which has produced immense amounts of literary criticism, and is probably one of the most emblematic and studied Chicano novels.

The publication of Bless Me Ultima was favored by the times of transition experienced in the early 1970s, at the height of the Chicano boom. Anaya reports that before being accepted by Quinto Sol, he had been rejected many times by other publishers. Not only was his first novel published, but it was also awarded the Quinto Sol Prize in its second year since being instituted. ${ }^{17}$ Quinto Sol was a small publishing house created in 1967 as an outlet for Chicano literature - the first of its kind - and it was the first prize for Chicano or Mexican American literature ever established at the national

\footnotetext{
${ }^{17}$ The first year award went to Tomás Rivera for “...y no se lo tragó la tierra / and the earth did not part” in 1971. Quinto Sol was also the first publishing house to put to press the first anthology of Chicano creative writing.
} 
level. ${ }^{18}$ "Quinto Sol and the intellectuals, artists, and writers associated with it proved vital to this historical, political, and cultural process” (López 184). The contribution of Quinto Sol for the so-called Chicano "flourishing" cannot be emphasized enough as it opened up an outlet for Chicanos' cultural and literary expression: “Quinto Sol, though not unique or alone in its activities, proved indispensable to the advancement and institutionalization of Chicano nationalism, especially Chicano literary nationalism” (López 185), thus legitimizing Chicano literature. Quinto Sol came to join the numerous specialized Chicano journals that were appearing at the time and was the opening door for Chicano literature. They took it upon itself to publish Chicano authors who would not be published otherwise by mainstream publishers. It goes without saying that Chicano literature was not part of the canon. As succinctly put by Horst Tonn, Bless Me Ultima "seems to have been the right book at the right time" (1).

Another major contributor to the publication of Chicano literature at the time of Bless Me Ultima was El Grito: A Journal of Contemporary Mexican-American Thought, a journal whose first issue appeared in 1967, and it was the first journal of its kind to appear in the United States. Its purpose was to serve as a forum for the expression of Chicano issues of the time. El Grito promoted the ideas of the Chicano Movement and attempted to counter some negative views and to raise awareness about Chicanos mainly through the publishing of essays, short stories, poetry and even novels. Works were published mainly in English but also in Spanish and sometimes in bilingual form. El Grito was discontinued in 1974 and became Grito del Sol, which was then published by

\footnotetext{
${ }^{18}$ Quinto Sol refers to the Aztec myth of Nahui Ollin, "the fifth sun.”
} 
Quinto Sol Publications. Both El Grito and Quinto Sol played pivotal roles in the legitimization of Chicano culture, which in turn contributed to the formation of a Chicano literary canon. Though Mexican Americans have been writing for over a hundred years, with the help of Quinto Sol and El Grito, "Chicanos could lay claim to a homeland, a distinctive linguistic modality, and a direct link to an ancient mythology. It became clear that the identity Chicanos so ardently sought through cultural nationalism was now complete” (Lomelí 92). This was happening at a time when only 4.7\% of the population in the United States was Hispanic. ${ }^{19}$

In summary, the contributions of Quinto Sol and El Grito and other supporters of Chicano literature can be signaled as having opened the door to a new form of writing that mainstream presses had rejected until then. This new form of writing meant not only new themes but also a new language for writing: bilingual, interlingual or codeswitching, which came to be viewed as an innovation of Chicano writers. ${ }^{20}$ Such a bold step would encourage other writers and publishers to follow suit once the existence of a reading audience was identified.

\subsection{SUMMARY AND THEMES OF BLESS ME ULTIMA}

Despite the combativeness attributed to Chicano literature, Bless Me Ultima is not a political novel that would join the voices of the Chicano Movement of the time, nor does it connect to the social struggle taking place around its time. Rather, Bless Me Ultima exploits the mythical dimension of the Chicano culture and gives validity to its

\footnotetext{
${ }^{19}$ Source: U.S. Census Bureau, 1970, 1980, 1990, and 2000 Decennial Censuses; 2008 National Population Projections.

${ }^{20}$ Not all Chicano writers write in this mode but it was the first group to experiment with codeswitching writing in literature in the English-Spanish combination in the United States.
} 
traditions by connecting itself to the land in a kind of magical realism narrative, also popular at the time. ${ }^{21}$

According to Haslhofer, “Anaya’s success can largely be attributed to the overly positive harmonizing message of the novel. In fact, Anaya manages to illustrate that periods of transition, although usually full of conflict can be overcome by the creation of something new, something beautifully reconciled” (78), such harmony also earned Anaya some criticism for being ahistorical and dissonant with contemporary Chicano writers, whose agenda he does not seem to adopt or deny, and his voice—allegedly—did not join the protests of the time. However, the exploration of the issue of identity and validation of the cultural heritage of the protagonist seem to fit the mold of the Chicano novel, which clearly allowed it entry into this category. However, in terms of style, Bless Me Ultima is one of the most emblematic of Chicano writing. According to Ernst Rudin: "Ultima is the text that corresponds most faithfully to the stereotypical and hypothetical Chicano novel” (36).

Bless Me Ultima is a bildungsroman that follows the life of Antonio growing up in the town of Guadalupe, in rural Eastern New Mexico, prior to, during, and after World War II. Antonio is guided by Ultima, a curandera or folk healer—who is related to the family—and who comes to live in their home when he is seven years old. He becomes her apprentice and is introduced to her knowledge of healing, magic, and shamanic powers. There is tension in the novel as Ultima is accused of being a witch due to her healing powers, which is seen in the novel as going against the religious beliefs of the

\footnotetext{
21 The Latin American Boom, to which Magical Realism is attributed ran almost parallel to the Chicano Movement (1960 to 1970).
} 
inhabitants of a Catholic and devoted community. Only the family, and of course the readers, know that Ultima is a special and kind woman, but is despised by the town for her alleged special powers.

Though admired by Antonio, her presence makes him question his Catholic upbringing as he searches for his true identity. Antonio lives in a world of opposites, caught between the Marezes (his father's family) and the Lunas (his mother's family) who have different values and traditions: cowboys and farmers, accordingly; Catholicism and the indigenous religion and shamanic practices; the llano and the city; good and evil; his ancestral culture and American culture; English and Spanish.

Antonio's split identity, or biculturalism, is present throughout the novel; his use of Spanish both as a character and as a narrator reinforces his hybrid condition. As Antonio goes to school, he begins an assimilation process, which is probably the reconciliation Anaya was aiming at. According to Haslhofer: "Instead of promoting a universal common Chicano identity, Anaya embraces a celebration of cultural diversity, presenting a possible identity construction that goes beyond categories and dualisms" (124). Perhaps it is this attempt to bridge his two cultures that won him recognition.

Ultima teaches Antonio that harmony between the opposites he sees around him is possible; that he does not have to choose one over the other. Ultima dies leaving Antonio a stronger boy, no longer ambivalent or confused about his beliefs. He has found a way of harmonizing his ancestry with his surroundings; which is ultimately the struggle every Chicano must overcome, and hence its importance as a Chicano novel. The contribution of Anaya is that it legitimized Chicano literature by incorporating into it mythical 
dimensions that were unexplored until then. Bless Me Ultima is a Chicano novel written by a Chicano and for Chicanos, in the Chicano language.

\subsection{CODESWITCHING IN BLESS ME ULTIMA}

Anaya was one of the first authors to introduce codeswitching in a novel at a time when views about language correctness and grammar-abiding writers did not contemplate such fusion of codes. Codeswitching was-and still is-viewed as substandard phenomenon even in its spoken form. In general terms, written language is expected to adhere more strictly to grammatical rules due to its permanent nature (i.e., it stays on the page), as opposed to oral language, which is more permissible due to its spontaneity and transience. Literary language can be seen as an even more formal context than other forms of writing, to which the strictest grammar rules apply. Anaya's choice to employ codeswitching for his writing—going against the views regarding language—was a bold proposition. His use of codeswitching was later imitated by other Chicano writers. Nevertheless, Anaya's codeswitching in Bless Me Ultima is not drastic but rather timid, still catering largely to an Anglo audience. However, considering the time at which it was published, his introduction of Spanish switches in the novel did represent a risk for his publishing goals, had it not been for Quinto Sol who took the risk of publishing it. To attenuate such drastic use of codeswitching - that is, to make it more palatable to Anglo readers - the author uses at least five identifiable strategies:

1. Explanation: Occasional explanation is provided within the text for some Spanish terms or phrases. For example: 
"It was because Ultima was a curandera, a woman who knew the herbs and remedies of the ancients, a miracle-worker who could heal the sick" (4). The explanation of what a curandera (healer) is follows the word.

““Adiós, mamá, adiós, Ultima,” I waved”. (149). The meaning of “adiós” is clarified by the act of "waiving."

2. Immediate glossing: Provided immediately before or after the Spanish word, so that the meaning of the Spanish word is clear. Examples:

““A nightmare,’ I mumbled, ‘pesadilla’” (258).

“...to exorcise el encanto, the curse, and he had failed” (87).

3. Indirect glossing: Indirect glossing provided, sometimes in the same sentence or paragraph. The meaning of the Spanish word is not explicitly translated but the reader is not left in the dark. For example:

“"Sangre!” she whispered. It was the blood of Narciso on my hands.” (179). The second sentence explains the meaning of "sangre."

“...there would be a long velorio, the time of her wake” (277).

4. Context: Context is provided, without translation or explanation, to the Spanish utterance so that the reader can infer its meaning: For example:

“‘¿Cómo te llamas?’ She asked. ‘Antonio Márez,’ I replied” (61). The answer provides a clue to what the question was.

““Sí, tío,’ I replied. I liked my uncle Pedro...” (49). The second sentence clarifies the meaning of the first.

5. Set of repeated words: Among the many Spanish words used throughout the novel, there is a sub-group of words that have a high repetition rate, which helps the reader 
gather their meaning from context based on their frequent repetition: llano, bruja, chingada, curandera, ay, papá, mamá, cabrón, diablo, virgen, hijo, etc.

6. Simple Spanish: Short phrases in easy Spanish are ubiquitous, which may be understood with just a limited knowledge of Spanish: “iAndale, hombre, andale!” [sic] (17), “Está loco!” (21), ¡Amigo! (23), “Buenos días le dé Dios” (33), “Ave María Purísima” (93), “AAdiós!” (94), “Gracias por mi vida,” (108), “Dios mío!” (107), “¿Cómo está?”, “Aleluya! Aleluya! Aleluya!” (200).

In addition to the strategies above, some editions of Bless Me Ultima come with a glossary at the end of the book, listing most or all the Spanish words used in the novel. However, the inclusion of a glossary seems to be the publishers' choice (or request), rather than the author's, as not all issues include one. The insertion of a glossary contributes to the reading experience of the Anglo reader, just like the strategies above. It is a statement that tells the reader that he/she needs to know the meaning of such words, and it is not the author's intention to leave the reader wondering about their meaning.

There are only a few instances in which no glossing or explanation is provided, which could be considered the most daring use of codeswitching in Anaya's novel: “"Es una mujer que no ha pecado...' some would whisper of Ultima” (35). The reader is left without any explanation of what is said about Ultima. This sentence, however, is repeated many times throughout the novel. This category of codeswitching is the scarcest in Anaya's work. 
There are a little over 1,000 Spanish tokens in Bless Me Ultima, which is equivalent to an average of 3.5 tokens per page. ${ }^{22}$ The intention of the author to use as much Spanish as possible without risking his readership is obvious from the strategies explained. The single most obvious example of this is the numbering of each of the 22 chapters, for which Anaya spells out number words in Spanish: Uno, Dos, Tres, etc. He does this as opposed to using numerals, rendering its usage almost deliberate.

Anaya's codeswitching — though limited compared to later authors, and despite his attempt to provide a "cushioned" reading experience—should not be underestimated. This approach to language in Chicano literature is a well thought-out method devised by Chicano authors to render a text that is both easy to comprehend for the monolingual but that has the appearance of using a high amount of Spanish. When considering the level of codeswitching, the methods employed by the author to present codeswitching content in the text is just as important as the complexity of the words used.

Compared to later works by other Chicano and Latino writers, Anaya's codeswitching may seem timid and scarce, limited to word borrowing, rather than codeswitching per se. Although the definition of codeswitching covers a wide spectrum, one of its manifestations contemplates the juxtaposition of the grammar systems of both languages into a single utterance, which is rare in Bless Me Ultima. Nevertheless, Anaya is one of the pioneers in devising this new literary language that would come to identify Chicano writing and other Latino writers. Bless Me Ultima was published in 1972, when only a handful of Chicano novels had been published, and codeswitching in literature had

\footnotetext{
${ }^{22}$ In my edition (Anaya, Rudolfo A. Bless Me, Ultima. New York: Warner Books, 1994), the novel is 277 pages long.
} 
only been done sporadically. The codeswitching in Bless Me Ultima must be seen under such light.

\subsection{TYPOLOGY AND CLASSIFICATION OF CODESWITCHING IN BLESS ME}

\section{ULTIMA}

One of the questions that arises when studying codeswitching in literature is whether the language combination adopted by the author does indeed fall into a strict classification of codeswitching, as hinted above. Recalling from the Introduction, there is not one single unequivocal definition of codeswitching that has been agreed among linguists. Rather, it is seen as a continuum that goes from single lexical (e.g., vocabulary) entries to a full integration of both grammar systems. Therefore, all the forms in between should be considered codeswitching, which is the definition that this study has adopted.

Bless Me Ultima uses the following types of codeswitching, as classified by Myers-Scotton (1993): intersentential, intrasentential and tag switching. Examples of these include:

Intersentential codeswitching: “He killed my brother! ¡Está loco!” (21). Sentences alternate between English and Spanish.

Intrasentential codeswitching: “The pain and sadness seemed to spread to my soul and I felt for the first time what the grown-ups call, la tristesa de la vida.” [sic] (62). Codeswitching is inserted in the middle or somewhere within the sentence.

Tag switching: "Ay Dios, it was so hard without you...” (66). Also in the form of interjections, both at the beginning or at the end of a sentence. 
A closer analysis of the Spanish tokens provides the following major lexical categories, which have been grouped based on what they denote semantically, rather than by their grammatical classification, as most of the tokens fall in the noun category: ${ }^{23}$

1. References to people/entities: vaquero, compadre, llanero, amigo, curandera, bruja, virgen, hermano, loco, hechicera, diablo, muchacho, mujer, policía, chico, ranchero, hombre, médica, vieja, puta, jefe, jefa, médica, vieja, vatos, comanchero.

2. Culinary terms: bizcochito, chile, maíz, tortillas, orégano, manzanilla, atole, ristras, yerba de la víbora.

3. Ethnographic terms: curandera, valle, lazo, cuentos, yerba del manso, oshá, ristra, Llano Estacado, mitote, bulto, la Llorona, crudo.

4. Locations: llano, mesa, sala, casa, valle, campo santo, casa.

5. Terms of address: mamá, papá, hijo, hijito, hermano, amigo, tío, abuelo, abuela.

6. Religious terms: Ave María Purísima, Espíritu de mi alma, Dios mío, gracias a Dios, nuestra señora de Guadalupe, madre de Dios, a la madre, adiós, aleluya, que Dios te bendiga, Virgen de Guadalupe, Jesús, María y José, San Martín, San Cristobal.

7. Swear words: cabrón, cabroncito, hijo de la puta, ay diablo, chingada, borracho, cabrón, maldecido, mierda, puto, jodido, a la veca, maldito, desgraciado, pendejo, pinche, chinga tu madre.

\footnotetext{
${ }^{23}$ Some tokens fall in more than one category and may be duplicated.
} 
8. Songs, sayings, prayers: Una mujer con un diente que llama a toda la gente, Padre nuestro que estás en los cielos, la campana de la iglesia está doblando, arrímense vivos y difultos aquí estamos todos juntos..., te doy esta bendición en el nombre del padre, del hijo y del espíritu santo [sic].

9. Interjections, tags, and exclamations: ¡ay!, ¡Qué lástima!, ¡Está loco!, ¡Mira!, ¡Qué suerte!, ¡Vamos!, ¡Bueno!, ¡Oye!, ¡Mis hijos!, ¡Cuidado!, ¡Toma!, ¡Borracho!, ¡Puto!

10. Social exchanges: Adiós, buenos días, gracias, ¿cómo está(s)?, ¿qué pasa?, ¿qué?

11. Miscellaneous lexical items: farol, cuento, pueblito, gente, bulto, abrazo, grillo, pesadilla, tripas, piñón, pecado, encanto.

The categories above show that the codeswitching observed in Bless Me Ultima is closer to word borrowing on the codeswitching continuum than it is to syntactic or grammatical codeswitching; an overwhelming majority are nouns, followed by interjections and some independent clauses. Rarely, if at all, are the grammars of both languages integrated. That is, English, as the matrix language (the language that makes the largest contribution) provides the structural frame of the utterance, while Spanish provides content morphemes only (i.e., lexical entries). This quantitative consideration provides confirmation that codeswitching in Bless Me Ultima is largely lexical borrowings of nouns in the absence of adjectives, verbs, adverbs or other lexical categories, except for a few tokens of each.

Considering that Bless Me Ultima makes an intensive use of lexical borrowings or content morphemes represented in the form of nouns, the next distinction that needs to be made is whether such entries can be classified as core borrowings or cultural borrowings, 
which would throw some light as to the positioning of the author in the linguistic market. According to Myers-Scotton, core borrowings are words for which there is an equivalent in the matrix language (e.g., bruja, for witch; sala for living room; farol for lamp; etc.); cultural borrowings, on the other hand, are words for objects that are new to the culture of the matrix language and no other word is available in that language (e.g., tortilla, ristras, novena, curandera, etc.) (Contact 41). A tally shows twice as many core borrowings as there are cultural borrowings. This is a significant distinction since cultural borrowings are more likely to be accepted by the reader under the assumption that they are replacing a concept for which no English word is available. Conversely, core borrowings can easily be replaced by an English word and the use of a Spanish word may seem unnecessary to the reader, unless the motivation is one that the reader does not perceive at first sight, which is a claim made by this study. In other words, the intention of codeswitching is not visible at the surface level of the text, but globally.

\subsection{CODESWITCHING AS A LITERARY DEVICE IN BLESS ME ULTIMA}

Having considered the typology and categories of codeswitching in Bless Me Ultima, this study will now look at the use of the codeswitching as a literary device. This study claims that codeswitching in Chicano and Latino literature plays either just a literary role, or a literary and a political role. Bilingual—or bicultural—writers who have a second language at their disposal find opportunities to enhance their writing by inserting L2 content, whenever possible. However, just like any other literary technique, such insertion must be justified or it risks being artificial, which in literature, is a recipe for failure. In connection to codeswitching in Chicano poetry, Gary Keller confirms that "because codeswitching is a radical, overt stylistic occurrence, it requires justification in 
order to be deemed valid or successful” (Stratagems 311). This section outlines how codeswitching is used for literary purposes in Bless Me Ultima.

Bless Me Ultima tells the story of Antonio narrated in the first person, as an "Inarrator.” Although he is speaking - or rather writing - to us in English, very soon we learn that everything around him is happening in Spanish. The first voice heard that is reported by the narrator-Antonio-in Chapter 1 of the novel is: “'Está sola,’ my father said, 'ya no queda gente en el pueblito de Las Pasturas-' He spoke in Spanish, and the village he mentioned was his home.” (2). It is clear from this moment on that Antonio is acting as an interpreter for the reader and that anything that he reports to us as having been uttered by anyone in his home will be in Spanish, whether he indicates it is a translation or not. A few pages later he adds: "All of the older people spoke in Spanish, and I myself understood only Spanish. It was only after one went to school that one learned English” (10). Further down, he reiterates the fact that he did not speak English: "I told her I did not speak English” (61). Anaya gives the reader ample justification for him and his narrator to code-switch by constantly alluding to the surrounding presence of Spanish, which contributes to the realism of the story.

Such mimesis of speech responds to a good portion of the code-switched text in Bless Me Ultima, regardless of its authenticity or realism. A close analysis of a few examples would prove that the codeswitching presented in the novel fails to resemble actual use of codeswitching, which is grammatically governed when used correctly. However, such deviation from actual use of codeswitching should not invalidate the author's attempt to recreate the actual speech of Chicanos, for it is well known, as stated by Keller, that "literature aspires to become the microcosm and mirror of the social 
macrocosm" (Bilingual 172), in line with the aesthetics of realism. However, anyone familiar with codeswitching in speech would know that the codeswitching used by Anaya in Bless Me Ultima does not really reflect what happens orally among Chicanos or Latinos, as actual codeswitching is more than the sporadic insertion of Spanish nouns. Keller, in his study of Chicano poetry, has observed that: "Much codeswitching that has been thought by readers or critics to be high-fidelity renditions of the "real stuff" simply isn't and doesn't have to be” (Stratagems 302). However, the fact that codeswitching is used at all in literature, here or elsewhere, still plays a significant literary role. Considering codeswitching artificial in literature, is the same as considering any other dialogue in literature as artificial. The planning aspect of writing is true for any type of dialogue used in literature, even monolingual. Steven Gross sees this literary technique as a "self-conscious act of writing", in which "the author is able to create the illusion of spontaneous conversation, while the reader creates meaning from the characters' utterances as if they were produced in real time” (1291). As readers, we are trained and are made to believe that we are reading a realistic rendition of a given dialogue, even if perceived as artificial. This is also true in literature using codeswitching.

If the author wishes to justify codeswitching a handy resource is to put it in the voice of the characters, other than the I-narrator. In Bless Me Ultima, the secondary characters are Antonio's brothers and sisters and his parents. Ultima, Antonio's companion and guide, would be considered a co-protagonist, since she plays a prominent role. Then, there are tertiary characters (everyone else in the novel). A close analysis of utterances throughout the novel shows that everyone in the story code-switches at some point. All the characters are Chicanos. However, the amount of codeswitching is limited 
and insufficient to determine their level of bilingualism or to find any patterns in the use of codeswitching for characterization. It could even be said that codeswitching is used equally by all characters, which reveals the artificiality thereof, and reinforces the intentionality of codeswitching, posited by this study.

Thus, the use of Spanish by all the characters, from a literary point of view, helps to define them as Chicano characters, as members of a Chicano community with Chicano values. The fact that Spanish is spoken to them or by them (in vocative form) without any warning gives the reader the impression that their communication is usually in this manner, in which case codeswitching reinforces their characterization and adds verosimilitude to the story.

An analysis of the text reveals that most of the codeswitching content is uttered by Antonio, the narrator. However, he is speaking —or writing - to us, the readers, as an adult and a fully fluent English speaker, but we know this was not always the case; he did not speak English as a child. When the narrator is addressing the reader, codeswitching is assumed to be his own speech. The use of codeswitching on behalf of the narrator can serve two purposes: to remind the reader that he remains loyal to his ethnicity, despite having grown up and learned English; and to get closer to the reader (i.e., the Chicano reader) by evoking the language of his childhood. Mendieta and Cintron see this as "a literary strategy that makes the author more accessible to the reader/audience. In this way, the poet attempts to establish a linguistic link with the audience that calls forth their identity and solidarity” (566). If this is true, the question that follows is: What happens to the Anglo reader? Does approaching the Chicano reader mean distancing himself from the Anglo reader? Or, does Anaya have the Anglo reader in mind at all? This research 
provides an answer to this question; codeswitching may be used to get closer or to distance from one’s audience. "Cushioned” codeswitching brings the Anglo reader closer to the text, whereas "uncushioned" codeswitching distances the monolingual in favor of the bilingual.

If mimetic representation justifies the use of codeswitching, we can ask whether it is possible to narrate a story in which the events occurred in a second language without ever uttering a word in that language. This research posits that it is indeed possible, but with different results. By the same token, trying to recreate the events using the original language in which the events took place cannot be denied as an enhancing literary device at the disposal of the bilingual writer only. In this case, the use of codeswitching can be seen as a validation tool that reinforces the narrator's authority and gives more credibility to the story. In other words, the writer is benefitting or taking advantage of his/her knowledge about that second language in which the events happen to have taken place, in order to claim more authoritative knowledge. This should have the effect of making the reader feel closer to the events narrated and to experience them with greater proximity.

Another major justification for codeswitching in Bless Me Ultima is the theme itself. The fact that the author writes about Antonio's experience as a Chicano boy, who lives in a Chicano community where most of the adults speak Spanish, where codeswitching is the unmarked code (the default code), writing using the same language of the characters of the novel makes perfect sense. Using codeswitching highlights and reinforces the theme even more. One of the major themes in Bless Me Ultima is the search for identity, and identity is inextricably connected to language. Antonio is growing up in a Chicano home but attends school and church in English, among other 
formal interactions. He is caught between the two languages and is learning to navigate in the two worlds as he is growing up. His "in-betweenness" is underscored by his need to use Spanish as he narrates. In this case, we can connect the narrator's identity struggle to the author's ideology, as they both need Spanish as their medium of expression.

From the point of view of the stylistics of fiction, codeswitching is used on two levels: by the narrator and by the characters. When used by the narrator, it is perceived by the reader as the narrator's choice of speech and can be interpreted as a sample of his or her own speech, since it is his or her choice to speak to the reader using codeswitching. On the other hand, when codeswitching is used by the characters, it provides the author an opportunity to transfer codeswitching to the characters without having to use it himself or herself, as reported speech, for which he or she is not taking any position, but is merely repeating what he or she has heard. In this particular novel, the use of codeswitching by the characters provides an additional opportunity.

An extensive amount of codeswitching found in the novel corresponds to what has been termed "identity markers," which, according to Keller "are used to establish rapport in Spanish between the author and his Chicano readers” (Bilingual 174). Both Keller and Valdés have studied the use of codeswitching in highlighting theme in the Chicano novel. Identity markers are numerous in Bless Me Ultima and include interjections, tags, items with little or no grammatical or lexical content, such as: Ay, chingada, ¡vamos!, ¡cabrones!, ¡bueno!, ¡Ave María Purísima!, ¡oye!, ¡adiós!, ¡Sí!, ¡Mira!, ¡Gracias! Identity markers are sometimes void of meaning (beyond a simple interjection) and are there to reinforce the language stance of the author. Such is the case in Bless Me Ultima, in which identity markers are not only numerous but they also belong 
to the category of words of high repetition rate, which facilitates their understanding by the reader.

Another approach to codeswitching as a literary device in Bless Me Ultima is its aesthetic dimension or its use as a decoration element, what Lipski describes as "a handful of L2 words thrown in for flavor...” (78). An analysis of the Spanish content in Bless Me Ultima - to determine what counts as decoration (or artificial) and what counts as cultural elements (or authentic)—shows that the author makes use of several lexemes that occur in isolation, which is not characteristic of codeswitching. While this study claims that codeswitching is justified for cultural reasons, that is, to express what can only be said in Spanish, a detailed analysis of the Spanish content in the book shows that this is not always the case. That is, there are single nouns such as: sala, amigo, hombre, bruja, grillo, mujer, chico, etc. that could be replaced by English words that would convey the same concept as in Spanish to the Spanish or bilingual speaker, which were termed above as core borrowings. Thus, the logical conclusion is that the only explanation for such words is that of serving as a decoration element, from a literary point of view. In the sentence "He was a man from Méjico” (122), the author’s choice to spell Mexico with a “j” and adding the diacritical accent serves no other literary purpose, except than a decorative one (at least at the surface level of the text). Examples of this kind abound in the novel.

Despite the rather timid use of codeswitching in Bless Me Ultima, compared to a much more dynamic interconnection of the two languages found in later works by other Chicano and Latino writers, the use of codeswitching in Bless Me Ultima is well justified-for the most part-for literary purposes as outlined above. Ernst Rudin's 
dissertation on the "Spanish in the Chicano Novel in English" attempts to debunk the importance of codeswitching found in the Chicano novel by demonstrating the artificiality thereof. He argues against its so-called bilingualism and questions whether there is any merit in studying it from a sociolinguistic perspective. While I agree with Rudin that codeswitching is incipient and at times artificial in the Chicano novel, I would argue that Bless Me Ultima, which had its height in the 1970s, must be analyzed in the context in which it was written (i.e., codeswitching was unheard of in literature, the prescriptive views existing at the time about language use, and the smaller bilingual population). This novel served as the starting point for future authors who would take codeswitching to another level. Therefore, Bless Me Ultima is a stepping stone in the affirmation of Chicano and Latino literature.

\subsection{CODESWITCHING AS AN ELEMENT OF POWER IN BLESS ME ULTIMA}

Codeswitching such as that found in Bless Me Ultima can be described as the minimum amount of Spanish words that are necessary to be considered a Chicano novel, at least at the time of its publication. It is unknown if a more dynamic or intensive use of codeswitching in Bless Me Ultima would have still managed to get it published or whether it would have been received differently by the readership. A comparison with other later works by the same author shows to a certain degree, the same level of codeswitching, in which case, his choice for codeswitching could be also a matter of style. The careful dosing—and strategic glossing—of codeswitching in Bless Me Ultima can also be explained by a possible interest to cater not only to a Chicano or Latino readership, but to an Anglo audience as well. The author seems to have maintained this approach throughout all his works, even later works from 2011 and 2013. However, there 
are critics who would consider Anaya's codeswitching drastic, as there are indeed several words left untranslated or unexplained, which would preclude monolingual English readers from fully understanding; a position that this study considers intentional.

It is worth recalling that Anaya is writing at the height of the Chicano Movement when this minority was starting to receive well-deserved attention. Anaya is using the spotlight that had been placed upon Chicano writers to tell readers about their existence, their plight, their history, their culture, and their language. However, writers such as Anaya (i.e., Chicano writers whose native language is English) do not and cannot write in Spanish. The second best thing they can do is to insert as much Spanish as possible in their literary production to establish the connection between their people and the Spanish language. Anaya exploits in his writing what Pierre Bourdieu calls "cultural capital.” The political turmoil of the time (i.e., The Chicano Movement, The Civil Rights Movement) afforded Anaya (and other writers like him) the opportunity to present an otherwise "ethnic" or minority novel to the general audience. In this section, I try to show how a large percentage of the Spanish content in his novel is a manifestation of the power that such cultural capital earned him: He dares to codeswitch to Spanish because he can.

Evidence for the above statement comes from the above analysis of the codeswitched content, which reveals that it is largely artificial in the sense that it is not justified to advance communication, except for certain tokens of codeswitching content. One of the questions that could be made regarding the use of codeswitching in Bless Me Ultima is to what extent the Spanish content therein can accurately be replaced by English words, without sacrificing meaning. As the linguistic analysis above has shown, a large portion of the codeswitching text represents "core borrowings," meaning that they 
are replacing words for which there are perfectly translatable equivalents in the matrix language. ${ }^{24}$ This is in addition to another category of words, which I have termed "people," which also have equivalent English words. ${ }^{25}$ These two categories together represent $48 \%$ of the codeswitched content. The remaining categories can be justified as they correspond to ethnic terms, cultural elements, and expressions. The largest body of codeswitching tokens is found in interjections (including tags), which alone correspond to $35 \%$ of all the code-switched content. Such expressions do have English equivalents for the most part, but they will be treated as inherent cultural content justified by a literary need to imitate the speech of a community. Examples are: “iAy Dios mío!” (9), “iÁndale, hombre!” (16), “iMira”! (44), “iChingada!” (152).

After removing codeswitching text that is justified for its cultural content, mimetic representation or literary use, we are still left with codeswitching that responds to pragmatic use-as it lacks any apparent justification. A simple but obvious example is the word "Sí," which appears 21 times throughout the novel, the only intention of which is to insert a Spanish word that is very likely to be understood by any reader—bilingual or not. Other tokens in this category are words easily understood by the English speaker such as: Buenos días, buenas noches, adiós, gracias, papá, mamá, qué, qué pasa, mira, etc., which are words of high repetition in the novel. The same goes for the chapter numbers, which are spelled out in words in Spanish, from one through 22, without using numerals or any translation. The author is clearly taking advantage of common Spanish

\footnotetext{
${ }^{24}$ Approximately 100 entries are considered core borrowings.

${ }^{25}$ Approximately 125 entries belong to the "people” category.
} 
or self-explanatory words that he does not need to gloss or explain. These switches have been termed by Montes Alcalá as "free switches,” which she defines as switches with "no apparent underlying function” (42), and therefore are of a pragmatic nature; they are there to reinforce the linguistic and political stance of the author vis-à-vis mainstream literature.

Another category of pragmatic codeswitching is that found in songs, sayings, expressions, prayers, etc., of which there are quite a few in the novel: "una mujer con un diente, que llama a toda la gente” (37), "la campana de la iglesia está doblando...” (37), “arrímense vivos y difuntos / aquí estamos todos juntos..." (37), "por la sangre de Lupito, todos debemos de rogar, que Dios la saque de pena y la lleve a descansar...” (34), "nuestra casa es su casa” (12). In addition to reinforcing the Chicano world, these are also pragmatic switches as they perform a metaphorical role more than a communicative role. They are usually left untranslated, without any context to gather meaning. However, their meaning does not advance the storyline. This is a risky move by the author, as the monolingual reader is left in the dark as to their meaning since they are full sentences that cannot be easily looked up in a dictionary, or in the glossary, if one is provided.

A total of 66 switches are related to religious terms (Virgen de Guadalupe, Dios mío, Ave María Purísima, Jesús, María y José, Dios, adiós, Madre de Dios, Madre mía, gracias a Dios, etc.), which are closely connected to the cultural component. All these terms have English equivalents, but the author chooses to keep the Spanish, so as to contribute to the mythical aura of the novel and add semantic force, which would be lacking if they had been provided in English. 
Swear words are even more numerous than religious terms, some of which are particular to those used by Mexicans and Chicanos. Undoubtedly, these contribute to the Chicano atmosphere, but their frequency is also a sign of intentional use.

Finally, interjections and tags are also frequent switches in Bless Me Ultima. The interjection "ay" appears 59 times. "Ay" is an interjection that expresses pain or affliction. It usually precedes a person (or entity) to whom the complaint is expressed, that is, in the vocative form: "ay Dios” (31), “ay que Lupito” (17), “ay, hijito” (44), "ay papá” (51), “¡Ay, Dios mío! (89), “Ay, Jesús, María y José” (178), etc. It is also reinforces any statement: “¡Ay sí!” (139), “¡Ay no!” (155), “iAy maldecido!” (169), “¡Ay que diablo! (170), “Ay cabroncito” (198), “ay, mujer” (239), etc. It also appears by itself, followed by a switch to English, which denotes the intention of identifying the utterance as probably being spoken in Spanish prior to being translated into English by the narrator.

This study argues that the author tries to find every opportunity to insert Spanish text as frequent as possible without making the read impossible to a monolingual English speaker, except for a few tokens, for which the author uses different strategies. Codeswitching is either found in the speech of the narrator or in that of the characters. I have put forth above that the character that makes the most use of codeswitching is the narrator himself (who is also a character), however Anaya tries to maintain a balance and transfers some codeswitching to the other characters. Therefore, much codeswitching appears in the form of direct quotes: "Está sola, "my father said” (2), “'Ave María Purísima,' my mother made the sign of the cross...” (3), “'Sí, mamá,' Theresa repeated.” (8), “‘Jasón no está aquí,’ she said.” (10), “‘Mi hermano, mi hermano!’ Chávez sobbed.” (17), “’Por Dios, hombres!' he shouted.” (21), “‘AAmigo!’ Narciso shouted.” (23), ““Ay, 
María Luna,’ Ultima interrupted” (33), “‘Es una mujer que no ha pecado...’ some would whisper of Ultima” (35), etc. Almost every character in the novel uses Spanish at some point, even if briefly. This demonstrates the author's intent to portray all of his characters as Chicanos and as speakers of Spanish, whose dialogues he is mediating and translating into English.

A bold proposition by Anaya, as opposed to some of his contemporary and fellow Chicano writers, is that he refrains from typographically marking the code-switched text in any way (e.g., italics). Inserting full Spanish words, without any clarification or translation is certainly a pragmatic move: " $Y$ You do not have the huevos!" (169), is uttered by one of the characters, Narciso, meaning "you do not have the guts", in which case, a literal translation of "huevos" (eggs) would not help the reader understand the phrase. There are also idiomatic expressions, some of which are particular to the Chicano community, and not even accessible to other Spanish speakers: “...voy a tirar tripas...” (218) (meaning “I am going to throw up”), “a la veca” (which is an attenuated version of another stronger profanity: “a la verga”).

The author also makes an effort (although not always) to use Spanish orthographic symbols, such as tildes, diacritical accent marks, initial or opening question and exclamation marks, as used in Spanish: “Adiós! ¡Adiós!” (148), “¿Qué? ¿Qué pasa?” (273) (notice the diacritical accent marks and the opening exclamation/question marks). By using Spanish orthographic symbols, the author wishes to show full command of the embedded language-information to which the reader would have no knowledge otherwise. 
This study posits that any instance of codeswitching which is not justified by literary or cultural reasons, as described above, is a pragmatic move on behalf of the author, who wishes to make the reader aware of the language that he is using. In analyzing the language of a literary work it is necessary to be reminded of the two-level structure present in any work of fiction. At one level, the narrator is telling the reader a story, but he or she (the narrator) may be fictitious, just as the events. At another level, there is the author, who undertakes the task of writing and making explicit language choices. Therefore, codeswitching in Bless Me Ultima cannot be blamed on the characters as they are only the product of the author's creation. It is the author who has made the linguistic choices that readers see on the page, and hence the importance of understanding what those language choices mean. codeswitching is performing roles well beyond communication.

\subsection{PARTIAL FINDINGS}

It is not until the early 1960s that literature written in a mixed code (i.e., codeswitching) begins to appear, fostered by the newly created Chicano Movement. However, the birth of such a movement was not fortuitous. Rather, it was the result of decades of marginalization of the people — and their descendants—-who inhabited the American Southwest before its annexation by the United States in 1848. Their artistic manifestations documenting this experience were varied, literature being one of them.

Because of their connection to Mexico and to the Spanish language, these writers chose to write using a mix of English and Spanish—-technically called codeswitchingwhich they found mirrored adequately their feelings of in-betweenness, alienation, identity and ethnic struggles, marginalization, discrimination, etc., to which they had 
been subjected for decades. Such themes are reflected in most, if not all, the Chicano literature of the time. Thus, in addition to creating literature, the artistic production of the time also became the political arm that would spread the word around the country about the Chicano predicament. These productions used the recently created Chicano cultural outlets. Such was the case of the novel Bless Me Ultima, by Rudolfo Anaya, which was published by one of such Chicano outlets in 1972. It gained prominence very quickly and set the tone for dozens more to come by other Chicano writers, who, having seen the success obtained by Bless Me Ultima, did not hesitate to follow its pattern.

Chicano literature was characterized by the use of codeswitching, at least in the works produced during the height of the Movement. Such language was appropriated at the time of the Chicano Renaissance as an additional combative element for the advancement of a Chicano agenda, not entirely because it reflected the speech of Chicanos—although it could be argued that a mimetic effect is intended and achieved at times-but to take advantage of the momentum and open up space for the Spanish language in mainstream America.

This study claims that knowledge of Spanish by the authors is not relevant and cannot be ascertained from their writings, nor is it required to produce Chicano literature. Its use is of a pragmatic nature. The employment of Spanish adds an extra element of validation and credibility to the Chicano novel, and to justify it, it is used as a literary technique.

It is important to stress the fact that fiction works produced at the height of the Chicano Movement, particularly in the period to which Bless Me Ultima is ascribed, were among the first excursions of codeswitching in literature. Although there had been uses of 
codeswitching before outside the U.S. context, in the Spanish-English combination, Chicano writers were the first to venture to codeswitch. This bold stance has been instrumental for other writers to follow suit. Hence, the codeswitching exhibited by most early Chicano writers is rather timid and scarce-when compared to later writers-and has to be viewed against its historical and political context.

Above, I have described the uses, extent, classification, strategies, and other characteristics of codeswitching in Bless Me Ultima. As argued in the Introduction, codeswitching is not merely a decorative devise, as a cursory analysis may indicate. Still, decoration cannot be ruled out as one of the purposes of codeswitching. In the case of Bless Me Ultima, the topic itself is a major justification of codeswitching from a literary point of view. After all, a novel written by a Chicano in a Chicano context and in Chicano territory should incorporate the language of Chicanos to validate its credibility. Doing so also imprints a distinctive character to the novel. In addition to that, as listed in the sections above, ethnic terms, culinary terms, endearment terms, and cultural expressions are considered cultural borrowings, for which no English word might be available. This also justifies codeswitching. However, all of the above corresponds to the surface level of the text. It does not reveal much about its ideology. Furthermore, the codeswitching exhibited in Bless Me Ultima cannot be considered a reflection of the author's bilingualism either. In addition to these justified uses of codeswitching, this study posits that codeswitching is highly deliberate, and responds to motivations beyond the surface level of the text. (i.e., at the pragmatic level), which can only be seen when studying the text as a whole. 


\section{CHAPTER 2}

\section{NUYORICANS: NEITHER HERE NOR THERE}

I am two parts/a person / boricua/spic / past and present / alive and oppressed / given a cultural beauty / ... and robbed of a cultural identity /

I speak the alien tongue in sweet boriqueño thoughts / know love mixed with pain / have tasted spit on ghetto stairways / ...here, it must be changed / we must change it

\subsection{INTRODUCTION}

Here-Sandra María Esteves

Writers of the Puerto Rican diaspora have adopted the use of codeswitching in their production since the late 1960s, whether in the form of novel, play, autobiography, memoir or poetry. Puerto Rican literature written in the United States was most prolific at the height of the Civil Rights Movement in the 1960s and 1970s, a cause that New York Puerto Ricans readily joined after many years of social injustice. As a result, New York Puerto Rican writers obtained similar recognition as did the Chicano movement in the U.S. Southwest around the same time.

In Chapter 1, this dissertation explored the first literary productions that incorporated the use of codeswitching in the United States and how this linguistic feature is used beyond a decorative or literary element with social and political significance. It is widely accepted in the sociolinguistic realm that the use of codeswitching by a minority group performs a role beyond mere communication. In the case of literature, codeswitching seeks in-group solidarity, helps gain recognition or attention outside the minority group, establishes a voice, style and theme for the group, and gives validity to the embedded language (i.e., Spanish) and by extension, to the community that speaks it. 
It also allows writers to expand their readership outside their own communities and to inform a broader audience about their culture.

In this chapter, this dissertation will take a 20-year leap forward and will now focus on Esmeralda Santiago, a Puerto Rican author from New York who began writing in the 1990s, once the literary boom experienced by Puerto Rican writers in the United States had already died down. It is expected that taking some distance from the author studied in the previous chapter will allow us to view Latino literature diachronically and observe how new or different social and political conditions hinder or promote the use of codeswitching.

Santiago migrated as a child to New York City and lived the "neither here nor there" experience, as clearly portrayed in her work—particularly in her memoir from 1993, When I was Puerto Rican and its sequel Almost a Woman. This first memoir will be the subject of study for this chapter, with the aim of gaining an insight into the writing of the Puerto Rican diaspora, and in turn into that of Latino literature as a whole.

Unlike the writers from the Nuyorican Movement who engaged in a very dynamic use of codeswitching that it became an intrinsic part of their literary expression—form and content complementing each other-Santiago exhibits a more calculated use of codeswitching, which she only uses in the minimum amount necessary. Her codeswitching performs a literary role and gives her work a Latino flavor. This chapter will delve into her memoir in order to understand how the use of codeswitching varies depending on the times and external conditions in which the authors find themselves, which is one of the tenets of this dissertation. 
The following sections provide a background of the historical, political, and cultural contexts of the Puerto Rican immigration to the United States-particularly to New York City during the first half of the twentieth century - that are essential to understanding Santiago's work and her use of codeswitching.

\subsection{PUERTO RICANS, BORICUAS, NUYORICANS: HISTORICAL OVERVIEW}

Puerto Ricans are the second largest Hispanic group, after Mexicans, to have migrated to the United States. Their first migrations date back to the second half of the nineteenth century, which makes them the second Hispanic group to have been in the United States the longest, after Chicanos. An estimated 5.1 million Puerto Ricans are said to have immigrated to the United States to date, particularly to the New York region, a huge number compared to 3.5 million people living on the island today. ${ }^{26}$ Despite a continuous migration and back and forth commuting between the island and the mainland, most historians and scholars of the Puerto Rican diaspora agree on at least three large migratory movements to the United States.

The first migration was around the end of the nineteenth century, when political activists and independence revolutionaries left the island in exile. These were educated individuals and included some prominent figures such as Ramón E. Betances, Lola Rodriguez de Tió, and Eugenio María de Hostos, among many others. This first group is referred to as the pioneros. The second migration took place during the first half of the twentieth century, around the time Puerto Ricans acquired U.S. citizenship (1917) under

\footnotetext{
${ }^{26}$ Source: U.S. Census Bureau, 2014
} 
the Jones Act. ${ }^{27}$ The third group—and the largest of all—known as the "Puerto Rican diaspora” or the "Great Migration” was between 1946 and 1964 (Chabrán, Flores, Aparicio, Epple). ${ }^{28}$ This was largely caused by the post-war industrial boom in New York and New Jersey—particularly in the garment and tobacco industries—, the dire economic conditions on the island, and the establishment of non-stop routes between New York and San Juan by American Airlines (la "guagua aérea” or the flying bus), thus giving way to what has become to be known as the "revolving door" or "commuter" migration, or "wholesale importation" (Flores). ${ }^{29}$ This migration has also been identified as the "first airborne migration” (Soto-Crespo ix) in history, due the huge distance between Puerto Rico and New York (1,380 miles). Since then, Puerto Rican migration has not stopped, however, it is not happening en masse as it did in mid-century.

Migration to the mainland would increase or decrease based on the economic conditions both on the mainland and on the island. Right after World War II, Puerto Rico was characterized as having high unemployment—as high as 40 percent at times. In 1946 travel restrictions imposed during wartime were lifted and the result was the migration of thousands of people, as described above. By the end of World War II, approximately 135,000 Puerto Ricans lived in New York, and by 1960, more than 1 million were in the country (González 81). Operation Bootstrap, a program launched by the U.S.

\footnotetext{
27 Puerto Ricans have had right to U.S. citizenship since 1917; 19 years after their land was ceded to the United States following the Spanish-American War of 1898 when it became unincorporated territory.

${ }^{28}$ Diaspora, as opposed to migration, has the implicit meaning of being involuntary, or being forced to leave one's land in mass, and implies the lack of assimilation to the host country. This is the term used by many scholars to refer to the Puerto Rican migration.

${ }^{29}$ Metaphor coined by Luis Rafael Sánchez in an essay from 1993 "La guagua aérea," which refers to the constant travellers between Puerto Rico and New York.
} 
Government in 1948, sought to industrialize the economy of the island "and make Puerto Rico a showcase of the Caribbean” (Luis 104). It proved to be insufficient to keep Puerto Ricans on the island, who emigrated massively to the United States in search for higher wages as the program failed to improve their living and working conditions and —on the contrary—forced them to abandon the fields.

Ironically, because of their U.S. citizenship—which should have meant they could not be exploited as other undocumented immigrants on the mainland were-Puerto Ricans were not the desired laborers, thus marking the beginning of their history of exploitation, discrimination, poverty, and political disenfranchisement. Puerto Ricans have occupied the lowest rung of the social ladder in the United States. Juan González explains that despite their "de jure citizenship, the average North American, whether white or black, continues to regard Puerto Ricans as de facto foreigners" (81). Such attitudes of discrimination were reinforced by movies or plays such as West Side Story (1957), The Young Savages (1961), etc., which portrayed Puerto Ricans as violent, addicted to drugs, and uneducated. In addition, Puerto Ricans have lived as colonial subjects on the island and have experienced cultural, linguistic, and racial discrimination on the mainland. Paradoxically, they have fared worse than other immigrant groups, despite their right to U.S. citizenship. As noted by Jean Franco in the Introduction to Divided Borders by Juan Flores, Puerto Rico "is an island and a continent, a colony and a nation, a community bound by a language that some Puerto Ricans do not speak” (9).

In order to distinguish New York Puerto Ricans from those on the island, the former came to be known as Nuyoricans, a term that was originally pejorative or derisive, but was eventually adopted by New York Puerto Ricans themselves to mark such 
distinction and to imply a collective identity of émigrés. ${ }^{30}$ Thus, for the purposes of this study, Nuyorican has the latter meaning, however anachronistic or geographically inaccurate it might be as the Puerto Rican diaspora is no longer confined to the New York area as it once was. Nuyorican here is employed as a historical term that represents the artistic and literary production of New York Puerto Ricans.

Just as Chicanos adopted the mythical region of Aztlán as a connection to the land, Puerto Ricans have adopted the Borinquen in search for their roots, to trace their origins back to Pre-Columbian times, which is the origin of the self-affirmation term "Boricua."31 Juan A. Epple explains that: "Borinquen was transformed, in accordance to the ethnic mythology of the times, into a lost tropical paradise" (345). Thus, the adjective Boricuas—-those belonging to Borinquen—is, in the words of Margarita Melville, "a self designation that emphasizes the struggle for a non-colonial status that rejects both Spanish and United States’ hegemony over them” (92). Nuyorican and Boricua are terms that denote cultural affiliation and self-affirmation, the former is certainly tied to a geographic space, namely, New York.

Although this dissertation deals with Puerto Ricans in the United States, the experience of Puerto Ricans on the island is inextricably tied to the diaspora. Puerto Ricans on the island also have their share of complaints vis-à-vis the United States; their pseudo-colony or neo-colony condition being one of them-under the label of “commonwealth”- -but whose status of subordination to the United States is uncontested

\footnotetext{
${ }^{30}$ Term coined as self-defining in the 1970s by avant-garde poets Algarín and Piñeros in New York City.

${ }^{31}$ Indigenous Taino name of Puerto Rico that means the Land of the Valiant Lord, as recorded by Spanish chroniclers.
} 
by autonomists, statehood supporters and independentists alike. ${ }^{32,33}$ The word "libre" in the official Spanish name of Estado Libre Asociado is misleading for some. For José L. Torres-Padilla, "It promotes that illusion because it gives the sensation that the Puerto Rican people are controlling an 'internal space' outside hegemonic capitalist control when ultimate power remains in the hands of the U.S. Congress and president” (86). The issue of the status of Puerto Rico—-known as the world's oldest colony—and its relationship with the United States is the most debated topic in Puerto Rican politics today that comes up more strongly than any other during election time:

At the heart of the status question we find the explosive theme of cultural destiny: Is Puerto Rico to became an independent nation, a federated state, or an enhanced commonwealth? This is the driving concern of the Puerto Rican community on the island. It not only preoccupies their daily life but also constrains the way they perceive themselves and their global location. (Soto-Crespo xiii)

Several voices are in agreement on defining Puerto Rico's political status as one of subordination to the United States and calling it a colony, including Juan Flores, a scholar of Puerto Rican studies, who claims that "this island nation is still a colony by all indicators of international relations, its economic and political life fully orchestrated by its mighty neighbor to the north, the putative leader of world democracy and sovereignty" (9). Flores defines Puerto Rico's notion of colonialism as "lite colonialism," when

\footnotetext{
32 The status of Commonwealth allows Puerto Ricans to decide on their own on issues that are outside federal jurisdiction, such as education, and local taxes, but have no participation at the federal level.

${ }^{33}$ The three political tendencies found on the island are: 1 . Independentists, those who seek to become an independent country. 2. Statehood supporters, those who claim the right to be considered the 51st state of the Union. 3. Supporters of the status quo, the Commonwealth status.
} 
compared to more traditional definitions of colonialism; one that is more based on consumption as opposed to the traditional one based on the exploitation of the colony's production. Also, for Lisa Sánchez González, even if not provided by the U.S. Constitution, "all Puerto Ricans are both American citizens and colonial subjects by birth according to international law" (1). The above are just some of the voices on this heated debate. To say the least, the relationship of Puerto Rico to the United States is unique and anomalous with no solution in sight.

The history of the Puerto Rican status goes back a long time, but the latest event in this complicated dilemma is that a relative majority (54\%) of Puerto Ricans seems to reject the current "commonwealth" status, according to the referendum held on the island in November 2012. Also, 61.2\% of those dissatisfied with the status quo voted for statehood (Garret). However, such results were too close and not very clear, at least not conclusive enough to present a solid case in Congress. ${ }^{34}$ Perhaps the words of President Taft still resonate strongly when in 1912 he clearly said to Congress—when discussing U.S. citizenship for Puerto Ricans—-that citizenship "in the minds of most Porto Ricans [sic] [must be] entirely dissociated from any thought of statehood” (quoted in González 303). Such a choice speaks volumes about the dissatisfaction of Puerto Ricans with the treatment of the island as a mere colony: only contributing to the colonizer but without receiving full benefits. What was clear from the plebiscite is that the majority of Puerto Ricans do not favor independence either. More than becoming an independent country—

\footnotetext{
${ }^{34}$ There have been five referenda on the status question to date. In November 2012, Puerto Ricans were asked whether they wished the maintain the current Commonwealth status, to which $54 \%$ of voters answered "No." In a second question, voters were given three choices if they answered "No" to the first one. 61.2\% chose for statehood. (Source: "Puerto Rico's Political Status and the 2012 Plebiscite: Background and Key Questions.” Congressional Research Service, June 2013.)
} 
which they have never been-they wish to be treated as equals in the Union. This rejection for independence could also be read as a fear to assume the responsibility for their own destiny, which can be explained in the words of Frantz Fanon, the post-colonial theorist, who argues that: "The effect consciously sought by colonialism [is] to drive into the native's heads the idea that if the settlers were to leave, they would at once fall back into barbarism, degradation, and bestiality” (210-11). This insecurity to survive on their own could be explained by their "lack of history" since the history Puerto Ricans have been taught in school is that of the United States. As explained by González: "For the first fifty years of the U.S. occupation, public schools on the island sought to bury any memory of a culture and history that existed before the U.S. flag was planted” (289). In the second half of the twentieth century efforts were made to recover such erased history with the establishment of the Institute of Puerto Rican Culture in 1955, among other undertakings.

This issue is relevant to this dissertation since the fact that Puerto Rico is not an incorporated state of the nation has also contributed to the barriers Puerto Ricans have had to face to succeed on the continent. For some Puerto Rican scholars, the inability of Puerto Ricans to succeed on the mainland is partially explained by the mentality of colonial subjects they have been carrying for generations. Such mentality is absent from other immigrant groups, who may have immigrated for the same economic pressures as Puerto Ricans. Not having a history of their own prevents them from having ownership on the issues of the island. Rather, its history is closely tied to that the United States, but it seldom appears that way. As argued by Flores, 
Its occupation in 1989 after four centuries of Spanish colonialism, the decades of imposition of English, the unilateral decreeing of American citizenship in 1917, economic and social crisis during the Depression years, externally controlled industrialization, unprecedented migration of the work force and sterilization of the women, ecological depletion and contamination, relentless cultural saturation—all these events pertain not only to Puerto Rican historical reality but to the recent American past as well. (Divided 143)

From the above, it is easy to understand the dissatisfaction of both Puerto Ricans on the island and on the mainland. This also explains the source of the identity issues that are evident in their literature, including their linguistic dichotomy.

The linguistic identity of Puerto Ricans also deserves attention. On the island, Puerto Ricans are highly influenced by English due to the intensive American presence in the media, businesses, products, education, etc. On the mainland, such influence is even stronger as the next sections will show.

\subsection{THE LANGUAGE OF NEW YORK PUERTO RICANS}

Reviewing the sociolinguistic situation of New York Puerto Ricans is relevant to this research to continue exploring how codeswitching is used and its connection to Latino literature. It was observed in the previous chapter how Chicanos used codeswitching in their writing as an additional element in the affirmation of their ethnicity, despite the negative views of codeswitching existing at the time, and that still remain to this date. 
It is also important to highlight the difference in codeswitching between Chicanos and New York Puerto Ricans, which has been studied by some scholars (Peñalosa 1995, Mendoza-Denton 1999) derived from different processes of bilingualism. Whereas all living Chicanos were most likely born on U.S. territory, there are New York Puerto Ricans who were not born in the mainland for whom Spanish is still their native language, given different historical processes for each group. The implication of this is that first, second, and third generation New York Puerto Ricans-even if born in the mainland—may still hear Spanish at home from their elders who still retain the language, which might not be case for Chicanos. In addition to this, the circular migratory pattern between Puerto Rico and New York has fostered a distinctive codeswitching style. For Shana Poplack, New York Puerto Ricans are a "stable bilingual community, rather than a transitional one." She also claims that this community has been able to maintain their native language longer in contrast to other immigration groups who usually complete their language conversion by the third generation (582). On the other hand, even though current Chicanos were born in the United States and have for the most part inserted themselves in the American education system, their proximity to Mexico has also had an influence on the amount of Spanish spoken at home (Mendoza-Denton 381). The result of these differences in geographical, historical, and linguistic conditions can have an influence on how codeswitching is used or viewed by these speakers.

The term Nuyorican already implies the switching between the two languages, or what is commonly known as "Spanglish," which is regarded as an inferior language by those on the island—and elsewhere—even if they themselves speak a form of Spanish highly influenced by English, but different, nonetheless. Hence, in linguistic issues, 
Nuyoricans are subject to double discrimination: on the mainland for speaking an imperfect English, and on the island for speaking an imperfect Spanish.

In the past, sociolinguists have turned their attention to the linguistic situation of Nuyoricans, which has proven to be a fertile area for the study of codeswitching. Because of the close-knit communities existing in East Harlem, the South Bronx, and Lower East Side of Manhattan some sociolinguistic studies (Poplack, 1980; Zentella, 1981; Pedraza, 1985; Mendoza-Denton, 1999) have been conducted aiming at explaining such a phenomenon. Poplack claims that because of the size of the Puerto Rican community and the state of continuous contact with the island, the presence of Spanish or an EnglishSpanish hybrid has been maintained (582). Poplack's assertion would imply that Puerto Ricans codeswitch more than other immigrant groups, which is something that lacks sufficient research, if any. However, it is easy to assume that due to the ghettoization of Puerto Ricans in New York members of this community are more likely to engage in speech acts in which codeswitching is the norm than if such condensation of bilingual speakers did not exist in their communities. This claim is also supported by MyersScotton's Markedness Model, which indicates that there are situations in which codeswitching is so normal that it becomes the unmarked or usual code for conversation rather than the marked or unusual code (Social Motivations 114).

One of the motivations for this research is to see to what extent such language hybridity has been transferred to the literature produced by this group. Another important goal is to see how codeswitching by Nuyorican authors is different from or more/less intensive than that practiced by other immigrant groups, or by other Puerto Ricans that were writing outside the Nuyorican literary movement in order to determine whether 
there is any forward movement or intensification on the use of codeswitching, both orally and in writing.

When comparing the Chicano language to that of Puerto Ricans, one of the main differences is that the language adopted by Chicano authors in their writings in the 1960s and 1970s was not necessarily a reflection of their own spoken language. Even though many Chicanos speak Spanish, it is unlikely that Spanish would be their first language. A simple explanation is that they do not have the institutional support (i.e., the school system) to have acquired and maintained Spanish as their native language beyond the home environment. Puerto Ricans, on the contrary, have a permanent contact with the island due to their constant travels, and since their migration to the United States can be traced back to around the middle of the twentieth century, it is possible to posit a closer connection to the Spanish language for being either first generation immigrants—or what is called "1.5 generation"—-and having household members whose native language is still Spanish. This places them under a different framework than Chicanos. Still, this difference does not provide clear clues as to how their writing would be different, due to the artificiality of the written language in literature.

As suggested by the sociolinguistic studies referenced above, Puerto Ricans in New York engage in active codeswitching, despite the negative views of such language use, which portray Puerto Ricans as deficient speakers of both languages, in addition to their association with poverty and ignorance. This study will turn its focus to the literature produced by New York Puerto Ricans to see how much of that intensively practiced codeswitching is transferred to the written page. 


\subsection{HISTORICAL OVERVIEW OF NUYORICAN LITERATURE}

Just as the migratory movements can be divided in different groups as outlined above, so can Nuyorican literature. Puerto Ricans in the mainland have been writing since the arrival of the group of émigrés that have been described as political exiles who were escaping from the persecution of the Spanish Crown. This first group wrote in Spanish and their production was mainly journalistic, testimonial, and autobiographical writing in defense of their cause for independence of the island. These works were still strongly tied to "views from the island" (in Flores's words) and constitute the first samples of diasporic writing, most of which is hardly known, studied or recorded as part of American literary history or of any other history.

The first samples of writing by authors who "were here to stay" (Flores’s term) are the Memoirs of Bernardo Vega by Bernardo Vega, and A Puerto Rican in New York by Jesús Colón, published in 1977 (posthumously) and 1961 respectively, but written in the 1940s. They anticipate a more militant generation of writers that would come in the next decades. Colón has been identified by some as the "Father" of the Nuyorican Movement, due to his denunciation of racism experienced by Puerto Ricans, as Colón was a Black Puerto Rican. These authors, who provide an account of the life of Puerto Ricans in New York, are grouped separately from other writers such as William Carlos Williams, Pedro Juan Labarthe, and Richard Ruiz, who present a more private and personal account that is disconnected from the diasporic experience of their Nuyorican predecessors and successors, as "they inscribe themselves within the individualistic values of middle-class America” (Aparicio F. 26). Using Aparicio’s terminology, this first group can be identified as "proto-Nuyoricans.” 
The second wave includes second generation Puerto Ricans, and spans from the late 1960s to the mid 1970s — the height of the Nuyorican Movement—, which is what most people identify as Puerto Rican literature today. Running almost parallel to the Chicano Movement in the Southwest, the Puerto Rican immigrant community of New York also had its awakening (also known as the Nuyorican Renaissance, analogous to the Chicano Reinassance), influenced and brought about by the same conditions as the former. Just as their Chicano counterparts, the basis for their discrimination was not for being undocumented or "illegal" but for their racial condition, which made them one of the poorest Latino communities in the United States.

After a presence of almost 100 years in the continent, Nuyoricans began to articulate their dissatisfaction by creating and presenting to the public a bilingual and bicultural identity through a Nuyorican aesthetics to distinguish themselves from the insular writers. ${ }^{35}$ Writers such as Pirri Thomas, Sandra María Esteves, Miguel Piñero, Miguel Algarín, Tato Laviera, Pedro Pietri, Lucky Cienfuegos, and Nicholasa Mohr, among others, were the first to dare to speak in a language that reflected their hybridity and marginalized condition. ${ }^{36}$ These were members of the Nuyorican Movement and the Young Lords Party, two revolutionary movements created by New York Puerto Ricans at the time, which reached its prominence between 1969 and 1972 and whose members became influential community leaders. According to Sánchez González: "the primary

\footnotetext{
${ }^{35}$ This was by no means the first Puerto Rican writers to write from the mainland but were the first to come together as a group. Previous writers include William Carlos Wiliams, Pura Belpré, Arturo Schomburg, Luisa Capetillo, among others, which Lisa Sánchez González calls “Old School” Boricua intellectual tradition, from the turn of the twentieth century to the early 1960s (102).

${ }^{36}$ All of these authors, poets, playwrights, essayists and novelists were born in New York City before or around 1950.
} 
underlying concern among them as a group is the construction, through literature, of Boricua cultural citizenship as an organic—and organically resistant—North American formation” (103). Drawing on the precepts of Pierre Bourdieu, I claim that this second group of writers was instrumental to earning cultural and linguistic capital for New York Puerto Ricans, which led them to occupy a distinctive place in Latino letters today.

As pointed out by Flores, Nuyorican literature can be equated to that of Chicanos due to the "long standing history of conquest and colonization ... which contrasts with that of comparatively recent arrivals from countries with less direct ties to U.S. imperial power" (Bomba 176) He claims that "the newly arrived Latino writers, immigrating from countries relatively free of direct colonial subordination, find some degree of accommodation within the support structures provided by their nation-states of origin” (Bomba 177), such as embassies, cultural offices, consulates, etc. To replace such a void, the Nuyorican Poet's Café and the New Rican Village were established, which would house - and promote - the cultural production of Puerto Rican émigrés in New York, where the majority of Puerto Ricans have traditionally settled. ${ }^{37}$ The Nuyorican Poet's Café was established around 1973 as a non-for-profit organization, and gathered some of the most prominent Puerto Rican poets. Today, the Nuyorican Poet’s Café is a multi-arts and multi-cultural institution that gives voice to minority and underprivileged artists, filmmakers, poets, musicians, etc. who have not found mainstream outlets for their work.

Like Chicano literature, Nuyorican literature speaks of the experience in el barrio (East Harlem), discrimination, lack of opportunity, poverty; in sum, the struggles and

\footnotetext{
${ }^{37}$ Other vehicles that had previously promoted the Nuyorican literature were newspapers such as Gráfico (1926-1931), La Defensa (1941), El Diario (1948), and magazines such as Artes y Letras (1933)
} 
inequalities facing diasporic Puerto Ricans, their colonial condition, and their need for social justice and civil rights—all in vogue at the time, what Sánchez González terms “ghetto testimonials" (134). ${ }^{38}$

With an American presence on the island that has extended over a century, the issue of cultural identity is a frequent topic in Puerto Rican literary production on both sides of the ocean. On the one hand, Puerto Ricans share the experience of colonialism and identity concerns, and on the other hand, they are separated by language, all of which is manifested in their writing. As pointed out by Edna Acosta-Belén, Nuyorican literature provides a "means of cultural validation and affirmation of a collective sense of identity that served to counteract the detrimental effects of the socioeconomic and racial marginalization that Puerto Ricans have experienced in the metropolis” (980). Nuyorican literature is both a continuation of the cultural traditions of the island as well as a new form of culture conceived in their new home.

In an attempt to identify the topics that pervade Nuyorican literature, AcostaBelén suggests four different issues that summarize the dialectic tension between the island and the mainland: 1 . The fragmentation of identity produced by marginalization and oscillation between the two cultural and linguistic contexts; 2. The geographical separation; 3. The distance produced by social and cultural differences; 4 . The clash between the values of a materialistic society and the spiritual values attributed to the oppressed class (993-4).

\footnotetext{
${ }^{38}$ Piri Thomas in Down These Mean Streets epitomizes life in the barrio in a Nuyorican memoir that reveals the identity struggle of a Puerto Rican who has to deal with cultural and racial differences as he survives in the ghetto.
} 
Nuyorican literature is not intellectual or academic, but urban; from the ghetto, the factory, the bodega, the barrio, the street, the sidewalk, the dilapidated concrete buildings that have already succumbed to gentrification. The most emblematic of Nuyorican literature, Down These Mean Streets narrates the story of its author, Pirri Thomas, in which he tells us of his growing up and surviving in el barrio in the midst of drugs, gangs, and violence, and his time in and out of jail for several burglaries. As aptly worded by Frances Aparicio, Nuyorican literature consists of texts "not only of political resistance, but also of physical and existential endurance; they are testimonies of the need for survival amidst the subhuman living conditions in which Puerto Ricans lived” (26); still caught in what Oscar Lewis calls "the culture of poverty."

Having presented the proto-Nuyoricans and Nuyoricans, this chapter will turn to an author from the post-Nuyorican or third group: Esmeralda Santiago. Other postNuyorican authors include Giannina Braschi, Judith Ortiz Cofer, Martín Espada, Victor Hernández Cruz, Carmen de Monteflores, Luz Ivonne Ochart, Ernesto Quiñonez, Manuel Ramos Otero, Edward Rivera, Oswald Rivera, Abraham Rodriguez, Iván Silén, and Ed Vega. The narratives of Post-Nuyorican literature present more diversity of voices and themes, compared to their predecessors, but always connected to the struggles highlighted by the Nuyorican generation. Aparicio claims that the post-Nuyorican styles "represent both a continuity with, and a departure from, the original Nuyorican program" (28). However, it is important to cover the groundwork advanced by Nuyorican writers in terms of linguistic use so that we may draw more conclusive findings when comparing it to a previous and future generation of writers. 


\subsection{CODESWITCHING IN NUYORICAN LITERATURE}

As reviewed above, Nuyoricans engage in the mixing of English and Spanish, or codeswitching, in their regular speech, which is also present in their literature. This language alternation is not free from criticism by their fellow Puerto Ricans on the island (or others elsewhere), who see codeswitching as a sign of assimilation, Americanization, and adoption of U.S. culture to the detriment—or an abandoning — of the Puerto Rican culture, and as a lack of linguistic skills in both languages.

Because of their alleged inability to speak Spanish well, Nuyoricans are excluded from the Puerto Rican literary canon on the island and, needless to say, from the American canon as well. Such alienation "here and there" is addressed by many Nuyorican writers in their works. Nuyorican literature is the sum of their social, cultural, political, ethnic, and linguistic condition, written against the American grain. Since the issue of language is central to the project at hand, it is important to flesh out the implications of adopting (or not adopting) codeswitching for writing. The issue of language alternation is paramount to Nuyorican literature, and is valued by scholars of the Puerto Rican diaspora (Flores, Aparicio, Yudice) as an element of ethnic affirmation. In the words of Flores:

Rather than abandoning one language in favor of another, contemporary Puerto Rican literature in the United States actually exhibits the full range of bilingual and interlingual use. . . . It is a literature of recovery and collective affirmation, and it is a literature of "mingling and sharing”, of interaction and exchange with neighboring, complementary cultures. (Stages 65-6) 
The first anthology of Nuyorican Poetry, published in 1975, confirms the need of writers "to invent a new language, a new tradition of communication" which is to be used to "fight with words" (Algarin and Piñero 24). Thus, codeswitching became a brand, not only spoken at the bodegas in the streets of el barrio, but also in literature, of which the Nuyorican writer was proud.

Tato Laviera perfectly encapsulates all the tensions of this community in his emblematic poem "My Graduation Speech" (1979), which combines the issues of language, race, ethnicity, acculturation, longing and rejection for Puerto Rico, and the recognition that neither language allows him to express himself:

i think in spanish

i write in english

i want to go back to puerto rico,

but i wonder if my kink could live

in ponce, mayagüez and carolina

tengo las venas aculturadas

escribo en spanglish

abraham in español

abraham in english

tato in spanish

"taro" in English

tonto in both languages. (La Carreta 7)

Their artistic and linguistic licenses also encouraged Nuyorican writers to freely write using codeswitching since the motivation (and justification) to do so was explicit in 
their work and did not need an explanation, shown in the excerpt above. I side with Aparicio in his view that "codeswitching in literature also reaffirms and documents the linguistic practices of the community. It gives voice to those who have been silenced historically. It asserts bilingualism as a viable and valid mode of communication and of creativity, both oral and written” (28). Furthermore, it denounces exploitation and discrimination; it seeks to reaffirm identity and to voice communal concerns. Aparicio is optimistic in his appreciation of Puerto Rican literature in the United States, to him: "It is a political perspective which has resulted from years of further education, explorations and cultural insights that ethnic minorities have gained in the last twenty years. It is, definitely, a new and more profound analysis of our marginalized status” (36). It remains to be seen in the coming sections whether such gains he talks about hold true today.

Given the dynamic codeswitching found in Nuyorican literature, a question that arises is whether it was written with a specific audience in mind (i.e., other Puerto Ricans and Latinos) since some of the best Nuyorican texts require knowledge of Spanish and English for full understanding. In the case of poetry, it is widely accepted that the poet enjoys linguistic liberties and licenses even if such language choices obstruct meaning. Poetry is considered to be spontaneous and to mirror the poet's inner thoughts, as if he/she were writing for him/herself, which is less the case for the prose writer. On the use of language alternation by Nuyorican writers, Flores adds that:

As recent studies of Chicano literature show, bilingual writing entails more than merely utilizing the aggregate of expressive possibilities in each of the vernaculars, as if the options were simply between two fixed vocabularies. More than a poetic device, code switching corresponds 
directly to the generalized linguistic practices of Puerto Ricans and Chicanos whose experiences gave rise to, and are in turn recaptured in, the representative works of each new generation of writers. (Divided 175)

I have dwelled extensively on the Nuyorican literary movement because at the time it was most prolific (late 1960s to early 1970s), and it was believed to have made great advances for Nuyorican and Latino literature in general, and confirmed the adoption of codeswitching by Latino authors, following the steps of Chicanos who had started it in the Southwest. There is ample evidence in the literature available from this period that indeed, codeswitching became the norm — not only in poetry but in all Latino literature in general.

I now turn to Esmeralda Santiago-a post-Nuyorican writer-who is part of a newer generation of writers, from the 1990s, to observe a sample of literature produced outside the Nuyorican Movement. As opposed to Nuyorican literature that expressed the laments of this minority and their resistance to assimilate, writers such as Santiago find a more confortable position from which to write having finally made their way amidst the hostility of the metropolis, as will become evident in the following sections.

\subsection{WHEN I WAS PUERTO RICAN: SUMMARY AND THEMES}

The book selected for this chapter is Esmeralda Santiago's first work, published in 1993 in the form of a memoir. When I Was Puerto Rican tells the story of Negi, or Santiago as a diegetic narrator, growing up in rural Puerto Rico until she eventually arrives in Brooklyn, New York. This is the first part of her trilogy, which spans from the age of four to fourteen. After constantly moving around the island from one home to another, her mother makes the decision to move the family to New York in search of 
better opportunities and for medical treatment for Negi's younger brother, who had had an accident. In Puerto Rico, the family lives in an underdeveloped barrio in Macún, surrounded by poverty, which she narrates matter-of-factly, as if life were the same for everyone. Negi, the oldest of seven children, is often sent to relatives to be taken care of while her mother works or travels. Despite the economic conditions of her family, and her role as the oldest child who must help around the house and take care of her siblings, Negi's childhood is a happy one while in Puerto Rico, and she moves to New York reluctantly, particularly because her father is not coming with them. This also means the breakup of her parents due to his adulterous life. Once in New York, although Negi is not happy at first and misses Puerto Rico, she succeeds academically due to her hard work.

The story, narrated in the first person, reads like a novel—although the author calls it a memoir - and is the typical novel of development, coming of age or bildungsroman. However, behind the innocent voice of the narrator as she tells the reader about her mischievous behavior and childhood issues, she innocently addresses social and political issues such as the colonial condition of Puerto Rico before her move, and issues of racial and language discrimination once she is in New York. There, everyday life presents the same struggles as on the island, and perhaps even worse as she is no longer a little child and is more aware of her condition (i.e., racial, linguistic, economic). She experiences first hand "the continued exploitation of female labor, the same or worse living conditions and the hostile way that English as a second language is taught in New York’s public schools” (Sánchez-González 157). In New York, her family is also constantly moving in and out of homes due to economic pressures. 
Negi eventually becomes assimilated into the American culture, not painlessly though. The issue of identity is present from the title of the novel—When I was Puerto Rican — which is already an intentional statement of a split identity. Despite all the struggles Negi (or Esmeralda) has to overcome as she tries to assimilate into the American culture, When I Was Puerto Rican is a story of success, and she wants her readers to know that. In her epilogue, she concludes by telling readers of her successful audition at the Performing Arts School and then about her scholarship at Harvard. She certainly does not want her memoir to end on a sad note.

The fact that she makes explicit her obtaining a scholarship to get into Harvard is also a conciliatory closing with her life in the United States. It is a statement of accomplishment and self-recognition, and here her memoir takes the tone of a lesson to follow for her readers. Success, however, does not mean assimilation for Santiago. Through the end of the memoir, she claims to cling to her jibara identity; the epigraph for the epilogue is Same jíbaro different horse.

In an interview after the publication of her novel, she reports: "I learned to insist on my peculiar brand of Puerto Rican identity. One not bound by geographical, linguistic or behavioral boundaries, but rather, by a deep identification with a place, a people and a culture which, in spite of appearances, define my behavior and determine the rhythms of my days" (quoted in Flores, Bomba 56). This is Santiago's defense of her Puertoricanness as she has been harshly criticized for not denouncing enough the discrimination to which she was subjected while growing up in New York, and for the conciliatory tone of her novel, in addition to the title of her book which has been read by many Puerto Ricans as a renunciation to her roots. 
Here, I would like to bring in the notion of locus of enunciation, posited by Stuart Hall since Santiago's strongest critics come from the island. Her place of enunciation is crucial to understanding her mollifying attitude. Hall claims, "We all write and speak from a particular place and time, from a history and culture which is specific. What we say is always 'in context', positioned" (his emphasis 392). She has had to defend her position and explain that what she meant by the title was that her childhood is no longer possible in Puerto Rico today, as it has become a modern place. Another reason is the imposition of the terms Latino and Hispanic in the United States, which seem to replace one's own ethnic or national label, and a third reason is that the title refers to what she felt when she returned to Puerto Rico and was told that she was no longer Puerto Rican, despite her efforts for maintaining her ties to the island during her life in New York. Thus, the title describes her feelings of being considered an outsider by her own people (When I was Puerto Rican Title Question).

For her critics, it seems that one cannot de-identify oneself from one's place of origin, unless one has given up one's nationality. In this case, if one is born in Puerto Rico, one is always Puerto Rican since Puerto Rico does not confer a nationality but an ethnicity. Since she was fully Puerto Rican, she has had to adapt her identity to her new environment: Living in America. Such is the theme of her memoir: her acculturation to Anglo-American life. One can also read the past tense in the title as a transformation of Santiago from Puerto Rican to Nuyorican: She claims: "For me, the person I was becoming when we left was erased, and another one was created. The Puerto Rican jíbara who longed for the green quiet of a tropical afternoon was to become a hybrid who would never forgive the uprooting” (209). 
Even though it is Negi's voice as a young girl we hear, the actual voice is that of the grown up writer, Esmeralda Santiago, who is the summary of her experiences or in terms of Hall "what she has become." Negi the girl and Ms. Santiago, the celebrated writer, are not speaking at the same time or from the same place. Hall's theory encapsulates Santiago's narrative in the context of a post-colonial experience:

Cultural identities come from somewhere, have histories. But, like everything which is historical, they undergo constant transformation. Far from being eternally fixed in some essentialised past, they are subject to the continuous 'play' of history, culture and power. Far from being grounded in a mere 'recovery' of the past, which is waiting to be found, and which, when found, will secure our sense of ourselves into eternity, identities are the names we give to the different ways we are positioned by, and position ourselves within the narratives of the past. (394)

I dwell extensively on Santiago's place and time of enunciation because as it will become evident in the following sections, the same conditions under which she narrates her story are also present in the language choices she makes for her storytelling. It is also clear that her themes and tone depart from those adopted by her predecessors in the Nuyorican Movement. I argue there is a connection between the writer's position vis-ávis her experience in the United States and the level of language alternation used in her writing. For that, the following sections will dissect the codeswitching observed in her book. 


\subsection{CODESWITCHING IN WHEN I WAS PUERTO RICAN}

As pointed out above, Spanglish or Nuyorican Spanish became the brand of Nuyorican poets such as Tato Laviera, and Maria Esteves, to the point that Nuyorican and Spanglish became synonymous, as articulated by Algarín: "The experience of Puerto Ricans on the streets of New York has caused a new language to grow: Nuyorican. . . . There is also a lot of Spanish, and Spanish is now gaining” (15), and indeed in general, Algarín celebrates the presence of Spanish and the hybridity of cultures in New York. This was the case in the early seventies. Hence, it is surprising —or maybe not, as it will become evident below—-to see that almost two decades later, Esmeralda Santiago does not follow the distinctive language that her fellow Puerto Ricans had been using two decades before, which they considered gained territory. She has clearly expressed her views on language, which talk about her cultural and linguistic dichotomy:

When I write in English, I have to translate from the Spanish that preserves my memories. When I speak Spanish, I have to translate from the English that defines my present. And when I write in Spanish, I find myself in the middle of three languages, the Spanish of my childhood, the English of my adulthood, and the Spanglish that crosses over from one world to the other like we ourselves crossed over from one neighborhood in Puerto Rico to the borough of Brooklyn. (quoted in Sprouse 108)

Despite expressing being caught between two languages and two cultures, such hybridity is not as evident in her writing as she reports. She painstakingly avoids making Spanish switches except when the words would be transparent to the reader. She has crafted the language of her book in a way that it appears as if she were switching 
languages when in truth she is not by using the accommodation strategies explained below. Authors from the Nuyorican Movement did not accommodate their language for their readers. They deliberately and generously mixed the two languages without regard for the monolingual reader; a strategy that implies a political stance and was believed to contribute to the positioning of Latino literature.

The only distinction in her favor that can be made from her predecessors is that her predecessors were writing poetry. Writing poetry and narrative are indeed two very distinct forms of literary expression. As stated elsewhere in this research, poetry—which accounts for the largest production of Nuyorican art—is more permissive of language use and it is thought to be spontaneous writing, whereas writing a novel requires planning, organizing and arranging one's thoughts in a more structured way, which includes a careful selection of language choices. However, there are examples of other Nuyorican writers of narrative that are contemporary with Santiago, such as Giannina Braschi,attributed with having written the first fully Spanglish novel: Yo-Yo Boing! published in 1998 - who make no concessions to the monolingual Anglo reader. From this, it is possible to posit that the choice to codeswitch is a personal one and may not be attributed to a whole group.

Browsing through the pages of When I was Puerto Rican, one can observe the presence of Spanish words, as they are clearly identified in italics. However, a closer look and more detailed analysis offered below in this section reveals that codeswitching, in its strict sense, does not occur except for a couple of instances: "Te preguntó el Mr. Barone, you know, lo que querías hacer when you grow up?’ I asked. 'Sí, pero, I didn’t know. ¿Y tú?' 'Yo tampoco. He said, que I like to help people. Pero, you know, a mí no me gusta 
mucho la gente’” (258). This dialogue is offered by the narrator as a sample of her conversation with other immigrants, which she claims she uses for everyday speech: "We spoke in Spanglish, a combination of English and Spanish in which we hopped from one language to the other depending on which word came first” (256), but she never employs codeswitching herself in her narration or in the voice of her characters.

The codeswitching exhibited in her work is sporadic and limited to the insertion of isolated switches and when used, the author almost always provides some type of glossing or explanation. The strategies used to compensate whenever Spanish switches are made are summarized as follows:

1. Explanation: An explanation is provided by the narrator or the speaker after Spanish terms or phrases are used. For example:

““Papi, what's a jamona?’ I asked... 'It’s a woman who has never married’” (89) “Sí! I would! ¡Sí!” (53)

“...Mami always told me to be más disimulada when I stared at people, which meant that I should pretend I wasn’t interested” (239).

“At home we listened to aguinaldos, songs about the birth of Jesus and the joys of spending Christmas surrounded by family and friends. We sang about the Christmas traditions of Puerto Rico, about the parrandas, in which people went from house to house singing....and ron cañita, homemade rum, which is plentiful during the holidays” (40).

2. Immediate or direct glossing: A direct, literal translation is provided right after the Spanish phrase. Glossing is usually provided in the voice of the narrator. The clearest example is the epigraphs at the beginning of every chapter. For example: 
Chapter 1 - “Barco que no anda, no llega a puerto. A ship that doesn’t sail, never reaches port” (3). Chapter 2 - "Al jíbaro nunca se le quita la mancha de plátano. A jíbaro can never wash away the stain of the plantain” (7). Chapter 3 "Enamorado hasta de un palo de escobas. He falls in love even with broomsticks" (21).

“iCochino! Pig!” (119)

““¡Sí, cuando las gallinas meen!’ Doña Lola laughed, and Mami chuckled, her eyes twinkling at me to see if I understood what Doña Lola meant by 'when hens learn to pee’” (110).

“...una gente rica -rich folks” (190)

“‘`Viejo asqueroso!’ I screamed in a voice and tone borrowed from my mother. Filthy old man!” (179)

“I loved Doña Lola’s refranes, the sayings she came up with....” (56).

"Bohío, the kind of house jibaros lived in” (12).

“Mami called her Muñequita, Little Doll” (13).

"Mami and Papi had passed on to me what they knew of buenos modales, good manners” (30).

3. Indirect glossing: Indirect glossing is provided, sometimes in the same sentence or paragraph. The meaning of the Spanish phrase is not explicitly translated but the reader is provided with context from which to gather meaning. For example: “...so that we can eat like Americanos cuando el hambre apriete. She kept them there for a long time but took them down one by one so that, as she promised, we ate like Americans when hunger cramped our bellies” (68). 
"Del dicho al hecho hay un gran trecho." "What does that mean?" "It means that there's a long way between what people say and what is” (55).

"Men, I was learning, were sinvergüenzas, which meant they had no shame and indulged in behavior that never failed to surprise women but caused them much suffering” (29).

"An austere Evangelical church rose next to a botánica where one could buy plaster saints” (38).

"I touched my hair, which was not curly like Delsa's, nor pasita, raisined like Papi's” (13).

"Doña Lola... cooked huge vats of rice and beans to sell in the refillable aluminum canisters called fiambreras...” (111).

4. Contextualized switches: These switches require the reader to make a connection between the switch and the broader context of the utterance in order to gather meaning. For example:

The night before, Mami had bathed me in alcoholado, which soothed my skin and cooled the hot itch (11).

"On the way to the bus, men stared, whistled, mumbled piropos" (190).

“...would have got me a swift slap or a cocotazo from Mami’s sharp knuckles” (125)

““We are going to Mass,' she said, pulling out a small white mantilla, which I was to wear during the service ... but the white mantilla tickled my neck and the sides of my face” (96). 
5. Void meaning or simple expressions: These are expressions used usually at the beginning of a sentence, such as tags, or interjections, which do not obstruct meaning if left in Spanish. For example:

“¡Muy bien!”, “ay”, “nena”, “muchas gracias”, “iQué bueno!”, “hola”, “buenas tardes”, “Ay Dios mío”, "buenos días.”

6. Transparent words/cognates: These are words that do not need translation or explanation as they are Latin-origin cognates existing in the two languages with similar meanings or other easily recognizable words. For example:

centro communal, president, gringos, sí, Americanos [sic], repugnante, alcoholado, plaza del mercado, público, hola, señorita, macho, mal educada, president, sombrero, nervios, purgante, mantilla.

Excepting cultural borrowings and terms of endearment for which no translation is provided, there are very few words for which no cushioning or compensation is provided: fogón, puta, finca, velorio, el cura, artesanías, vaguadas, solitaria, escupidera, huevos, cocotazos, marido. These words are considered core borrowings, meaning that they could be replaced by equivalent English words: fire, whore, farm, wake, priest, handicrafts, trough, tapeworm, bedpan, eggs, smack, husband, that have no cultural component attached to them and are therefore unjustified or deliberate switches for which the author does not provide any strategy within the same text in order to extract meaning. However, they are all listed in a glossary at the end of the book. An additional strategy to cushion her Spanish switches is to use italics, just as it is customary in formal writing. By italicizing her switches, she is warning the readers that she is using a 
foreign language and calling their attention to look for clues to derive the meaning of the switch through one of the many strategies listed above. It is clear she does not wish to challenge the established language policies.

There is very little deliberate use of Spanish, and it is clear that the author has made an effort to only provide enough Spanish switches to remind the reader every so many pages that the story being narrated is happening in Puerto Rico, with Spanish speaking characters. It seems that the author could have taken many more liberties in codeswitching justified by the fact that the events narrated in the first half of the story are happening in Puerto Rico. The second part of the book takes places in New York but there, the narrator is also in permanent contact with Spanish or Spanglish.

This research argues that codeswitching is an intentional linguistic feature that is used by Latino authors as an ethnic identifier to establish a difference from Anglo writers, among other uses. Santiago's reluctance to codeswitch could have several interpretations, among them: fear of losing readers among Anglos; indifference to Latino issues; thoughts on language purity or correctness; etc. Most importantly, and it is the claim made in this dissertation, Santiago appears not to see a benefit in engaging in a more dynamic codeswiching as her predecessors did. For some sociolinguists, this attitude may be explained by the speaker's (in this case, the author's) belief that codeswitching does not have any "market value.” Monica Heller—who has drawn on the postulates of Pierre Bourdieu regarding linguistic capital—claims that when a bilingual speaker abstains from codeswitching — when authorized to do so-is relying "on norms of language choice to maintain symbolic domination." Writers on the other side of the 
continuum (i.e. those who codeswitch) "may use codeswitching to resist or redefine the value of symbolic resources in the linguistic marketplace” (quoted in Nilep 13)

As reviewed in the previous chapter, there are reasons and motivations to codeswitch. Likewise, abstaining from codeswitching has implications as well. However, we can only guess about the writer's decision to codeswitch sparingly. What we do know, though, are the effects of not codeswitching. As Woolard suggests, the basic question should be not why speakers make use of the various forms available to them, but why speakers would not make use of all available forms (quoted in Nilep). I claim that Santiago has resources available that would allow her to codeswitch: her bilingualism; her self-identification as a Latina writer; the theme of her book; the precedent established by her predecessors (i.e. the Nuyorican writers), but she has chosen not to as she does not have the necessary symbolic capital.

Let us be reminded that here I am transferring the notions of codeswitching in spoken form, which in my opinion, hold even stronger when referring to the written word, due to the intentionality of writing. Perhaps Santiago does feel entitled to codeswitch. For Myers-Scotton, individuals in bilingual situations have different sets of rights and obligations, depending on their role in the speech act. Based on her theoryone of the pillars of this study—one can conclude that Santiago is not making use of her set of rights and obligations and prefers to use the unmarked code for her writing. MyersScotton explains how no two individuals view the value or the cost of codeswitching similarly: "Speakers do not make identical choices in their own CS [codeswitching] practices because they have differing views regarding the relative costs and rewards of one choice over another” (Social Motivations 7). 


\subsection{TYPOLOGY AND CLASSIFICATION OF CODESWITCHING IN WHEN I WAS}

PUERTO RICAN

Classifying the uses of codeswitching in categories would help us understand the role it is accomplishing as not all switches perform the same role. Making a switch without any warning or providing any cushioning to the reader is not the same as making a switch to a cognate or to a common Spanish word that the writer expects the reader to understand. The book opens with an epigraph, which is a poem by Luis Llorréns Torres, who was a Puerto Rican politician and an advocate for the independence of Puerto Rico at the time of the Spanish-American War. The poem is fully translated into English right below the Spanish version. In addition to that, the book is divided in chapters, each of which opens with a shorter epigraph, usually a Spanish proverb, which is literally translated into English right below it.

It is calculated that $85 \%$ of all the switches are nouns. The remaining $15 \%$ are noun phrases, or full sentences that form songs or idioms. To break down the instances of codeswitching, they are classified in the following categories:

1. References to people/entities: el cura, señorita, Americanos, americanitos, señor, el presidente, gringo, doña, don, muchachos, muchachas.

2. Culinary terms: pasteles, cañita, morcillas, pomarrosa, name, yautía, sancochos, café con leche, alcapurrias, arroz con dulce, tembleque, pasteles, malanga, asopao, achiote, coquito.

3. Ethnographic terms: moriviví, chachachá, barrio, alcoholado, jíbaro, bohío, pasita, quinqué, boleros, guayaberas, botánica, piraguas, piragüero, coquí, aguinaldos, machetazo, agua florida, novenas, machete, vaguadas, jamona, 
merengues, mantilla, curandera, aguinaldo, guiros, morenos, bodega, flamboyán, güiro, parrandas, pocavergüenza, guarachas, maracas.

4. Locations: Nueva Yores, Nueva Yor, los Estados Unidos, centro comunal, plaza del mercado, cafetín, iglesia. Estado Libre Asociado, botánica.

5. Terms of address/endearment: negrita, titi, tía, mami, papi, abuela, tú, tío, abuelo, mamita, papito.

6. Religious terms/expressions: aleluya, ay Dios mío, Papa Dios, ¡Ay Señor, Dios Santo!, ¡Ay Santo Dios, bendícemela!, a Dios gracias, ay bendito.

7. Swear words: puta, coño, carajo, hija de la gran puta,

8. Songs, sayings, prayers: "Barco que no anda, no llega a Puerto;" “Al jíbaro nunca se le quita la mancha de plátano;" "Enamorado hasta de un palo de escoba;” "Borrón y cuenta nueva;” “Lo que no mata, engorda;” "La verdad, aunque severa, es amiga verdadera;” “Con el agua al cuello y la marea subiendo;” “De Guatemala a guata-peor;” “Escapé del trueno y di con el relámpago;” “Dime con quién andas y te dire quién eres;" "El mismo jíbaro con distinto caballo;” “Con la música por dentro;” “Cuando las gallinas meen;” “A otro perro con ese hueso;” "Yo conozco al buey que faja y a la víbora que pica;” “Ahí fué donde la puerca entorchó el rabo;” “Te conozco bacalao, aunque vengas disfrazao.”

“¡Qué llueva, qué llueva! / La Virgen en la cueva, /los pajaritos cantan, la Virgen se levanta. / Adios Candelaria Hermosa / Las espaldas te voy dando, No siento lo que me llevo / Sino lo que voy dejando”.

9. Interjections, tags, and exclamations: ¡Qué bueno!, ¡Carajo!, ¡Buenas! ¡Ay qué lindos!, ¡Viejo asqueroso!, ¡Hola negrita!, ¡Qué bonita te ves!, ¡Cochino! 
10. Social exchanges: Buenas tardes, buenos días, hola.

11. Miscellaneous lexical items: fogón, muñequita, dignidad, sinvergüenza, buenos modales, público, sombrero, finca, pocavergüenza, velorio, artesanías, refranes, gallina, lápiz, pluma, ventana, puerta, maestra, piso, repugnante, cocotazos, siesta, fiambrera, pollitos, escupidera, caldero, calle, avenida, parcelas, piropo, sí, macho, colibrí, huevos, purgante, solitaria, iglesia.

The above shows that the largest category of switches corresponds to songs, sayings and expressions, followed by ethnographic terms. As argued elsewhere in this dissertation, the fact that the author provides a translation for almost every Spanish switch does not account for actual codeswitching. The switch is limited to a decorative function and to remind us of the connection with a Spanish-speaking environment.

2.9. CODESWITCHING AS A LITERARY DEVICE IN WHEN I WAS PUERTO RICAN

Codeswitching in When I Was Puerto Rican performs the role of a literary device. Santiago uses just enough Spanish switches to season her prose with Puerto Rican flavor. She is very conscious of her use of Spanish, which she does not forget to gloss immediately after she has used a Spanish token. This is what Sonja Burrows in her dissertation on U.S. Latino texts calls "Spanish Made Easy." Santiago herself has said that "I pay a lot of attention to the weight of words. Any word that's in Spanish in my English texts is not there by accident, or because I couldn’t figure out how to translate it, but rather because it has a resonance in Spanish that it doesn't have in English” (quoted in Kevane and Heredia 135). By saying that she "pays a lot of attention to the weight of words" she is actually revealing how she is accommodating the text for her readers, and 
confirms how her use of language is premeditated. This statement also reveals that she tries to find the perfect balance between her audience, which she assumes to be monolingual, and her need to codeswitch for literary reasons.

As When I was Puerto Rican is a memoir, all the characters in the book are voiced through Negi, the narrator, but she allows them to speak by using direct speech as opposed to indirect speech. Since the story takes place both in Puerto Rico and in New York, it is assumed that characters in Puerto Rico would speak Spanish, which the narrator is supposedly translating into English. Only very seldom does the narrator let the reader hear the actual voice of any the characters in Spanish:

““Ay Dios Santo, qué cosa tan fea,' said a woman as she crossed herself” (65).

““Toda una señorita,’ Tata said, her eyes misty” (262).

“‘Te preguntó el Mr. Barone, you know, lo que querías hacer when you grow up?’ I asked” (258).

“'Yo tampoco. He said, que I like to help people. Pero, you know, a mi no me gusta mucho la gente” (258).

““Ay, Señor, Dios Santo!’ Mami cried” (252).

Furthermore, Santiago makes use of codeswitching for characterization to some extent. For instance, Doña Lola, one of the characters, who is a neighbor in Macún, Puerto Rico is known for her proverbs: “I loved Doña Lola’s refranes, they sayings she came up with...” (56). The reader hears Doña Lola offer her timely proverbs in her own voice: “‘¡Sí, cuando las gallinas meen!’ Doña Lola laughed...” (110)

Another accurate characterization she makes is with her own accented English: "My mother she no spik inglish. My mother she look for work evree day and nothin. My 
mother she say she don’t want her children suffer. My mother she say she want work bot she lay off. My mother she only need help a leetle while” (249). She is also reminding us of what her English sounded like before or when she was Puerto Rican. Elsewhere, she provides the reader with yet another sample of what her English was like: "Ju bee lonh 2 a type dats berry cómo in dis kuntree, Meeses Felps. A type off selfcent red self pee tee in sun de boring tie gress wid on men shon ah ball pro klee be tees on de side” (264), this is a monologue she had memorized for her audition to the Performing Arts school, from a play by Sidney Howard.

“'Seven gray?’ ... I no guan seven gray. I eight gray. I teeneyer”” (226), again, this is a sample of her own English pronunciation shortly after she has arrived in New York and of how she had to defend herself in school to avoid being placed in a lower grade because of her English limitations.

Never during the story does she make reference to the language aspect while the story takes place in Puerto Rico. Nor does she refer to her linguistic mediation; her book reads as if all the characters spoke English, except for the few exceptions listed above. A very striking example is when making an allusion to Spanish literature, she says: "The texts were in formal Spanish, with thee and thou, and grammar that was hard to follow" (191). It is surprising to see that she even uses English words to explain a grammar issue in Spanish. Certainly thee and thou are not Spanish words but she uses them to illustrate the formality of Spanish, as opposed to using actual Spanish examples.

The literary use of codeswitching in When I was Puerto Rican fails to convey authenticity. The dialogues feel artificial as there is very little mimesis of real oral exchanges. It is important to clarify that I am not implying that it is necessary for a novel 
to be written in the language in which the events took place. Memories can be experienced in any language and presented in any language. However, there needs to be a closer connection between the events and the language in which it is narrated for the novel to be credible. Verisimilitude is essential in literature-in line with the practices of realism—and Santiago does not achieve it due to her catering to the English monolingual reader.

It is an established tenet of literary theory that the reception of a given literary work is not the same for every reader, nor will the reader read the work in the manner that the writer intended. Hence, it can be argued that the reception of Santiago's memoir is not the same for the Anglo monolingual reader than it is for the Latino reader. This work posits that Santiago was more successful at using codeswitching for her Anglo audience, for which it performs a literary and decorative role that seems more authentic than it does for the Latino reader. The Latino reader, based on his/her knowledge of Spanish could sense the author's codeswitching as more artificial, which is invisible to the Anglo reader. This is why When I was Puerto Rican makes a good book to be read in high school or college classes as a sample of Latino literature, due to the accommodations that the author provides to English monolinguals.

\subsection{PARTIAL FINDINGS}

Above, I have presented Santiago’s codeswitching as limited and unnatural, meaning that it does not reflect the actual codeswitching that takes place between bilingual speakers during spontaneous oral exchanges. I also argue that she does not follow the dynamic codeswitching that had been observed by earlier Nuyorican or Chicano writers. This is not to say it is wrong, as there is not a right or wrong way to codeswitch or a 
specific amount that is required. Codeswitching extends on a continuum that goes from the sporadic switch to the embedded language to a full integration of the two languages. What this study aims to show is to contrast or compare Santiago's style of language alternation with other writers before and after her and find what this means to Latino literature as a whole, and in turn, to the Latino community. Nor am I suggesting that she should have codeswitched more aggressively, as my analysis is merely descriptive. What I argue is that the author-given the precedent in Latino literature-does not exploit to her advantage this linguistic capital available to the Latino writer. Her novel/memoir is almost transparent for the Anglo reader. There are very few Spanish switches for which the Anglo reader could struggle for meaning, as I have listed above. I claim that if Santiago had wished to do so, she could have codeswitched more aggressively considering that she presents herself as Puerto Rican, identifies herself with her culture, uses her cultural knowledge, her story takes place in Puerto Rico, and is writing, most likely, for a Latino audience-if not fully at least partially. Her selective codeswitching is a reflection of her circumstances, which reveals that codeswitching is a personal choice and any precedent of its use cannot be read as advancement for the minority that is using it. Clearly, in line with Bourdieu's terms, she does not possess the symbolic capital that would allow her to codeswitch as part of political strategy. There is no political strategy in her work.

Codeswitching is not a static practice, as posited by Myers-Scotton. It may come and go depending on the conditions surrounding the speakers and on personal language preferences. It is evident that either the conditions were not ideal for Santiago at the time of her memoir or she deliberately chose to adhere to language "cleanliness." This 
conclusion is very revealing for the aims of this dissertation. Viewing four different novels written in a span of 35 years should tell us something about the effect of codeswitching in literature and whether it means anything for Latinos as a group.

What distinguishes the writing of Santiago from that of the Chicano author studied in the previous chapter is that for Anaya, codeswitching was fashionable at the time and was part of the Chicano identity. Santiago, who has "made it" in the mainland, stays away from Spanish, which can only be explained by the same story of discrimination she is telling us about in her memoir. However, the previous generation of Nuyorican writers chose to use the integration of the two languages more aggressively and used language to denounce their discrimination. Her story is a successful one and a less subversive language is required, one in line with the "language correctness" views of the hegemonic culture, even if that means sacrificing language authenticity. This may explain how Santiago, who lived for the first 13 years of her life in a Spanish speaking territory, uses less Spanish in her book than Rudolfo Anaya, who was born in the United States and was in contact with English since he started school and—most likely—never went to school in Spanish. One logical explanation is that the time of the production of their respective novels promoted or discouraged codeswitching.

It should be clear, though, that whether Santiago codeswitches in her everyday speech or not is not relevant; what is clear are the pressures and linguistic demands to which she was exposed at the time of her memoir. To tell us her story of success, she has to show us how well she was able to master the English language, hence the contrast she makes from the time she did not speak English well with the present, or the time of narration. When I was Puerto Rican is a memoir that reflects the times in which it was 
written, when the boom of the Nuyorican movement back in the 1960s and 1970s was long over. The author does not exploit or does not have the cultural, linguistic or symbolic capital that her fellow-Nuyoricans did back then. Conventional language practices represent relatively stable relations of power, while violations can be seen as forms of resistance (Heller, Language Choice 123). Showing resistance was not Santiago's intention, nor did she consider codeswitching the appropriate language for the appropriate market (Bourdieu).

It is impossible to know what would have been the reception of Santiago's memoir if she had used a more dynamic level of codeswitching. If it had been accepted just the same, it would have been a gain for Latino literature-if language use can be equated to a greater recognition of the Latino minority. Codeswitching has been present in Latino literature since the 1960s. It is possible to assume that it would have been accepted just the same. Let us be reminded that the theme, the setting, and the characters would justify the use of codeswitching.

From the introduction, I have established the intentionality of the written word and its premeditation on the effects it may have as opposed to being a random choice of words. What is said is just as important as how it is said. Writers are not obligated to codeswitch, but if they wish to exploit their cultural capital and be viewed as Latinos, there needs to be a stronger connection between the topic and the choice of language. "Language acts are acts of identity" claim Le Page and Tabouret-Keller (quoted in Coulmas 315) Claiming a connection with a particular cultural heritage implies obligations with that culture, in which language cannot be set aside. 
I therefore conclude that When I was Puerto Rican was not written with a Latino audience in mind, regardless of appearing as such at a surface level. The language was carefully selected to attempt to appeal to all audiences, but the text has been extremely "sanitized" to the point that any ethnic component of Puerto Rican culture is totally transparent to the monolingual English reader. This marketing strategy is totally valid and proven successful in this case, as it is ultimately the publishers' decision about what gets published. The claim being made here is that Post-Nuyorican writers, such as Santiago, have kept their texts accessible to all audiences and have softened the posture assumed by the writers from the Nuyorican period. It is also proof that codeswitching is a personal choice that is based on one's views on language and that it cannot be read as a style for a group nor seen as a contribution to the minority using it. 


\title{
CHAPTER 3
}

\section{THE CUBAN CONDITION: FROM EXILE TO IMMIGRATION}

\author{
The hyphenated man \\ lurks beneath that confident exterior, \\ and it's time you consider \\ Hyphens Anonymous, where the confused straddlers find refuge \\ and solace. \\ They meet once a week, \\ talk Spanglish to their hearts' content, \\ eat mariquitas with hot dogs, and Cuban coffee with Dunkin Donuts, \\ without explanations or alienations.
}

The hyphenated man-Carolina Hospital

\subsection{INTRODUCTION}

The notion of exile has been identified as the common denominator in the production of Cuban-American authors, poets, singers, playwrights, essayists, artists, etc., setting this community apart from other Latino minorities, who might exhibit a wider array of topics in their cultural expression. A vast number of studies have been devoted to the topic of exile or diaspora, particularly in connection to Cuban-American literature, since it began to be produced in earnest, around the 1980s.

In particular, this chapter wishes to study the linguistic features of the literary production of Cuban Americans; the second largest Latino immigrant community in the United States. This chapter explores whether this production exhibits the same or different linguistic patterns in terms of language alternation from those found in other Latino minority literatures. Linguistically, it is expected that Cuban-American authors, who enjoy different degrees of bilingualism; would engage in codeswitching in their literary writing, as observed in other Latino authors. Codeswitching, beyond its use as an aesthetic element, can provide clues to the political stance of the user, as observed in 
previous chapters, which in turn can have implications for the Latino community as a whole.

It is an accepted fact that Cubans enjoy different, or better, conditions for migrating to the United States than other Latin Americans. In addition, they have a unique relationship with their home country, which is different from that of other immigrants with their own homeland. Exploring whether these factors have any effect on their writing, particularly in their use of codeswitching, may provide us with some insight as to the choices writers make and to establish whether there is a connection between such writing choices and the social and political conditions that surround each Latino minority.

Previous chapters showed a shift between the writers from the Chicano and Nuyorican Movements—which adopted codeswitching as the brand for Latino literature in the Southwest and the Northeast—and writers from later decades. ${ }^{39}$ It was argued that the conditions for Latino writers were not as propitious after the Chicano and Nuyorican "boom” was over, which resulted in a less aggressive writing both in form and in content. However, the picture of Latino literature in the United States would not be complete without considering the contributions made by Cuban-American authors, which occupy a significant place among Latino letters.

This chapter will focus on Cuban-American writer Cristina García and her bestselling novel, Dreaming in Cuban published in 1992. Before delving further into this

\footnotetext{
${ }^{39}$ Chicano and Nuyorican literature had their boom at the time of the Civil Rights movement in the 1960s and early 1970s.
} 
work, the following sections will present an overview of the Cuban diaspora, its migration, its literature, and its language in order to provide the necessary context.

\subsection{EXILE, DIASPORA, OR IMMIGRATION?}

Cubans who have migrated to the United States are usually referred to as exiles. The term “exile,” as opposed to “diaspora” or "immigration,” makes a statement about the detachment from one's home country in the hopes of returning to it, even if that is never accomplished. It also implies being forced to leave one’s own country (McClennen 5). The immigrants of a diaspora (from Greek “to spread about”), on the other hand, do not seek to return or do not have a place to return to. In opposition to the previous two conditions is the term "immigration," which implies a choice. Many Cubans who left their country out of need resist (or used to resist) this term. The exile condition is supposedly a temporary one; its extension in time tends to convert it into immigration. Accepting the switch to immigration may be seen as surrender, since the exile condition is also a political statement. It can be read as a defiance for a change back home that many exiles are not wiling to give up yet.

Cuban immigration across the Florida Straits dates back to the nineteenth century, to Cuban pre-independence, when revolutionary activists sought refuge on U.S. soil, and included eminent names such as poet José Martí. More specifically, Florida, and in particular Tampa and Key West were enclaves for the production of cigars during the nineteenth and the beginning of the twentieth centuries. South Florida, given its short geographical distance from Cuba, has always been the preferred destination for Cubans seeking political exile or asylum from left or right wing governments at various times 
throughout Cuba's convulsive history, Cuban migration has since fluctuated based on economic and political conditions in the island.

Before the Cuban Revolution, some 100,000 Cubans had arrived to the United States between 1941 and 1959: then from 1959 to 1962 alone, some 215,000 arrived. This flow was disrupted by the Cuban Missile Crisis, upon which all direct travel options were discontinued. By 1990, there were at least one million Cubans in the United States (Poyo and Diaz-Miranda), and as of 2012, 1.3 million Cubans had been legally admitted (Duany 13). Such influx has been fully endorsed by the U.S. government.

As historian María Cristina García asserts, the Cuban Refugee Program established in 1961 was "the most comprehensive refugee assistance program in American immigration history” (2). This program provided financial assistance, including loans for education, health care, re-training, and resettlement, as well as care of unaccompanied children. Marisa Alicea argues that President John F. Kennedy, at the time, "sold the program as important to the fight against communism” (52), thus gaining broad support. A few years into the program, President Jimmy Carter would declare that the United States would continue to "provide an open heart and open arms" (Garcia, Maria C. 65) to the people fleeing from Cuba seeking freedom from Communist domination. This welcoming statement by each successive U.S. president was also a political statement to delegitimize the Cuban Revolution, meant to prove the point that the more people that fled the island the more unsuccessful the Revolution. Such a welcoming stance towards Cubans is what Alicea calls a migration "institutionalized by both the United States and the Cuban government” (49). Alicea implies that the decision to allow the exiles into the United States was not entirely motivated by humanitarian 
concerns but also by the desire to overthrow Castro by means of exile forces, and to discredit the Cuban government (51). This was in line with Cold War ideology of the time. In turn, such massive departures allowed the Cuban government to consolidate its power by getting rid of those who opposed the Revolution. Such a direct relationship between U.S. foreign policy and Cuban immigration seems undeniable.

The migratory waves most readily identified by scholars are, in addition to the pre-Castro wave:

1. The Revolution wave (1959-1962)—also known as The Golden Exile—which brought over 200,000 Cubans; it consisted of the political elite that supported the Batista government, and were followed by middle-class entrepreneurs, professionals and small business owners who began to flee the island as pressure from economic reforms increased. In the meantime, the Cuban Children's Program, known as the Operation Pedro Pan brought over 14,000 unaccompanied children to the United States, purportedly, "to avoid their political indoctrination" (Alicea 52).

2. A second wave—which brought approximately 5,000 exiles—-left through the Port of Camarioca starting in December 1965, when the Cuban government announced it would allow Cubans with relatives in the United States to leave. However, the dangers posed by the sea led to the establishment of an airlift—which came to be known as the Freedom Flights — which brought over 340,000 Cubans to Florida between 1965 to 1973. Additionally, in October 1978, an estimated 10,000 to 14,000 persons, former prisoners and their families were allowed to leave for the United States (Alicea 53).

3. Then, the largest Cuban migration in a single year, known as Marielitos—due to their departure from the Port of Mariel—took place from May to September, 1980, bringing 
125,000 Cubans to the United States (Alicea 52). This is in addition to the permanent influx of balseros and other migrants who came by air around to this date.

Cuban exiles are often grouped as one monolithic entity, despite the classifications described above. Each wave of migration brought a different Cuban; therefore the above-described classifications are only political and differ significantly in socio-economic conditions. The first wave, right after the Revolution, is believed to have consisted of wealthy middle-class White, with each successive wave bringing a more diverse mix of Cubans, both racially and economically.

After describing the composition of the Cuban exile, the question that comes to mind, and that is relevant to the study at hand, is how Cuban migration differs from that of other Latino communities. Undoubtedly, each migrant or exile has his or her own particular story, regardless of the country of origin. However, it is generally believed that most Cuban immigrants share a similar political view that led them to make the decision to leave the island, which might not be the case for immigrants from other nations. Despite such claims of ideological sameness, the line between economic need and political disaffection is not very clear, as economic conditions in Cuba may be equally or more largely responsible for people fleeing the island. The difference for Cubans, in any case, is that their emigration has become unidirectional; a permanent decision with no option for circular migration. Of course, the first Cubans to leave the island after the 1959 Revolution did so thinking that they would return soon when the new Cuban government was toppled; their hopes began to fade away with the failure of the U.S.sponsored Bay of Pigs invasion in 1961, and as the Castro brothers consolidated their hold in power. 
According to the U.S. Census Bureau, Cubans are the second largest group of immigrants from a foreign country (1.957 million) in the United States, or the third if Puerto Ricans are counted as immigrants. ${ }^{40}$ In terms of education, a Pew Hispanic Center poll reports that 58\% percent of Cuban Americans speak English fluently, and enjoy educational levels higher than the rest of the Latino community: one quarter of Cuban Americans hold a university degree, compared to only $12.9 \%$ for other Latinos, and rank among the highest in school completion rates in the country. This rate is also due to the fact that many Cubans completed their education in Cuba. The same poll reports that Cubans are the most geographically concentrated of the 12 largest Hispanic origin groups; $70 \%$ live in Florida. ${ }^{41}$ Their average income almost equals the national average, and they own or have created the most lucrative Hispanic businesses in the nation. By 2001, there were 124,273 Cuban-owned firms nationwide, which reached 26.4 billion dollars in aggregate receipts, most of which are located in the Miami-Ft. Lauderdale area.

Additionally, their naturalization rates are among the highest of any Latino or immigrant group; more than half of Cubans in the United States (58.2\%) in 2008 were U.S. citizens. The paradox here is that citizenship does not seem to work for the benefit of other Latino groups, such as Chicanos or Puerto Ricans, who are U.S. citizens from birth but are economically less successful. Hence, the reasons for the prosperity of Cubans lie elsewhere. To this question, Falcon and Gilbarg argue that one of the reasons for the greater prosperity of Cuban-Americans is that

\footnotetext{
${ }^{40}$ The first two largest groups are Mexicans with 34 million and Puerto Ricans with 4.970 million) Source: U.S. Census Bureau, Nation's Hispanic Population Grew Four Times Faster than Total U.S. Population, press release (May 26, 2011), http://factfinder.census.gov/home/saff/aff_transition.html

${ }^{41}$ http://www.pewhispanic.org/2013/06/19/hispanics-of-cuban-origin-in-the-united-states-2011/
} 
the Cuban working-class immigrants of the 1970 s were incorporated to a large degree into a Cuban enclave economy already established by the earlier waves of Cuban immigrants, who were more likely to come from a more privileged background. This ethnic enclave economy made it possible for a much higher proportion of Cubans than Mexicans to become self-employed or to work for ethnic employers who could provide them greater opportunities for training and mobility. (70)

It is also argued that Cuban immigrants from the 1960s brought entrepreneurial skills and pre-established connections with American businesses, while others brought capital, which allowed them to quickly get established as business owners in South Florida. This is in addition to the support provided by the U.S. government in the form of loans and other aid, which established a precedent never before seen for any other immigrant group.

Because of their long-standing presence in the United States, the higher level of education they enjoy, and all the conditions outlined above, Cubans also have much greater political representation than other immigrant groups at all levels of government: local, state, and federal. They also have higher voter registration and voting rates. Cubans dominate the city commission of the city of Miami; have been city and county managers, and mayors; have held seats in the state legislature; have had senators; and congressmen/women in the House of Representatives; a Chief Justice of the Florida Supreme Court, not to mention top positions in large private enterprises in Florida and nationwide. 
More recent data, however, indicates that Cuban-Americans no longer enjoy their ranking as the wealthiest Latino minority, due in part to the inflow of exiles with less economic capital, a trend that began since the Mariel exodus, and in part to the elimination of the resettlement aid programs (Duany). However, the Cuban Adjustment Act continues to grant all Cubans who set foot in U.S. shores automatic legal status.

Establishing these demographics and immigration patterns is important for this study as it will allow for an understanding of the attitudes of Cuban Americans and their linguistic composition when compared to other communities. This will prove to be relevant in the coming sections as we explore their choices in literary writing.

\subsection{THE LANGUAGE OF CUBAN AMERICANS}

The relationship between identity and language has been sufficiently discussed earlier in the Introduction. In the case of Cuban-Americans, such relationship warrants an even closer analysis due to the different degrees of bilingualism they exhibit, which run the gamut from English or Spanish monolingualism to bilingualism. ${ }^{42}$ The preferred language will be defined by the linguistic conditions of each speaker such as the age of arrival in the United States, the time he/she has lived in an English speaking environment, the language in which he/she was educated, his/her geographic location, etc. However, despite the particularities, there are also some commonalities that may produce similar linguistic patterns, such as a common history and shared identity and ethnicity, which may promote a common language.

\footnotetext{
${ }^{42}$ According to a 2011 Pew Research report, out of 1,889,000 Hispanics of Cuban origin, 77\% speak a language other than English at home even though the same percentage speaks English well or less than very well.
} 
No other Latino community enjoys a more comfortable linguistic environment than Cuban Americans in Miami-Dade County, Florida, which is home to approximately $50 \%$ of all Cubans living in the United States, constituting the largest community of Cubans outside Cuba. This means that speaking Spanish in Miami-Dade is the norm rather than the exception, compared to the rest of the United States. According to Otheguy et al: "More Cuban Americans than Mexican Americans and Puerto Rican Americans spoke Spanish at home, and their English ability was less than that of these two groups” (170). This statement is even more significant when considering that Cuban Americans enjoyed for a long time the highest economic status among Latinos, as discussed in the previous section. From this, we can conclude that lacking English skills has not obstructed economic success for Cubans, at least not in Miami. This is no longer the case when compared to other Americans, but it does tell us something about language attitudes based on geographic location, which is also relevant to this dissertation.

Given such a comfortable linguistic situation for Cuban Americans in their enclave it becomes essential to understand how such favorable conditions, economically and linguistically, foster or hinder the use of codeswitching both orally and in writing. Thus, it is common to use or hear solely Spanish or a combination of English and Spanish as people go about their daily business for work, school or entertainment activities in Miami-Dade County. Otheyguy claims that

The greater socioeconomic power of Latinos in Miami-Dade gives the Spanish language a greater role in public and official life than in any other U.S. context. ... They know neither the English monolingual context that is the norm in most settings in the United States nor the Spanish 
monolingual context that is the norm in their country of origin. Young Cuban Americans thus have little need to speak either solely in English or solely in Spanish. (177)

Paradoxically, despite the fact that Miami-Dade has the highest percentage of foreign-born residents in the United States and the largest population density of Spanish speakers (Otheguy et al.), Florida is one of 31 states in the country to have an official language (English) and to have joined the English-Only Movement in 1980. Therefore, it warrants exploring whether such an extensive presence of Spanish means anything for the empowerment of Latinos in the United States, which is ultimately one of the goals of this study. Also, contrary to other Latinos, earlier Cubans were eager to assimilate into American culture and accepted English only policies.

From the above, it is clear that Cubans and Cuban Americans in Miami have a choice in language, depending on the context in which they are found and on their individual linguistic situation (solely English, solely Spanish or a combination of both, i.e., codeswitching). More specifically, this research wishes to see what choices are made for literary writing. As stated elsewhere in this dissertation, due to the fixed nature of the written word, language choices for literary writing may reveal one’s views on language, ethnicity, identity, and even politics.

Cuban-American scholar, Gustavo Pérez-Firmat has expressed his feelings regarding the language for literary writing of Cuban-Americans, which is shared by many of his fellow writers:

I have always felt a mixture of regret and remorse that I have not done more of my writing and living in Spanish. Sometimes I have even thought 
that every single one of my English sentences—including this one—hides the absence of the Spanish sentence that I wasn't willing or able to write. And if I handle English more or less well, it is because I want to write such clear, clean prose that no one will miss the Spanish that it replaces (and that it can never replace). Why I haven't tried to write more Spanish is something that I've wondered about, something that I am wondering right now, but that I don’t entirely understand. I know the practical reasons for my use of English, but I also suspect that there may be other, more murky motives of which I'm only half-aware: anger, fear of failure, maybe even a little self-hatred. (Tongue 2)

Cuban-American authors who have chosen to write in Spanish, are thought to wish to maintain a closer connection to the island, whereas those who write in English can be seen as using language as a way of distancing themselves from the exile condition of their parents and because Spanish is no longer their dominant language. This is in addition to the difficulties in publishing in Spanish or the lack of mainstream Spanish publishers or the fact that those who write in Spanish started their careers in Cuba. Isabel Álvarez-Borland, who specializes in Cuban-American literature, claims that "the English branch seeks to create a distinctive culture of Cuban roots, whereas the Spanish branch wishes to preserve Cuban culture and seeks affiliation with the canon of Cuban and Latin American letters” (Cuban-American 154). However, I would add, this divide is also generational and based on each writer's language skills; it is expected that those who obtained an education in English (i.e., those who grew up in the United States) would feel more comfortable speaking or writing in English than in Spanish. There are only a 
handful of writers who were educated in English who still prefer to write in Spanish, or in both.

Pérez-Firmat, who has explored the subject at length, summarizes the language struggle of Cuban Americans very well in his poem "Dedication:"

The fact that I am writing to you in English already

falsifies what I wanted to tell you. My subject: how to

explain to you that I don't belong to English though I

belong nowhere else, if not here in English. (Triple Crown 127)

Having identified linguistics preferences and conditions for Cuban Americans, it now becomes essential to look at the evolution of their literature in order to understand what the role of codeswitching has been, and whether it is any different from that of other ethnic groups studied in this dissertation.

\subsection{CUBAN-AMERICAN LITERATURE}

Discussing Cuban-American literature calls for a distinction between the different generations of writers that to a certain extent may correspond to-and explain — the distinct themes addressed by Cuban or Cuban-American writers. Among the several classifications found, Rodolfo Cortina offers one that distinguishes three groups of writers: those who emigrated from Cuba as adults, who do or did their writing in Spanish, and "whose main, though not sole preoccupation lies in their testimony, attack and/or condemnation, if not outright vilification, of the Castro regime” (46). Other themes include anti-communism, personal plight to escape from the island, nostalgic family remembrances, injustice, or their experiences as immigrants. The recurrence of these 
themes, as explained by William Luis is because "the exile refuses to let go of the past; he relives it, and perpetuates this existence abroad” (95).

Cortina's second group begins with the Mariel Boatlift. To him this event "changed the character of the Cuban presence in the United States. . . . It signals a new set of sensibilities” (47); it begins to transform the exile into immigration, as the prospect of returning to Cuba begins to wane. A key figure in this group is Reinaldo Arenas (1943-1990). The third group includes writers born or raised in the United States who arrived at a young age, either as children or teenagers. Cortina labels these as the "CubanAmerican” novelists and include Roberto Fernandez, Virgil Suárez, Oscar Hijuelos, and Elias Miguel Muñoz, to name just a few.

As to language choices, it is expected that the first and second group would write in Spanish, but the latter in English or a combination thereof. Writers who left Cuba as adults and wrote in Spanish include Cabrera Infante, Reinaldo Arenas, Lydia Cabrera, Severo Sarduy, Novás Calvo, Hilda Perera, Heberto Padilla, and Antonio Benitez Rojo. Second generation writers, "one-and-a-halfers," and Cuban-American writers include Gustavo Pérez-Firmat, Oscar Hijuelos, Elias Miguel Muñoz, Achy Obejas, Eliana Rivero, Ruth Behar, Pablo Medina, Omar Torres, Margarita Engle, Cristina García, Roberto G. Fernández, Dolores Prida, Ricardo Pau-Llosa, who are mainly writing in English. This latter group is the focus of this chapter.

In addition to the generational classification above, distinctions may also be made within a same generation, as not all Cuban-American literature deals with the topic of exile; similarly not all Cuban-Americans are white, upper middle-class, conservative, or live in Miami. On the contrary, Cuban-American literature exhibits a wide array of 
experiences, backgrounds, themes, political views, and language choice. Every CubanAmerican writer has a story to tell, whether it is related to his/her exodus, identity and/or language conflict, or the struggle as an ethnic subject in his/her assimilation process. However, it is indeed true that for a large part of these writers, the idea of a nostalgic past derived from their exile condition is a constant in their writing even if only in the background of every personal story. It is also true that the topic of exile has waned as the events of 1959, and the exodus experience become more distant in time. As Pérez-Firmat argues: "La temática del exilio no solo se ha hecho crónica sino también anacrónica, especialmente para aquellos de nosotros que llegamos a este país hace muchos años, en ciertos casos siendo niños todavía. Para esta generación, el exilio se ha convertido en un cómodo cliché, una especie de hábito político y literario” (Trascender 5).

Undoubtedly, Cuban-American literature has expanded its themes beyond the Cuban Revolution and the exile, these topics have not disappeared altogether. They are still visible and may be viewed as a unifying theme, particularly when compared to other ethnic writers, who might tell a more personal story. Eleana Rivero, a scholar on the Cuban diaspora, speaks of such oneness and division of themes:

How do we reconcile the oneness with a real diversity of individual visions and styles? There are certainly common denominators that can be recognized. We U.S. Cubans can not only imagine, but are able to see and configure ourselves as hybrid people, and indeed can frequently pass for border entities, both in the social and in the metaphysical (or even spiritual) sense of the term: within the national political panorama, within the U.S. Latino cultural landscape, and some even within our own national 
subgroup. ... At the same time, all Cuban Americans are associated by birth or by kinship with a primal image; a peculiarity shaped by an extension of land surrounded by sea. (Writing 109)

Rivero is one of many scholars who have suggested that there is a certain uniqueness to Cuban Americans, which informs their writing. It is now time to ask how Cuban-American literature is different from that of other ethnic groups writing in the United States. The answer probably lies in the very conditions that differ between CubanAmericans and other ethnic groups. As seen above, it can be argued that the privileged conditions of migration offered to Cubans-unavailable to other communities-places the newly arrived émigrés under different conditions, in which being an undocumented or alienated immigrant is not a concern, particularly if arriving at an established Cuban enclave, such as Miami. The question then is whether these favorable conditions foster an easier or faster assimilation than for other Latino groups and what the consequences of this so-called privileged position are in the literature they produce and the language they use, which this dissertation wishes to unveil.

Rivero addresses these claims and attempts to respond to this difference by looking at both the commonalities and differences between Cuban-Americans and other Latino minorities:

When I read works by Cuban Americans (or when I myself write poetry or personal essays) I recognize a hybrid sensibility that we share with other ethnic minorities. ... Fortunately, most of us seem to be able to imagine a collective ethnonational identity, both at the existential and public levels, which can benefit from our very hybridity and not be narrowly framed by 
limitations of how we are perceived by society at large or by other groups. Thus, in spite of the stereotypical classification of Cuban immigrants and Cuban Americans as 'privileged' in American society, due in no small part to the widespread perception of our social and political conservatism as related to exceptional circumstances surrounding our migration, settlement, education, economic success, and/or insertion into the American middle class, our notions of individual social self-worth often vary from those common views. (Writing 110)

One clear distinction between Cuban-American literature and that of other Latino groups is that the former did not spring out of the Civil Rights movement as did the latter — such was the case for Chicano and Nuyorican literature. At that time, Cubans who were already on U.S. soil were struggling with their own issues, and did not join the cause-probably still thinking about their return to Cuba or having more pressing concerns at hand, such as getting settled in their new home.

Cuban-American literature appears to be less concerned with issues of alienation and discrimination than their Puerto Rican and Chicano counterparts, which is easily explained by the better economic conditions they have enjoyed, including less discrimination, at least within their own enclaves. Another unique concern is their concept of nation and nationalism as well as their relationship with their homeland, and with their host country. Conversely, they may struggle—depending on their particular circumstances - with issues of assimilation, identity, language, and cultural clash, common to other minorities. Pérez-Firmat explains this view: 
Since its emergence in the 1980's, Cuban-American literature has occupied an ambiguous place within the canon of imaginative writing by U.S. Latinos. As the only segment of this canon produced by political exiles and their children, this literature exhibits a nostalgic streak not shared-at least, not in the same degree-by Chicano, Dominican American, or U.S. Puerto Rican writers. (The Spell 15)

This confirms the claim that Cuban-American literature does not share the same motivations as that of other Latino minorities. In the same vein, Eliana Rivero adds that "Cuban 'writers in exile' -women and men—-tend to identify with the establishment and reject the Third World stance of many native Hispanic writers, and thus do not feel part of an underprivileged ethnic minority" (Immigrants 197). In other words, the State is their ally in the project of bringing democracy to Cuba, which is altogether different from the relationship of other Latino minorities vis-à-vis the United States. Pérez-Firmat agrees with this distinction:

Lo que esta generación tiene que acabar de comprender es que, aun cuando naciéramos en Cuba, nos formamos en Estados Unidos, y que aun cuando Cuba sea nuestra primera casa, Miami es nuestro hogar permanente. Y eso nos hace otros, distintos a los cubanos y distintos a los americanos. (Trascender 23-4)

Hence, I argue that there are two types of literature produced by Cuban Americans: ethnic and exile literature. Ethnic literature exhibits the need to explore one's roots, culture, and language, but vis-à-vis the host country; whereas exile literature displays nostalgia for the lost country, without consideration for the experience in the 
host country. As summarized by Álvarez: "If history drives the writing of the exiles, heritage becomes the main issue for the ethnic writer whose literature displays a need to explore the culture and language of their parents” (quoted in Gracia 118).

Eliana Rivero disagrees with that notion and claims more independence of CubanAmerican writers from the traditional themes: "It is easy to see that our literature in general is still stereotyped as representative of socially conservative (read anticommunist) immigrant values, rather than as an artistic embodiment of cultural ethnnationalism with a meritorious place in the American scene” (quoted in Álvarez Negotiating 119).

Whether Cuban-Americans are exile or ethnic writers only makes the study of their literature even more interesting. Which has more weight, the experience of alienation and discrimination from living as a minority or the exile experience? Are there as many ethnic writers as exile writers? Is this distinction even possible? I suggest a reconciliation of both groups in which the exile is in transition to the ethnic, in which case the former will end up in the long run resembling other Latino minorities in their approach to literature.

The metaphor of "the hyphen," (from a hyphenated identity) amply studied in the context of Cuban identity, is defined as "a commonly cited and celebrated space of resistance and protest and, on the other hand, as a space of tolerance, cosmopolitanism and multiculturalism” (Ochoa 14). This notion can easily be extended to other Latino minorities, even if they do not share the hyphenation in their designation (Chicanos, Nuyoricans), they do share the experience of being caught between two cultures and two languages, sometimes by the individuals' own choice to migrate but other times by their parents' decision to migrate. The hyphenation metaphor is a better fit for the ethnic writer 
than for the exile. As Ochoa suggests: "the contact zone called hyphen, where cultural and spatial negotiations are inevitable and cultural and linguistic battles take place revealing asymmetrical relations of power” (24).

This punctuation mark is ubiquitous when referring to hybrid and liminal individuals. Cuban-American writers, in particular, oscillate between Cuba, or the memory of a lost Cuban past, either their own or that of their parents, and the United States, closely tied to their cultural heritage, and their inbetweenness, liminality, and hyphenation become their story.

Cristina García’s Dreaming in Cuban (1992) will allow us to explore whether such themes are still present over 50 years after the arrival of the first waves of migration, and particularly to establish whether there is a connection with linguistic choices, as the following sections will show.

\subsection{CODESWITCHING IN CUBAN-AMERICAN LITERATURE}

This study wishes to explore how codeswitching is employed by Cuban-American writers, and compare it with that employed by other Latino writers in order to understand whether codeswitching plays a role beyond that of being a decorative feature. A review of the existing Cuban-American literature reveals that codeswitching is indeed used in writing by this group but to a lesser extent, when compared to the other Latino authors studied in this research so far (Chicano, Puerto Rican). This conclusion would not be as revealing were it not for the data cited above that indicates that Cuban Americans, in general, are intensive users of codeswitching in their oral interactions-given the extended enclaves in which most of them inhabit (i.e., Miami)—which would be expected to be transferred to the written page. 
Pérez-Firmat, who has written at length on the issue of language choice, had the following to say regarding the question of language choice when it comes to writing:

Cambiar de idioma es como cambiar de piel. Cuando estoy escribiendo algo en inglés, procuro rodearme de libros en inglés; cuando escribo algo en español, procuro rodearme de libros en español. Trato de mantener a cada idioma en su lugar porque si no las dos lenguas se me traban y no puedo escribir en ninguna: indecible por indecidible. No tiene que ser así, pero lo cierto es que así lo experimento: como rivalidad en vez de complicidad. (¿Existe una literatura cubanoamericana?)

This research is in agreement with his opinion in the sense that Cuban-American writers choose one of the two languages for their writing, as opposed to a mix thereof. As stated in the previous section, some Cuban-American writers write in English, others write in Spanish, still others write in either language at different times, or in a combination of both. However, the integration of the two, (i.e., codeswitching) is not as dynamic as that of other Latino groups.

Language choice is indeed based on personal preferences but there seems to be a clear divide between those who arrived young enough to have mastered English fully and those who have not; the former will write in English while the latter in Spanish, as each group wants to write properly in its dominant language. However, there are some bilingual authors who could write in either language. It is possible to assume that writing in English in the United States makes more sense from the commercial point of view, and indeed, there are by far many more books by Cuban-American writers written in English than in Spanish. That means that writing in English is doubly motivated: to increase the 
chances of being published (and read) and to write in the language that has become the dominant language for Cuban Americans. The younger they arrived in the United States, the more dominant their English would be. Therefore, the English/Spanish divide is easier to understand. Author Cristina García is an example of that. She was born in Cuba but arrived in the United States at the age of two. On the other hand, Reinaldo Arenas, for example, who was also born in Cuba, but arrived in the United States in 1980 at the age of 37, with a well-established literary career, wrote exclusively in Spanish. Also, the number of English speakers tends to increase in proportion to the rate of U.S.-born Cuban Americans coupled with the decrease in arrivals. ${ }^{43}$

Among the authors identified as "one-and-a-halfers," this study did not find any who engaged in a dynamic use of codeswitching in their literary works. Such findings suggest a possible explanation. Cuban-American authors do not see the need to use codeswitching to make their voices heard. When they do switch to Spanish is to bring a memory from their native island or to provide an exotic twist to their narrative. Whether they are writing about a nostalgic past, criticizing the Castro regime or sharing their experience in the United States as exiles, English alone can do the job. Contrarily, other ethnic groups studied earlier in this research have made language part of their arsenal when claiming their space in the American mainstream.

To say what they have to say, Cuban-American writers do not see the need to codeswitch, even if it comes naturally to them when speaking. Codeswitching is not part

\footnotetext{
43 There are some exceptions of authors who have experimented with a more aggressive language use, such is the case of Roberto G. Fernández, known for his grotesque satire of the Cuban American community, especially in his English-language novels, Raining Backwards and Holy Radishes! In these, he uses a dynamic mix of English and Spanish, employed as a parody element.
} 
of what they have to say, as it is for the other ethnic writers. Whereas the other ethnic writers may use language to show their divided identity, the exile writers can express their predicament in either language. On the issue of language duality and the divide between ethnic and exile writers, Pérez-Firmat claims that:

El escritor étnico admite que su patria no es ni puede llegar a ser su país. Más aún: esa quiebra no lo perturba en absoluto. Puesto que la identidad no le interesa, no está expuesto a las crisis de identidad; al contrario, se regodea en su propia dualidad, como los anfibios. He ahí una de las razones que explican que la literatura étnica sea a menudo multilingüe. El escritor étnico — que no se siente comprometido ni con su lengua materna ni con la otra— utiliza lo que pudiéramos llamar el "lenguaje pertinente”, o sea, la modalidad lingüística que mejor exprese su posición, equidistante de una y otra culturas. Si la literatura del exilio se escribe por lo general en el idioma de adopción, la literatura étnica se escribe en uno u otro idioma, o en una mezcla variable de ambos, dependiendo de las circunstancias. [El escritor] como el consumidor bien informado, cuando entra al mercado lingüístico se reserva el derecho y cultiva la habilidad de escoger sus palabras. (Trascender 18)

Above, I have tried to establish the disconnect between codeswitching and the writing of Cuban Americans, even if the authors themselves engage in codeswitching in their oral communication. I have also explained how codeswitching is more pertinent to the ethnic writer. The following sections will focus on the topics and linguistic traits of the novel Dreaming in Cuban, by Cuban-American writer Cristina García. 


\subsection{SUMMARY AND THEMES OF DREAMING IN CUBAN}

Dreaming in Cuban (1992) is a family saga that tells the story of the Del Pino family which, as a consequence of the Cuban Revolution, is split by politics and exile. It is the story of three women: Celia, the matriarch, who stayed in Cuba and is a passionate supporter of the Revolution, her daughter Lourdes who left in exile right after the Revolution and embraced wholeheartedly the American way of life, and the granddaughter, Pilar (Lourdes's daughter), a rebellious teenager caught between the influences of the two older women. Pilar left the island with her mother at the age of two, but despite the geographical and temporal distance, she feels drawn to Cuba and to her grandmother and maintains a connection to her through dreams or telepathy. Politically, the characters cover the full ideological spectrum, from supporters loyal to the Castro regime to his most fervent opponents.

The most important political events in the history of Cuba appear throughout the novel only as a backdrop: the Batista regime, the Revolution, the Bay of Pigs invasion, the Missile Crisis, the storming of the Peruvian Embassy and the subsequent exodus, etc., all of which appear intertwined with family events, and merely provide context to situate the story in place and time. Ideologically, the novel carefully attempts to maintain a balance between the two political views and there is no detectable inclination to favor one over the other. The author simultaneously criticizes and praises both Cuban and American societies. This neutralizing political view of the author has been observed by many scholars, such as Andrea O’Reilly, who claims that "the novel's politics are ambiguous for it fails to present a single reading of the Cuban Revolution” (81), and Williams Luis who sees that García “struggles with her Cuban identity and presents both 
sides of the Cuban question without appearing to privilege one point of view other the other" (216).

In an interview with Iraida López, García describes her motivation in writing Dreaming in Cuban: "I was trying to excavate new turf, to look at the costs to individuals, families, and relationships among women of public events such as a revolution” (107). García interprets and filters Cuban history through the collective memories and records of three generations of women by placing them along the political continuum that would allow her exploration without seeming to favor either side. In the same interview, she also claims that she "wanted to examine how women have responded and adapted to what happened to their families after 1959. I was also very interested in examining the emotional and political alliances that form within families” (106). Such statements distance García from the usual exile writer and her approach is clearly that of exploring the past rather than criticizing the events, but she does not altogether detach her writing from the topic of exile.

Through her characters, who are also given a psychological dimension, she explores the whole political spectrum, and the experience of each, both good and bad. From Celia, whose commitment to the Revolution and passion for El Líder (Castro) is almost sublime, to her daughter Lourdes, a fanatic patriot who volunteers as an auxiliary police in Brooklyn, so she would be ready to fight Communism. By moving from the particular to the general, García creates a microcosm of the Del Pino women and a macrocosm of the events in Cuba. She also uses the trope of the divided family to contrast life in the United States and in Cuba throughout the novel, as the author switches between the characters located at both ends of the continuum. Life in the United States is 
parodied by the extreme devotion of Lourdes to the American establishment, such that her bakery is named Yankee Doodle Bakery, a symbol of American success. At the same time that she celebrates freedom in the United States, Lourdes exploits and takes advantage of undocumented immigrants working for her. She is also depicted as racist and convinced of a certain superiority of Cubans over other immigrants. On the island side, the author does not limit herself to describing the material scarcities and limitations in Cuba but also describes the failure of some of its systems and programs, the political divide within families, and the lack of opportunities. She reveals how both systems lead their citizens to conform to the values that dominate the respective societies, in which one is no better than the other.

I side with Andrea O’Reilly in her analysis of Dreaming in Cuban as a memory collection, rather "concerned with the recording and the transmission of culture, $\mathrm{H} /$ history, and herstory. As the multiple references to (intergenerational) storytelling, music (Beny Moré), dance (the rumba) and Santería suggest, García’s novel attempts to preserve a cultural and personal past, which has been maintained in part, through oral tradition” (79). According to O’Reilly, García presents the "possibility of the 'one-andhalf-generation' to present an objective interpretation and account of the Revolution” (80).

A turning point in the novel is Pilar's trip to Cuba in her quest to search for her cultural roots. Her rebelliousness as a teenager, one who dabbles in art and in santería, may be explained by her uprootedness as she claims: "Even though I've been living in Brooklyn all my life, it doesn't feel like home to me. I'm not sure Cuba is, but I want to find out" (58). Her trip to Cuba is a disillusion, but not caused by the political or 
economic conditions, but by seeing the limitations to individual freedom. Once again, it is not a political view but a personal struggle. It is impossible not to connect Pilar's story with García’s own. García herself has admitted that Pilar is her alter ego and that the novel is "emotionally...very autobiographical” (quoted in López 107). García also visited Cuba for the first time in 1984, just like Pilar, and García’s trip to Cuba—in addition to serving as an inspiration for the novel—was meant to see Cuba for herself, which up to that point had been painted to her in "black and white” (López 103). García’s neutrality and lack of direct criticism of the Castro regime has been frowned upon by the more radical Cuban exile community in Miami. In the same interview, she claims that "they frequently called me a communist and attached all kinds of ridiculous labels to me just because I was registered Democrat” (López 104).

Pilar is the only character who is neutral to both positions given her hybrid perspective. The one-and-a-half generation is not interested in the political concerns of the exile but in looking back and understanding history for themselves, beyond what the exile community has told them, as was the case of Pilar the character, and García, the author. In the end, at least for Pilar, she realized that "sooner or later I'd have to return to New York. I know now it’s where I belong—not instead of here, but more than here...” (García 236). Such statement is an indication that she may have come to terms with her heritage after her "trip to the source."

In the previous section, a distinction was made to classify Cuban-American writers as either ethnic or exile writers, a distinction that is unique for this community. It was argued that the exile eventually may become ethnic as his/her concerns begin to shift. In the case of Cristina García, it is not possible to conclude that she has abandoned 
the topic of exile, which we see through the character Lourdes. However, the ethnic experience is portrayed through the character Pilar. The themes that seem to occupy her attention in this novel are the collective memory, the experience of exile, reconciliation, a divided identity, remembrance, and family rupture. Exile is still a major theme, even for writers who left the island too young to remember it. To summarize the themes of Dreaming in Cuba, I will use the words of Eliana Rivero

This book became paradigmatic of what it was to create fiction that, through evocative language, linked the two worlds of Cuban immigrant families and projected their exilic memories and their social and political hopes on both sides of the Florida straits. . . . Garcia's writing became emblematic of what it meant to be Cuban-American: Nostalgic family remembrances, re-creation of transnational and deterritorialized imaginaries, and the everyday experience of "living as Other”—all traits mentioned before-can be found in her novels, created and written in English. (Negotiating 117)

Having classified Dreaming in Cuban as straddling the exile and the ethnic novel, the next section will look at how codeswitching is used in this novel and its classification and degree in order to attempt to find a connection between the themes outlined above and the type of language used.

\subsection{CODESWITCHING IN DREAMING IN CUBAN}

Dreaming in Cuban was chosen for this study to represent the Cuban-American novel for its popularity and its immediate association with the Cuban exile, given its title. Its title, too, hints at a language conflict as it uses the adjective "Cuban" as if it were a 
type of language, parallel to saying "dreaming in Spanish.” Dreaming in Cuban is also the Cuban-American novel that has received the most attention and has produced a vast number of studies, for which it merits a closer look. Despite the wealth of research, none, to my knowledge, has addressed the topic of language.

Before opening the book, the reader would not be surprised to find a mixture of languages or codeswitching, given the association of Cuba with the Spanish language. Also, it was established earlier that codeswitching is commonly used by the CubanAmerican community in their oral interactions as part of their identity so much so that its presence in written form would be easily justified. As noted by Álvarez:

Choosing one language over the other becomes a complex matter for the Cuban Americans of the one-and-a-half generation. After all, for these writers, Spanish was the language of their childhoods, and English became the language of their mature lives. At times, neither choice produces entirely satisfactory results, since by choosing either Spanish or English these writers give up the idea of belonging to intellectual communities that are essential for their creative survival. (From person to persona 9)

Therefore, it is worth looking at a sample of Cuban-American literature-a very representative one-to explore whether and how it deals with codeswitching and compare it to other works by other Latino authors. Given the precedents in the use of codeswitching in Latino literature (as studied in previous chapters) since the early 1960s, it would not come as a surprise that Cuban-American writers would engage in the use of codeswitching for the same reasons that other authors have adopted it. However, a quick glimpse at the novel reveals a rather sparing use of codeswitching as compared to other 
ethnic novels. In fact, the number of codeswitches in Dreaming in Cuban is the lowest of all the novels studied in this dissertation. Thus, this study wishes to explore, as it has for the previous two novels, whether there is a connection between the language authors decide to adopt and the themes they address and, by extension, the authors' particular experiences.

Codeswitching, as established earlier in this study, is a strategy used by Latino authors as an additional element in their discourse designed to affirm their ethnicity, and to brand their literature with a distinctive style as they struggle to make their voices heard—as was the case for Chicano and Nuyorican writers in previous decades. At the same time, it serves literary a function in such a way that its use is justified and tolerated by the non-bilingual reader.

Dreaming in Cuban, which is 245 pages long, has approximately 400 switches to Spanish. ${ }^{44}$ When compared to the previous novels reviewed (525 for Bless Me Ultima and 770 for When I Was Puerto Rican), this is a rather low number of switches; considering that the plot would justify more dynamic codeswitching; all the characters in the novel are Spanish speakers and half of the story takes place in Cuba. What is important for this study, rather than to judge the choices made by the author, is to attempt to establish whether there is a connection between the themes of the novel and the language employed, as we have for the previous authors. In an interview, when asked about the novel's language and the recurrent topic of music, the author claims:

\footnotetext{
44 Alfred A. Knopf 1992 edition, 245 pp.
} 
I often thought of the book in musical terms. For me, I fueled this by reading a lot of poetry and paying attention to the musicality of each sentence. I also wanted to capture in English something of the rhythm and syncopation of the Spanish language. I wanted the book to feel as though the reader were experiencing it in Spanish. (A Conversation)

There is a clear attempt on behalf of the author to make the book feel Spanish, but oddly enough, she resorts not to codeswitching but to poetry, which based on her response would give her novel the musicality (or prosody) of the Spanish language. In the novel, there are three fragments of poems by Lorca, in addition to a couple of fragments from popular songs, all in Spanish without providing a translation.

Before delving further into the analysis of codeswitching as employed in the novel, it is necessary to understand its narrative structure: a non-linear plot with two chronologies 1) 1934 to 1959 in Cuba, and 2) 1972 to 1980 in the United States. Chapters are broken down by dates, narrators and settings: Section I: 'Ordinary Seductions;' Section II: 'Imagining Winter;' and Section III: 'The Languages Lost.' The narrative voice alternates between the third person omniscient narrator and the first person speech of different characters' voices (Pilar, Luz, Ivanito, Herminia). There is also the epistolary mode by the hand of Celia writing to her lover; letters she wrote to him between 1942 and 1959.

All the Spanish switches are spoken by the characters and almost never by the omniscient narrator. It has been observed that allowing the characters to make the switches to Spanish relieves the narrator from engaging in codeswitching, which places 
the "blame" on the characters, and lets the narrator get away with it. As remarked by Callahan in her study of codeswitching in Latino literature:

The use of codeswitching in the main narrative -i.e. in the author's voice—signals a willingness to go against convention by not following the standards for written language. These standards dictate that representations of non-standard varieties be limited to dialogue between characters, where any attendant connotations of their use can be ascribed to the fictional characters', rather than the author's sociopolitical stance.” (71)

Instead of using codeswitching as a sign of language conflict, such tension is established differently. There is little mention of language in the novel, which at times would seem necessary, at least as a reminder to the reader about the ethnicity of the characters. Celia and Pilar enjoy a certain connection, but it is unclear in what language this communication takes place. Pilar moved to the United States at the age of two, and it is unlikely that her grandmother back in Cuba would speak English. Pilar, whom García claims to be her alter ago, is an artist, and painting is her medium to express what her language cannot: "Translations just confuse it, dilute it, like words going from Spanish to English. I envy my mother her Spanish curses sometimes. They make my English collapse in a heap" (59). This implies that she has certain knowledge about Spanish but not enough to express herself. This is probably the case for many children of Cuban origin who have grown up and received their education in English but have been exposed to the Spanish language only through their parents or other older relatives. This language conflict is at the heart of every exile and is indeed in the novel, particularly in the voice 
of Pilar: "Who needs words when colors and lines conjure up their own language? That's what I want to do with my paintings, find a unique language, obliterate the clichés” (139). Elsewhere, in the same vein, Pilar, when referring to her boyfriend, claims: "We speak Spanish when we make love. English seems an impossible language for intimacy” (180). The language conflict comes to cause greater turmoil in the formation of her already conflicted identity as a hybrid individual. Spanish is both an element that helps her maintain her bond to Cuba and is also elusive to her as it fails to serve its purpose to communicate effectively.

Hence, in the novel, painting is used as a language; as an additional medium for expression, which accomplishes what language cannot. On the one hand, Pilar is privileged for knowing two languages, although they both seem to fail her when she attempts to express her divided identity. From the beginning of the novel, the reader is informed that Pilar does know Spanish but, as described by her grandmother: "Pilar... writes to her from Brooklyn in a Spanish that is no longer hers. She speaks the hardedged lexicon of bygone tourists itchy to throw dice on green felt asphalt” (7). Such divided identity is expressed by many ethnic writers in the form of codeswitching, but Pilar, "to counter the dilemma of language loss, finds that visual images communicate meaning much more effectively than language” (Álvarez-Borland, From Person to Persona 138).

In the previous chapters dealing with other novels, I have devoted a section to dissecting the strategies used by the authors to justify codeswitching. Such strategies are also used so as not to pose such a radical obstruction to the reading experience of the monolingual English reader, and needless to say, to pass the scrutiny of the publisher. In 
the case of García, there are fewer examples of strategies, since as discussed above, her codeswitching is almost imperceptible to the monolingual English reader. However, she does rely on certain strategies at times:

1. Immediate or direct glossing: “They called me brujita, little witch” (28), "Gustavo sang to her beauty mark, the lunar by her mouth” (36), “'Sácalo de aquí.' When I told her that Max spoke Spanish, she simply repeated what she said in English: 'Take him away”” (134), “... and five special oils: amor (love), sígueme (follow me), yo puedo y tú no (I can and you can’t), ven conmigo (come with me), and dominante (dominant)” (199). "In the summer it was the tiempo muerto, the dead time" (233), "Many wear signs saying, SOY UN GUSANO, 'I am a worm.’” (238).

2. Indirect glossing: “...visited the botánicas for untried potions” (36).

3. Contextualized switches: "No sign of gusano traitors," (3), "Can you believe this mierda?” (219).

4. Uncontextualized switches: "the black sound of the duende shivered in the air" (95), “There was a part of him that could never leave the finca or the comfort of its cycles..." (129), "Sixteen days before the asiento, Felicia...” (186), “...she hears some desgraciado selling peanuts...” (114), “They'll send us to the work camps with the maricones!” (241).

5. Simple expressions or fillers: “Sí, Abuela” (242), Dios mío (217), “mi amor” (206) (165), “mi hija” (194), “mi hijo” (89), “mi cielo” (173), querido (161), “mi reina” (153), “por Dios” (13), “mi corazón” (40). 
6. Transparent words/cognates/expressions: "microbios” (21), "perfecto” (61), “el Líder” (3), “yanquis” (3), “novelas” (121), “piñata” (122), “artista” (144), “socialismo” (221), “sí” (232)

It is important to mention that all switches are marked in italics, meaning that there is an attempt on behalf of the writer to call the readers' attention to the switch or alert or inform them that this is a foreign language word. Using italics also marks a conscious intention on behalf of the writer to use a loan word, which signals that it is also foreign for the writer. The largest category is that of fillers or simple expressions, followed by uncontextualized switches. This is paradoxical since the fillers and simple expressions allow the writer to "decorate" her novel with Spanish words at the same time that she maintains the text accessible to the monolingual reader. Conversely, the uncontextualized switches prevent the reader from fully understanding the sentence; however, this occurs only in a handful of instances.

In general, there is no drastic codeswitching in the sense that there are not whole sentences or longer segments of switches. Nor is there a dynamic alternation of the grammars of the two languages in one sentence (intrasentential codeswitching). There does not seem to be an attempt to switch to Spanish at every opportunity, and rather there are missed opportunities where the author could have switched, if that had been her intention. The following classification of switches should provide a better understanding of the switches and how they are employed. 


\subsection{TYPOLOGY AND CLASSIFICATION OF CODESWITCHING IN DREAMING IN}

\section{CUBAN}

Almost all (90\%) of the switches are isolated nouns and noun phrases, and they comprise a combination of core and cultural borrowings. The remaining percentage are fragments of poems or songs. The codeswitched items belong to the following lexical categories:

1. References to people/entities/places: El Líder, yanquis, compañero/a, santero/a, la madrina, gitanas, hijo/a, bruja, brujita, hombre, duende, maricones, chico, yanquis, tía, abuelo, abuela, mamá, papá, papi, caballero, doña, señora, puta, hijito, doña, Plaza de la Revolución, Niña, Pinta, Santamaría, campesino.

2. Culinary terms: arroz con pollo, palomilla, café con leche, yuca, carne asada, yerbabuena, guayaba, guayabita del pinar, novelas, natilla, ropa vieja, guarapo.

3. Ethnographic terms: machetero, danzón, guaracha, guayabera, cante jondo, finca, piñata, novelas, campesinos, botánica, guajiros, botánica, machetero, centrales, bodega, espartillo, latifundio, bohío, asiento (santería), maraca, plantados, asiento, casa de santo.

4. Terms of address/endearment: papi, mi corazón, mi querido, abuelo, abuela, tía, mi hija, mi cielo, mi hijo, mi hijito, doña, mi reina, mi reinita, señora, mi amor, querido, chiquitico, mi amor.

5. Swear words or insults: puta, mierda, desgraciada, asesino.

6. Songs, sayings, poems: Por las ramas del laurel..., Cuba... alegre como su sol, mírame, miénteme, pégame, mátame si quieres..., Me he perdido muchas veces por el mar / con el oído lleno de flores recién cortadas..., Ese lunar que tienes, cielito lindo..., 
Quieres regresar, pero es imposible..., El campo de olivos se abre y se cierra como un abanico...

7. Interjections, tags, and exclamations: ¡Así así!, perfecto!, vámonos, oye, por Dios, ay, mi cielo, sácalo de aquí, mira, sígueme, mi amor, bienvenida, ven conmigo, oye! bueno, socialismo o muerte, bienvenida, Cuba...alegre como su sol, sácalo de aquí, mira, bueno, yo puedo y tu no, Dios mío, por Dios, ay.

8. Miscellaneous lexical items: calle, sí, asesino, artista, bruja, dominante, amor, casa del santo, lunar, asiento, gusano, microbios, perfecto, duende, artista, finca, loca, sí, maricones, centrales, desgraciada, gitana, tu, muñeca, pañuelos, socialismo o muerte, socialismo es muerte.

As established for the previous novels, the division of switched items between core and cultural borrowings helps clarify how much of a conscious attempt there is on behalf of the writer to challenge the status quo and to make unexpected switches to Spanish when there is an equivalent translation readily available in the English language. Cultural borrowings are considered more acceptable as they denote concepts for which there might not be an English equivalent that can describe cultural items, such as those listed under the ethnographic terms category. However, core borrowings, which denote easily translated terms with an equivalent in the core language, are a bolder attempt on behalf of the writer to use a foreign word, which the monolingual English reader might not understand. The instances of core borrowings are listed under the miscellaneous lexical items. For these, the monolingual reader might be at a loss, if no contextualization or cushioning strategy is used. An excessive use of such category would make the reader feel like an "outsider" as opposed to only using a few Spanish switches for Latino flavor. 


\subsection{PARTIAL FINDINGS}

Cuban-American literature is written in either English or Spanish or in a combination thereof (i.e., codeswitching), depending on the particular linguistic circumstances of the author. First generation Cuban-American writers may still write in Spanish, but second generation authors write mostly in English, and may exhibit some codeswitching. However, when compared to other minority writers-such as those studied in previous chapters - there appears to be a different approach to how codeswitching is used, if it is used at all. Because of their particular history of exile and their relationship to the United States and to their own country, Cuban Americans do not share all of the same predicaments that have promoted the use of codeswitching in other ethnic literature (such as Nuyoricans and Chicanos), whose authors have participated more strongly in political advocacy issues and have made codeswitching an additional element in their claim for recognition. However, when it comes to using codeswitching as a literary or decorative element, Cuban-American writers do resort to it, as expected, to perform a mimetic function or to add to the novel's verosimilitude. This finding supports the claim made by this dissertation that codeswitching used in writing by minority authors presupposes a political stance that seeks, among other objectives, to establish a difference from mainstream writers, to claim a wider inclusion and to expand the space in which minority groups are allowed to operate, as well as to bring the reader-ethnic or not-into the world of the writer or that of his/her community. Álvarez Borland, a Cuban-American scholar who has written extensively on Cuban-American literature, aptly summarizes this distinction: 
With regard to literary aesthetics, Cuban-American writing in English opts for a more traditional expression than its other Latino/Hispanic counterparts. Unlike Chicano and Puerto Rican narratives, which often mix languages or create combinations of English and Spanish within the literary work (especially in their poetry), the Cuban-American narrative is usually either in English or in Spanish. The Cuban-Americans' preferential use of traditional English in their literary works could be

attributed in part to the fact that a Cuban-American literary expression in Spanish also exists in the United States today. (From Person to Persona 151)

While Cuban-American writers do share some of the experiences of other Latino communities in terms of a divided identity or the experience of being a minority in the United States, they are also vested with a political dimension in their relationship with their country that is not shared by other Latino communities, including their condition as exiles. However, for writers of later generations - whether second generation or the socalled one-and-a-half generation—who technically speaking are not "exiles," by choice, the term cannot have the same meaning it did for the first generation.

For second-generation authors such as Cristina García, writing about Cuba is both a search for identity—a topic shared with other Latino writers—and a reconstruction of memory. Writers like her, who were either born in or brought at a very young age to the United States, want to make sense of the history they have received from their elders. Works such as Dreaming in Cuban are attempts to revisit the events in the political history of Cuba and understand it on their own terms, and not through the filter of either 
their parents and the more radical Cuban exile community, or the U.S. media. In her novel, she also explores cultural concerns such as the practice of santería in Cuba, and through the story of the Del Pino family, she is able to explore the different political perspectives on the continuum from the most fervent supporters of the Cuban Revolution to the pro-American exiles.

In Dreaming in Cuban, Cristina García writes about Cuba, like most exile writing, but there seems to be an attempt to maintain a balance between the usual outright criticism of the Cuban government and a dispassionate description of events. The literature of Cuban exile writers of the first generation reflects nostalgia and anger toward Cuba, whereas that from the one-and-a-half generation or second generation is concerned with history, memory, and language loss. It does not show signs of defiance against the U.S. mainstream. It does not need to. It has its own space. It has its own predicaments. The writing medium (English, Spanish or codeswitching) is irrelevant for what they have to say. They can say it in either language, or in both. Language mixing, if used at all, is only to show a divided identity, not to defy the "English only" rule, as might be the case for other minority writers.

Cristina Garcĺa does not see the need to rebel through language. Whenever language is brought up in the novel, it is to grieve for its loss. In the novel, the characters know Spanish but seem unable to communicate in that language. Nevertheless, such loss is blamed on their exile condition, not on their condition as ethnic subjects. This claim is supported by Álvarez Borland:

For the Cuban-American ethnic writers, who had American childhoods and were brought up culturally from infancy, linguistic issues are of a 
different nature. For these writers, a need to transcend contradictions and a need to cope with the loss of Spanish as a creative language are personal issues of concern. These writers take up issues in their narratives that have mainly to do with their bicultural selves and how their dual culture affects their present-day life in the United States. (From Person to Persona 50)

Unlike other Latino authors who use their writing to make a statement or to voice the complaints of their community, García, has expressed her conformity with the space that Latino authors have achieved in the American mainstream. In an interview, to the question of whether novels by minority authors such as herself will eventually make their way into English literature departments, she responded: "The mainstream itself will be redefined to include us. We'll be part of the mainstream not by becoming more like 'them' and less like 'us', but by what it means to be an American in the twenty-first century. This is changing and its definition will be necessarily broader and more inclusive” (López 110).

This statement indicates that she is not asking for inclusion. She believes inclusion will come or feels already included. She is not writing to fight for such inclusion. She is writing to make sense of her identity, her Cuban culture and Cuban history. Using the metaphor of the hyphen, which has been appropriately assigned to Cuban-American writers, Cuban Americans see themselves as hyphenated not as alienated individuals. Even if second generation writers do not write with the anger and criticism of the previous generation, their literature is still grounded in the experience of exile. It is the exile of their parents that has produced their inbetweenness: "CubanAmerican literature begins at the point where collective experience -'our history'—gives 
way to personal fabulation - 'my imagination.' It is immaterial whether these fabulations are rendered in English or Spanish, or whether their author was conceived in Cuba or made in the U.S.A.” (Pérez-Firmat, The Spell 28).

These findings are in agreement with the codeswitching observed in the novel. There is only enough codeswitching to give the novel the necessary Cuban flavor, as a sporadic reminder that this is a novel about Cuba, in which all characters are Spanish speakers despite the English-speaking narrator, whose own codeswitching we cannot discern. 


\title{
CHAPTER 4
}

\section{DOMINICAN AMERICANS: UN PIE AQUÍ Y EL OTRO ALLÁ}

\author{
There's no guarantee \\ Ni aquí ni allá.... \\ God bless the child travelin' light \\ Here I am chewing English \\ And spitting Spanish.
}

Dominicanish—Josefina Báez

\subsection{INTRODUCTION}

Dominican American literature has only gained recognition in the last decade thanks to prominent award-winning writers such as Julia Álvarez and Junot Díaz. Without such names and the efforts of Dominican American scholars in anthologizing their work, Dominican American literature would likely not exist as an identifiable body of literature. ${ }^{45}$ Relative to the number of Dominican Americans living in the United States, they are largely underrepresented in all areas of society, including literature. The reason for such shortage should become evident in the following sections.

Nevertheless, as the third largest Latino immigrant community in the United States, a closer study is warranted in order to identify its contributions to Latino letters and thus complete this survey of Latino literature and its connection to codeswitching. In previous chapters, this dissertation addressed authors representing other Latino communities-Chicano, Puerto Rican, and Cuban-American-and identified how the particularities of each community have a bearing on how authors choose to write their

\footnotetext{
${ }^{45}$ Dominican American scholars Franklin Gutiérrez and Daisy Cocco-DeFilipis have been leaders in the study of Dominican American literature and have produced numerous essays and anthologies.
} 
works, despite the general notion of a monolithic Latino identity, which this dissertation challenges.

The study of Dominican Americans and their literature is expected to reveal additional clues regarding the linguistic choices of more recent Latino authorsDominican Americans were the last to begin to produce recognized writers from the groups studied in this dissertation —and how their particular immigrant experience informs their writing. In addition to closely analyzing the codeswitching in a novel by a Dominican-American author, this chapter will also explore whether this literature is affected by the particular conditions of this group such as the strong ties they maintain to their homeland, their concentration in a specific geographic location (i.e., New York City), their intensive political activism, as well as their particular identity and racial issues, among others, and how these conditions differ from those of other communities studied in previous chapters.

Junot Díaz's The Brief Wondrous Life of Oscar Wao has been selected to represent Dominican American literature given the accolades received from critics and readers alike, in addition to having been awarded the Pulitzer Prize for Fiction in 2008, the most important literary prize in the United States. The meaning of such distinction awarded to a Latino author is also worth exploring in order to determine what it means to Latino letters, and more generally, to the Latino community, if anything. The following sections will provide the necessary background to understand the particularities of this community—including their specific historical, political, social, and cultural contexts— before exploring the novel in detail. 


\subsection{IMMIGRATION OF DOMINICANS TO THE UNITED STATES}

Dominican migration to the United States cannot be explained without first referring to its dark history of dictatorship, U.S. intervention, and dire economic conditions, which have been largely responsible for the massive influx experienced since the mid 1960s. ${ }^{46}$

The end of Trujillo's era, or the Trujillato, as it has come to be known, was certainly a major trigger for immigration, considering that while Trujillo was in power, the number of Dominicans who were allowed to leave the country was very low. Restricting migration was used as an additional form of repression. Emigration was controlled by denying thousands of passport applications. It is believed that this was a way of preventing Dominicans from spreading the news abroad about the brutalities that were taking place on the island (Torres-Saillant and Hernández, The Dominican 34). Thus, after Trujillo’s death in 1961, massive emigration began in earnest. However, as expressed by Torres-Saillant and Hernández, authorities on the Dominican diaspora, the Dominican migration was not only a result of the search for better economic and more stable political conditions, but also "involved the power structures of both the sending and receiving societies” (36).

The elements that encouraged the exodus in the sending society are clear: political persecution, political and economic instability, human rights violations, tyranny, fear, poverty, and a lack of opportunities. In the receiving society (i.e., the United States), such

\footnotetext{
${ }^{46}$ Rafael Leonidas Trujillo was in power from 1930 until his assassination in 1961, acting either as president or as an unelected strongman under figurehead presidents. His dictatorship is considered one of the bloodiest in Latin America, in which more than 50,000 deaths are said to have occurred, including the genocide of as many as 25,000 Haitians living in the borderlands.
} 
conditions coincided with the long overdue reform of the Immigration Act of 1921, which had provided for a selective quota system that favored immigrants from Northern Europe and restricted immigration from Asian countries. The 1965 Amendments to the Immigration and Naturalization Act eliminated the racist quota system and gave way to a policy that emphasized family reunification. It also set numerical visas at 170,000 per year, in addition to immediate relatives of U.S. citizens, which meant an even larger number of beneficiaries.

Such a "welcoming” attitude was combined with the role of the United States in expediting the exit of dissidents that opposed the U.S.-backed Dominican government. ${ }^{47}$ The magnitude of the Dominican exodus after 1966 would suggest that "the doors were opened to expel surplus labor as well as dissidents” (Torres-Saillant and Hernández, The Dominican 40), or perhaps was the result of a miscalculation in the number of immigrants that such quotas actually allowed. Although no written agreement existed, the United States and the Dominican governments acted in unison. Political dissidents received visas to travel to the United States (Torres-Saillant and Hernández, The Dominican 39).

U.S. interests on the island date back to the nineteenth century, when the American government was trying to prevent it from becoming a protectorate of a European power, which would weaken U.S. control over the Caribbean. Because of the political instability of the Dominican Republic, there were talks to annex the island to the Union in 1849 (which had been under Haitian rule), under the mandate of the Monroe

\footnotetext{
${ }^{47}$ The United States government had supported the Trujillo government, and upon his death invaded the Dominican Republic in April 1965 to take control of the civil war that was taking place on the island, in order to prevent the emergence of "another Cuba" in the Caribbean.
} 
Doctrine. ${ }^{48}$ Even if annexation did not occur, the Americanization of the Dominican Republic did. A result of such a close relationship was the right of American companies to ship their products to the Dominican Republic duty-free, under the Tariff Act of 1919, and the continuous oversight of the island by the U.S. government.

It is worth mentioning that Trujillo, who gained power via a coup d'état was the chief of the Dominican Armed Forces, and had previously been a trainee of the American constabulary, during the first U.S. military occupation. He was fully supported by the United States. In 1916, upon the resignation of the then Dominican President Juan Isidro Jimenes, "declaring a state of occupation, the American authorities from that point onward decided not to recognize, or even allow, the rise of any Dominican chief of state who did not beforehand pledge to accept American economic and political guidance" (Torres-Saillant and Hernandez, The Dominican 27). ${ }^{49}$

As mentioned above, upon the death of Trujillo, emigration was unstoppable from the 1960s to the 1990s, largely promoted by the family reunification immigration law. By 1990, 511,297 Dominicans were living as permanent residents in the United States, 65\% of whom had settled around the New York region. Other destination states included New Jersey, Florida, Massachusetts, Rhode Island, Connecticut, California, Maryland, Texas, Pennsylvania, and Washington D.C. Even though the immigration of Dominicans officially began in 1962, it reached its peak in the 1990s. According to the 2011 American Community Survey of the Census Bureau, in the 5-year period of 2009-2013

\footnotetext{
${ }^{48}$ The Monroe Doctrine was adopted in 1823 as part of the United States' foreign policy, which justified the right to intervene in any country in order to prevent further colonization by European powers in Latin America.

49 The Dominican Republic was militarily occupied by the United States from 1916 to 1924, and then again in 1965 until 1966.
} 
there were 1,572,700 Dominicans living in the United States. ${ }^{50}$ The massive migration that took place in the 1990s would not have been possible had Dominicans not found the support of family networks established in earlier decades, such as the ethnic enclave established in New York City.

Even if economic conditions were not ideal in the United States for the incoming migrants, they were better than the prospects they had at home with political instability that prevented the country from guaranteeing its citizens' basic needs. The exodus of Dominicans has reached a number that could have never been predicted for a nation that is not connected by land to the continent, which requires migrants to arrive by air and hold a valid visa for entry into the United States. ${ }^{51}$

There is disagreement among scholars regarding the demographic background of Dominican immigrants—-whether they came from the countryside or from the city—but what is undeniable is that most Dominican immigrants to the United States occupied (and many still do) blue-collar and service jobs, with smaller percentages operating businesses of their own, such as the common bodega in the barrio, and even fewer holding more prominent positions. ${ }^{52}$

Research from the Pew Hispanic Center from 2011 shows Dominicans as having a poverty rate of $28 \%$, which is higher than the average for all Latinos (26\%), and with

\footnotetext{
${ }^{50}$ As per the 2009-2013 American Community Survey 5-Year Estimates of the United States Census Bureau.

${ }^{51}$ This figure can be compared to other immigrant communities with lower numbers for which access through the border and without a visa has been possible for decades, such as Central Americans.

${ }^{52}$ Dominicans in New York are known for owning grocery stores, taxi cab companies, sweatshops, travel agencies, ethnic restaurants, and beauty salons.
} 
median annual earnings of $\$ 20,000 .{ }^{53}$ This is not surprising as the demand for unskilled workers decreased in the New York area, while the demand for educated or technically skilled workers increased. Torres-Saillant and Hernández also point to the status of Dominican children in the classrooms, who have "one of the state's worst records with math and reading" and "one of the highest dropout rates in the entire United States" (87). They are also overrepresented in the jails of the state of New York (93). Just as they are overrepresented in the jails, they are underrepresented in the political sphere, except for a few names. As stated by Torres-Saillant and Hernández, "The community suffers from a political invisibility that is hardly justifiable in light of the great size of the Dominican population” (96).

We have seen that the experience of Dominican immigrants is no different-or perhaps only slightly different—from that of other Latinos coming to the United States, (i.e., searching for better job opportunities). Thus, the uniqueness of the Dominican immigrant lies elsewhere: in their racial identity, which merits a close study in the following section.

\subsection{RACE AND IDENTITY OF DOMINICAN AMERICANS}

Dominicans prefer to define their race in terms of language and ethnolinguistic heritage—either as Dominicans or Latin Americans—and not as Black or White. Due to the ideologies installed by white governments in the Dominican Republic who have convinced the population of the superiority of Caucasians, Dominicans have denied their Blackness for centuries. They have associated being Black with ignorance, poverty, and

\footnotetext{
${ }^{53}$ Hispanics of Dominican Origin the United States 2011. Pew Hispanic Center 2013.
} 
backwardness from decades of hearing such a discourse. Such "whitening" policies were also designed to distinguish themselves from Haitians. Torres-Saillant summarizes the Dominican concept of race as follows:

Blacks and mulattoes make up nearly $90 \%$ of the contemporary Dominican population. Yet no other country in the hemisphere exhibits greater indeterminacy regarding the population's sense of racial identity. To the bewilderment of outside observers, Afro-Dominicans have traditionally failed to flaunt their blackness as a collective banner to advance economic, cultural or political causes. (Dominican Blackness 4) Upon arrival in the United States, Dominicans—like other Hispanic immigrants— find themselves classified ethnically and racially, a classification previously unknown to them, since racial classifications do not operate the same way in Latin America and the Caribbean. Itzigsohn and Dore-Cabral succinctly summarize this difference:

In the United States, the color line divides Whites from Blacks in a binary division; in Latin America, race is organized along a continuum of categories that denotes different degrees of racial mixture. This continuum is hierarchically organized—whites on top, blacks on the bottom—but it establishes the presence of a number of intermediate categories in between. Moreover, the intermediate categories are defined not only by skin color, but also by socioeconomic status and cultural elements. (226)

Whereas for many Latinos it comes to them as a shock to find out they are not "White" upon arrival in the United States, Dominicans experience an even greater shock when they are told that not only are they not White, but that they are Black, a notion that 
they have traditionally rejected. It is not that Dominicans are color-blind, but rather, they prefer to resort to their Taino ethnic origin when defining their racial identity—although it is widely documented that there were few Tainos left by the sixteenth century.

Although criticized by some, it should not come as a surprise that Dominicans reject their Black identity. Experience has shown them that there is no profit in being Black, and that on the contrary, the ruling elites-including Trujillo, who banned the practice of vodou in 1943 as a way of dismissing any African heritage, as well as his successor Balaguer-made incredible efforts to convince the population that darker skin is associated with inferiority, against their racial identity, thus promoting a strong antiHaitianism and negrophobia. By the same token, Dominicans on the island never experienced a Civil Rights movement and are not familiar with the concept of using Blackness as an element of self-affirmation of their identity, as has occurred in the United States. In addition, their first loyalty lies with the country, rather than with a race.

Their relationship with their neighbor Haiti cannot be left out of this discussion. In addition to a lack of association with Black identity for the reasons outlined above, the Dominican Republic has been in permanent conflict with Haiti, whose inhabitants they do consider Black, and this serves as a way of differentiating themselves from this "enemy," by denying that they share the same race. ${ }^{54}$ Thus, the relationship with Haiti, at least partially, explains the problematic issue of race among Dominicans. Torres-Saillant states:

\footnotetext{
${ }^{54}$ Another source of anti-Haitianism attributed by scholars are the several attempts of Haitian leaders to bring the Dominican Republic under their rule, between 1844 and 1855.
} 
For Dominicans of African descent history has conspired against their development of a racial consciousness that would inform their building of alliances along ethnic lines. At the same time, their deracialized consciousness precluded the development of a discourse of black affirmation that would serve to counterbalance intellectual negrophobia. (Dominican Blackness 38)

The notion of Dominicans viewing themselves as Latin Americans rather than as members of a specific race is also explained by propositions made decades ago by Latin American philosophers, such as José de Vasconselos, who referred to Latin Americans as "the multicolor multiples of peoples that speak our language," and Pedro Henríquez Ureña: "What unites and unifies this race, an ideal rather than a real one, is the community of culture, determined primarily by the community of language" (quoted in Torres-Saillant Dominican Blackness 47). Thus "race" has become synonymous with "nation” and, for Dominicans, the multiple ethnic groups of Latin America form one single race. This can also be true of other Latin American countries but the difference for Dominicans lies in their darker skin, which is not obvious to them until they emigrate to the United States.

Thus, in the United States, in addition to the discrimination faced by other Latino immigrants based on language limitations, lack of education, and immigration status, Dominicans are also discriminated against racially, even more than other mixed-race Latinos, as they are generally darker than Puerto Ricans, Cubans and other Latinos. This places them in an even more disadvantaged position, that of being discriminated against on two accounts. As Dominicans arrive in the Unites States it soon becomes obvious to 
them than Americans do not distinguish them from Haitians as Dominicans would like them to.

Despite this, Dominican Diaspora scholars are beginning to see instances of the proud assertion of Blackness within Dominicans in the diaspora as members of this community gradually come to terms with their ethnic and cultural heritage with the passage of time and as they learn from the experience of African Americans and share urban spaces with that community. Dominican American sociologist Ramona Hernández observes that Dominican youngsters who have been raised in the United States have greater chances of classifying themselves as Black (quoted in Torres-Saillant, Dominican Blackness 59). This view coincides with historian Frank Moya Pons, who adds that "Dominicans discovered their 'black roots' in the United States and that they have in turn influenced their native land by returning home with their discovery" (quoted in TorresSaillant, Dominican Blackness 60). This is an important contribution that the diaspora could be making to the homeland—as they are known for maintaining close ties with relatives back home—if supported by its national institutions.

Similarly, second or third generation Dominicans are likely to gradually adopt the racial classifications that surround them. While it is not possible to claim that all Dominican Americans have fully come to terms with their Blackness, as this may be a life-long journey, the process may be liberating. Discovering their Blackness—albeit painfully—has given Dominicans a sense of empowerment that is not shared by other immigrants. To this, we can add their sense of community, their entrepreneurship, and the support of the enclaves they have established in certain key geographical regions of the 
country —all of which can help us understand how Dominicans have expanded their own space to operate as a cohesive community much better than other immigrant minorities.

Another source of empowerment, particularly for New York Dominicans is the achievements they have made in local politics. In her book, Dominicans in New York: Power from the Margins, Milagros Ricourt presents the gains made by Dominicans at the local level and claims that "Dominicans are the first group of new immigrants-those people migrating to the United States after 1965-who have gained electoral representation in both the New York City Council and the New York State Assembly. Despite their immigrant status and their poverty, Dominicans have managed to become an ethnic political force in New York" (3). According to Ricourt, the political gains for Dominicans have derived from "clinging to their ethnic identity as a social, political, and even a cultural strategy to improve their individual and collective welfare” (4), which has afforded them political recognition, understanding that the members of this community are dispersed along the continuum from Dominican to Dominican American, where we can find Dominicans who have just arrived, as well as the fully assimilated Dominican Americans who are engaged in advocacy issues and have attained a higher level of education.

Indeed, Dominican Americans are statistically poor, but they are a cohesive and extremely active minority whose members have found ways to incorporate themselves into American society through activism in multiple grassroot organizations and a strong geographic concentration. This has contributed to their empowerment and led them to collective action. Their political incorporation is fueled by their ethnic awareness, racial coalitions that they have established with other minorities, the gains of the civil rights 
movements, and their dual citizenship. They have also created "social capital," which they have learned to translate into political representation, strong community ties, and a sense of solidarity. ${ }^{55}$ It is this social capital that we see manifested in their literature, particularly that of Junot Díaz.

This is not to say that Dominicans have "made it," but in the midst of their precarious conditions, they have found that assimilation is not the only way to succeed in America. Rather, they have learned to exploit the political gains they have made as a minority and capitalize them to their advantage, which has expanded their space and augmented their long overdue visibility.

Ricourt is not alone in her assertion of Dominican empowerment. Ana Aparicio also claims that Dominicans have used their ethnicity to create stronger ties in the diaspora, which has helped catapult them into the New York's political landscape:

Identity formation is not merely a reactive force among exploited, impoverished groups that occupy lower rungs of political and economic hierarchies. It can be a strategy to achieve various resources and rights for a group. A self-conscious frame of reference as person of color, a Latino, or a member of the African diaspora carries with it strong proactive possibilities. (149)

Such political and social gains are what set Dominican Americans apart from other ethnic minorities. It is then safe to say that this group deals with race differently

\footnotetext{
${ }^{55}$ Social capital is "the aggregate of the actual or potential resources which are linked to possession of a durable network of more or less institutionalized relationships of mutual acquaintance and recognition” (P. Bourdieu).
} 
once they have understood how being Black in the United States is different from being Black in the Dominican Republic—not necessarily better though. Discussing the ethnic identity of Dominicans is relevant to this project since it allows us to better understand the particularities of the additional challenges faced by Dominican Americans, in addition to those experienced by other immigrants. Many Dominicans have accepted and even embraced their classification as Black due to the racial labels of the receiving society. In the diaspora, some of them have even become allies with Haitians since anti-Haitianism is no longer necessary or practicable.

\subsection{THE LANGUAGE OF DOMINICAN AMERICANS}

As Dominicans deal with their identity issues in racialized America, some of them have decided to accept their Blackness and have joined forces with African Americans in their struggle and have even found a way to participate in the space the community has claimed for itself, while others still resist such a classification. Those who resist it have resorted to reinforcing their Dominicanness; they cling to their Hispanic heritage and make their Spanish noticeable in order to distance themselves from a phenotype-racial categorization. Dominicans, as claimed by Toribio, are "the most Spanish monolingual of the Hispanic groups in New York” (Nosotros 261). Thus, their emphasis on portraying themselves as Hispanics - to avoid being taken for Blacks—-has promoted their use of Spanish even among U.S.-born Dominicans in view of the racial ideologies of the receiving society.

Benjamin Bailey has studied at length the issue of identity formation through the use of language among Dominican Americans. He explains this phenomenon by arguing that: "Negotiations of identity take place within the parameters that history has imposed 
in a particular time and place" (Language Alternation 32). In his essay "Language and negotiation of ethnic/racial identity among Dominican Americans," he provides the following comment by a high school student of Dominican descent regarding his Blackness as an example of what transpires in U.S. schools with Dominican kids:

Wilson: Like for example, like I told you before, a lot of people confuse me like I'm Black. Yesterday I got that comment, ...there was this Spanish kid, he was Dominican, I was standing next to him and this other friend of mine, he's Dominican too, he was talking to me, and he heard me speaking Spanish to the other kid, he said “Oh I could've sworn he was Black” ...he asked me, “Yo, you Black? You’re not Black, huh? I was like “Nah, I’m Spanish”. (Language and Negotiation 559)

The fact that Dominican Americans embrace their identity through the Spanish language is worth exploring, as it is particular to this community. It is also somewhat paradoxical considering that Dominican Spanish enjoys a lower prestige status, similar to that of Puerto Rican or Cuban Spanish—when compared to other varieties—among Spanish speakers from other countries and even among non-speakers of Spanish. ${ }^{56}$ This is largely due to the phonological, lexical, and morphosyntactic characteristics found in the Dominican variation, which linguists call 'linguistic innovation. ${ }^{57}$ Such innovation is shunned by other Spanish speakers who perceive the Dominican variation as inferior. To complicate matters, Dominicans themselves consider their own Spanish inferior: "The

\footnotetext{
${ }^{56}$ For a study on linguistic attitudes towards Dominican and Puerto Rican Spanish see SuárezBüdenbender, 2013.

${ }^{57}$ Some of the variations in Dominican Spanish include lambdacism, glide formation and rhotacism, weakening of syllable-final /s/, and in grammar, a marked use of subject pronouns, and altered word order for question formation.
} 
Dominican vernacular remains stigmatized and aesthetically undervalued, especially among the Dominican middle and upper classes, for lacking certain features of an idealized standard" (Toribio Nosotros 258). ${ }^{58}$ The Dominican vernacular is undervalued both on the island and among Spanish speakers in the United States for diverging from the standard variety. It is worth mentioning that Dominicans have lived alongside Colombians in New York City, who claim to have "the best Spanish."

Interestingly, despite the stigmatization of Dominican Spanish, it enjoys vitality in New York City: "Dominicans demonstrate extensive Spanish language usage in the private home domain with family members, as well as with in-group members such as friends, classmates, and co-workers, and in the extended out-group domains of the community" (Toribio Language Variation 1145). The fact that they continue using Spanish signals its value as an important feature of their identity, despite the negative opinions they themselves may have about their particular dialect. Dominicans use language to find solidarity, be it Spanish or codeswitching.

Based on the above, I argue that for Dominican Americans language does operate in the formation of their social identity, to which they remain loyal; it becomes their "linguistic capital" and an immutable marker of their identity, which may be used in addition to other identity markers such as social group, cultural traditions, ethnicity, etc. ${ }^{59}$ This language loyalty is what we will see exhibited in the literature they produce, and is one of the claims of this dissertation.

\footnotetext{
${ }^{58}$ For a detailed description of Dominican Spanish, see the research of Jacqueline Toribio and Benjamin Bailey who have studied this phenomenon at length.

${ }^{59}$ For a study on language and the formation of identity see Speaking Subjects: Language, Subject Formation, and the Crisis of Identity, Carter 2009.
} 
In addition to the Spanish language being used for identity formation—which is Bailey's claim—I claim that codeswitching also plays a major role among Dominican Americans. It is expected that U.S.-born Dominicans would feel more comfortable codeswitching between English and Spanish within their communities than speaking solely Spanish, regardless how well they might speak it. As noted by Bailey: "Displays of Spanish speaking trigger ascriptions of Latino identities from bystanders who might otherwise see individuals, based on physical appearance, as black or white” (Language Alternation 49). Thus, codeswitching is used for negotiating identity within their speech communities and providing them with an identity that prevents them from being classified as Black; tapping on their 'linguistic capital' is essential for U.S. Dominicans, more than for any other Latino community.

Bailey's research conducted on Dominican American high school students in Providence, Rhode Island, also found that "codeswitching was relatively frequent and unmarked" (Language Alternation 34) (my emphasis). By "unmarked" he means it occurs more frequently than the standard form, which points to the use of codeswitching as a discourse mode.

Toribio offers an additional explanation for the use of the Dominican vernacular to reinforce dominicanidad and to help promote unity and national identity in the diaspora: "The sustained language maintenance among Dominicans in the diaspora owes in large part to the nature and extent of their ties with their homeland; they are intensely loyal to their home country-they are Dominican first, Latinos second-and for many, return to the homeland is not a myth, but a mandate" (Toribio Nosotros 261). I would add that these factors apply to the use of codeswitching as well. 
To sum up, in the Dominican Republic, the focus on strengthening their hispanidad is to distance themselves from their neighbor Haiti; but in the United States, it is the Spanish language that provides the salient element. If they cannot be distinguished from African Americans by overt markers such as their physical appearance, then it is the Spanish language that affords one direct way of doing so, for which either Spanish, or codeswitching are the favored modes of communication in their speech communities.

Dominicans consider language a crucial aspect of their identity, which attests to their dominicanidad and distances them from blackness by U.S. standards. Language loyalty is an important feature for Dominican identity, even if they are aware of the low prestige enjoyed by their dialect vis-à-vis other variations. It binds them to other Latin American countries and keeps them separate from African roots. Dominicans do not gain from giving up their vernacular, particularly if their English is going to be accented. They stand to profit more by using Spanish whenever they can, and this includes using it in their literary writing.

\subsection{DOMINICAN AMERICAN LITERATURE}

Dominican American writers occupy what Homi Bhabha calls the "third space," which is defined as a cultural space that is neither here nor there or is both here and there, depending on each writer's particular conditions. This is true of recent immigrants, first, "one-and-a-half," second or third generation individuals who navigate both cultures and for whom complete assimilation is seldom complete as explained in previous sections. However, it is believed that Dominican Americans maintain stronger ties with their home country than other immigrant communities, and this allows them to straddle both cultures and fuel their Dominican identity. 
Contemporary Dominican American authors include Julia Álvarez, Junot Díaz, Angie Cruz, Loida Maritza Pérez, Nelly Rosario, Chiqui Vicioso, among other names, whose works feature a common theme: their "hyphenated" or divided identity and journey as they (and their characters) attempt to assimilate into Anglo culture. However, until the early 1990s, the only well-known Dominican American author was Julia Álvarez, with her highly-acclaimed bildungsroman How the Garcia Girls Lost Their Accents (1991). That is, they were extremely underrepresented considering the size of the Dominican American community, particularly on the East Coast, where one would expect a higher participation in Latino letters. Publications that discuss Dominican American literature are also scarce.

In any case, an attempt to discuss Dominican American literature should begin with a reminder that these writers include immigrants with different lengths of permanence in the United States as well as those born on U.S. soil, but this is also true for the other minorities studied in this dissertation, except that Dominicans were the last to arrive. In A Companion to U.S. Latino Literatures, Elizabeth Coonrod Martínez claims that "their works inaugurate a generation that is neither Dominican not American, forging a sort of Dominican-New York identity, akin to the Nuyorican ... Their works portray the problematic of inner-city life, dead-end jobs and the dream of making dollars and returning home to the island” (109).

Regarding the themes that are present in the diasporic writings of Dominican Americans, Torres-Saillant aptly summarizes them as follows:

The characters that populate the stories contained in the preceding books face obstacles that emanate from their precarious milieus, where they 
cannot take for granted amenities such as stable and urbane homes, quality schools, clean neighborhoods, language-rich environments, adequate health services, amicable support networks, and down-right physical safety. The awareness of their racialization, social impediments, and cultural otherness with respect to a distant and indifferent mainstream is thrust upon them by the ordinary drama of their struggle for material and spiritual survival. Key among their common features is the memory of the Dominican past as a source of clarity and potential strength even while they indict the less democratic and less ecumenical characteristics of the ancestral heritage. Reconnecting with Dominican history seems to be a strategy whereby their characters enhance their ability to cope with the ethnic, racial, sexual, and cultural antipathies they face in the United States. (Dominican-American 432)

The topics of immigration, the country left behind, the issue of a divided identity, the process of assimilation, the diasporic experience, feelings of alienation, and related topics are common to all Latino literature, but I would agree with Martínez in her appreciation of what distinguishes Dominican American literature from the rest of Latino literature: "Their novels demonstrate that the Dominican experience is one of a doublediaspora, that its African heritage needs to be discussed together with its island and Spanish history” (117). As discussed in previous sections, Dominican immigrants are faced with additional challenges regarding their African heritage, and part of their assimilation process is trying to come to terms with such heritage, which was not an issue before immigrating to the United States. Thus, as claimed by Martínez: "Dominican 
American literature constitutes a provocation against the official history of either the Spanish-Dominican or the US political context that separates Latino from AfricanAmerican” (117).

Eminent Dominican diaspora scholar Daisy Cocco-De Filippis has been a harsh critic of the exclusion of Dominican American authors from the anthologies and publications of Latino literature to date, including those by well known Latino scholars such as Nicolás Kanellos, William Luis, Harold Augenbraum and Margarite Fernández Olmos, who do not seem to notice contemporary Dominican American writers-not to mention Dominican authors from the first half of the twentieth century. This group, classified as "before the diaspora" authors, include prominent representatives such as Pedro Henríquez Ureña (1884-1946), his brother Max (1886-1968) and his sister Camila (1894-1973), Fabio Fiallo (1866-1942), José M. Bernard (1873-1954), Manuel Florentino Cestero (1879-1926), Jesusa Alfau Galván (1895-1945), and Francisco Henríquez y Carvajal (1859-1935). ${ }^{60}$ These were immigrant authors, writing in Spanish about a diasporic vision and maintained an exilic attitude, but they were the pioneers in establishing literary ties between New York and the Dominican Republic. For the most part, these were intellectuals belonging to the educated and political class, who had the means to travel abroad. We can also conclude that the reason for their exile was not economic, as was the case with later immigrants.

\footnotetext{
${ }^{60}$ Pedro Henríquez Ureña and Camila Henríquez Ureña are the children of the revered poet and pedagogist, Salomé Ureña and Francisco Henríquez Carvajal, a politician and president of the Dominican Republic. Pedro was an essayist, philosopher, humanist, philologist and literary critic. They were both professors of Hispanic Studies in the U.S. Camila was also one of the first Latina professors in the United States.
} 
Back in their time, some of the outlets available for publications in Spanish in New York were Visión, La Prensa, and El Diario de Nueva York (Pérez 12). For De Fillipis, “Pedro Henríquez Ureña’s presence and his reputation as a fine intellectual were pivotal to the promotion of Dominican letters in the U.S.” (280). Many of these authors published their work in the literary journal Las Novedades in New York (De Fillipis 34). In general, these nomadic authors wrote to share their experience as travellers. Other names include Gustavo Bergés Bordas (1895-1925), Angel Rafael Lamarche (18991962), Virginia de Peña de Bordas (1904-1948), and Andrés Francisco Requena (19081952), most of whom were intellectuals who produced a very different type of literature from those "after the diaspora." Most of the works of these intellectuals or writers in the United States have a political orientation and some of the texts (Galván, Florentino and Bergés) criticize the behavior, attitudes and values of Americans as seen by the outsider.

De Fillipis explains that many authors have published their work through small publishers or have sent their work to be published in the Dominican Republic, and hence have not earned recognition in the United States or outside their immediate community (151). ${ }^{61}$ Julia Álvarez’s How the Garcia Girls Lost Their Accent (1991) was the first Dominican-American work to attain national, and even international, attention. This lack of recognition of Dominican American authors claimed by some scholars is what the CUNY Dominican Studies Institute has attempted to compensate for, and it offers a

\footnotetext{
${ }^{61}$ Alcance is a Dominican community-based publishing house.
} 
venue to promote, support, and disseminate information about Dominican American writers. ${ }^{62}$

In the twentieth century, Trujillo’s dictatorship was the topic of a good portion of the literary production, written from the exile position. The works of Franklin Gutiérrez and Daisy Cocco De Fillipis have helped promote the dissemination of Dominican American literature, but there is not doubt that the names of Julia Álvarez and Junot Díaz have contributed to the creation of the brand of Dominican-American literature since the 1990s, when Álvarez acquired mainstream recognition, followed by Díaz in the 2000s. Despite the efforts by scholars to create anthologies before and after the diaspora, the list is limited compared to that of the other larger Latino communities studied in this dissertation (Chicano, Nuyorican and Cuban-American). Gutiérrez explains this shortage of writers as follows:

Los dominicanos radicados en New York en los años 70 partieron de la premisa falsa de que su distanciamiento de la patria no se prolongaría por más de dos o tres años, tiempo suficiente para producir un buen atajo de dólares e invertirlos en cualquier tipo de negocio que les permitiera vivir tranquilamente en su tierra natal. Esa creencia en el retorno inmediato a la isla tuvo resultados ambivalentes pues mientras, por un lado, los dominicanos desplazaban a judíos, griegos y cubanos de Washington Heights y se convertían en propietarios de la mayoría de los negocios de

\footnotetext{
${ }^{62}$ The CUNY Dominican Studies Institute was founded in 1992 and is the only research unit devoted to the study of people of Dominican descent in the United States, with the mission of producing and disseminating research and scholarship about Dominican Americans and the Dominican Republic. It is housed at the City College of New York and is currently headed by Dominican American sociologist Dr. Ramona Hernández.
} 
ese sector, por el otro descuidaban su ingreso a los centros académicos. En consecuencia la presencia de la literatura dominicana en el mercado de consumo y en las academias estadounidenses en los 70 fue escasa. (67)

As an additional explanation, I argue that such shortage of Dominican American authors may also be due to the fact that they have not reached the same degree of assimilation as other Latino communities, given that they were the latest group to immigrate. They began their exodus in the 1960s, at the same time as Cubans, but they reached their peak in the 1990s, which means that, given their less favorable economic conditions, they have not attained the level of education and insertion into American society that would allow them to produce enough writers. For those who have become writers, as De Fillipis argues, "the written word has become the means to an existence, to mark their presence, 'de hacer constar, .. . Language provides these writers with a biography by giving them the tools to record their lives both as individuals and as witness of history in the making” (268).

These scholars point to the 1980s as the decade of awakening of diasporic Dominican literature, when the first anthologies began to get published including names such as Tomás Rivera Martínez, Fermín Cruz, Rafael Díaz, Franklin Gutiérrez, Juan Torres, José Carvajal (Gutiérrez 68). ${ }^{63}$ Another attempt to promote Dominican American literature was the establishment of literary circles (Círculo de Escritores Dominicanos [1983], El Colectivo de Escritores Dominicanos [1984]) and magazines, such as Inquietudes, Letras e imágenes, Punto 7. An additional event aimed at strengthening

${ }^{63}$ Some of the first anthologies to collect Dominican-American authors include Esta urticante pasión de la pimienta (1983), Niveles del imán (1983), Voces del exilio, Estudios semióticos de poesía dominicana (1982), Poemas del exilio y otras inquietudes (1988) 
literary production were several conferences organized by Seton Hall University in 1986 and by Casa Cultural Dominicana in 1987, and 1989. Gutiérrez identifies 35 titles published in the 1980s (69).

Understandably, the most cultivated genre has been poetry and the predominant topics are the nostalgia for the country left behind and the emotional impact produced by U.S. society (Gutiérrez 70). Gutiérrez claims that the surge in Dominican writers in the 1990s was due, not only to the now larger number of Dominican immigrants, which included intellectuals, academics, journalists and national writers, but also to the existence of second and third generations of Dominicans born or educated in the United States who were entering the world of letters (71). In one of Gutiérrez's studies, he identified 138 Dominican writers in the United States, with 375 published works, 90 of whom live in New York, and the rest in other states. (71). He also remarks that the predominant theme, both in prose and poetry of the Dominican-New Yorker diaspora of the 1990s stays away from the melancholy and nostalgia exhibited by authors in previous decades (74). The topics, according to Gutiérrez, turn to a marked interest in the issues surrounding their geographic and social space:

New York deja de ser la ciudad perfecta, la fuente de producción de dólares, de enormes rascacielos y luces deslumbrantes idealizada por los inmigrantes dominicanos de los 70 para tornarse en un lugar real, en un medio donde hay que vencer la discriminación racial, satisfacer las necesidades de subsistencia y los conflictos de identidad que desde hace un par de lustros comenzaron a aflorar en las generaciones de los nacidos en New York quince o veinte años atrás. (74) 
It is interesting to note that, as opposed to the experience of Nuyorican and Cuban-American authors, the works of Dominican Americans are well known in the Dominican Republic, and enjoy a privileged position as attested by the literary awards these authors received in the Dominican Republic. Torres-Saillant argues that this may be due in part to the fact that "as Dominican society increased its economic dependence on the monetary remittances and other sorts of support coming to the country from the émigré population, the Dominican government has progressively heightened its effort to connect with Dominicans abroad” (Dominican-American 427), so much so that Dominicans have been able to vote in the United States since 1994 and are able to maintain dual citizenship. Another form of support was the creation of the Comisionado Dominicano de Cultura in the United States, a New York-based extension of the Dominican Ministry of Culture, which among other duties, hosts a yearly Dominican Book Fair since 1997. Thus, we can say that the relationship of the Dominican diaspora with the home country is a fluid one.

Above we have seen that a Dominican-American literature does have a place in Latino letters, despite being a latecomer, with a promising future fueled by the efforts of the community itself and the recent success of their two most identifiable figures: Álvarez and Díaz. It will be a matter of time before we begin to see more authors enter the mainstream as they traverse the road already paved by such distinguished names. Having established the existence of a Dominican-American literature we can move on to study one of its most prominent representatives, Junot Díaz. 


\subsection{SUMMARY AND THEMES OF THE BRIEF WONDROUS LIFE OF OSCAR WAO}

Junot Diaz's The Brief Wondrous Life of Oscar Wao is a seemingly coming-ofage novel that chronicles the life of Oscar de León (a.k.a. Oscar Wao), an overweight, socially inept (Afro)Dominican kid growing up in Paterson, New Jersey. Oscar does not seem to fit into either Dominican American or American society. He is obsessed with science fiction and fantasy novels, is nerdy and unable to attract any women. I say a "seemingly" coming of age novel because Oscar's life is only the vehicle used by the author to take the readers to life in the Dominican Republic through the Cabral family under the reign of Trujillo and at the same time to see first-hand the struggles of an immigrant kid in New Jersey. Whereas the beginning of the novel takes place in New Jersey, the middle sections take place in the Dominican Republic where the reader witnesses some of the cruelties of the Trujillato as experienced by Hypatía and Abelard, Oscar's mother and grandfather. The novel extends back to older generations of the Cabral family in order to expose the atrocities of the Trujillato, thus maintaining a balance between the events on the island and life in the diaspora, moving back and forth between the two places.

Despite the emphasis on Oscar's lack of social skills, which could be the case for any kid growing up regardless of his/her ethnic background, the main two themes that stand out are the split identity of an (Afro)Dominican American kid and life in the Dominican Republic during Trujillo's reign. The story is told by an apparently omniscient narrator, who turns out to be Yunior, Oscar's college roommate, and his 
sister's boyfriend. ${ }^{64}$ At the end of the novel, he reveals himself as a testimonial narrator who is writing his friend Oscar's story, now deceased.

The story is a series of family calamities that are justified by a fukú, a sort of curse or doom that has befallen the family, which is used as an excuse to justify the permanent bad luck of its characters. The fukú will be a constant theme throughout the book, which the narrator explains in the prologue: "It is perfectly fine if you don't believe in these “superstitions." In fact it is better than fine-it’s perfect. Because no matter what you believe, fukú believes in you” (5).

The book spans half a century of Dominican history from 1944 to 1995 covering three generations of the Cabral family. The stories are woven together in a way that exposes the reader to both the individual lives of the characters and to the larger theme of Dominican history, which revolves around the brutality of the Trujillo regime. The novel also explores and problematizes the Dominican exile community in terms of its identity issues through the story of the Cabral family, both in the United States and on the island. It does not follow a linear chronology of events, but rather jumps around throughout the twentieth century. It begins the story with Oscar and his sister Lola as they grow up, go through college, and become adults in Paterson, New Jersey. Then, the story turns to Belicia, their mother, how she came to immigrate to the United States, and through whom we learn some Dominican history, particularly its darkest period of dictatorship under Trujillo.

\footnotetext{
${ }^{64}$ Yunior has appeared in many of Diaz's short stories and is considered the author's alter ego.
} 
One of the successful elements of this novel is probably its language. The story is narrated in a funny, street-smart colloquial language, heavily inflected with Spanish and full of slang. Dominican history is narrated in a sarcastic and ironic voice, perhaps to soften it or to dare to say more under the spontaneous and humorous voice of the young narrator. For instance, when referring to Trujillo, he uses such informal language that it does not seem to correspond to real life events:

Homeboy dominated Santo Domingo like it was his very own private Mordor; not only did he lock the country away from the rest of the world, isolate it behind the Plátano Curtain, he acted like it was his very own plantation, acted like he owned everything and everyone, killed whomever he wanted to kill, sons, brothers, fathers, mothers, took women away from their husbands on their wedding nights and then would brag publicly about 'the great honeymoon' he'd had the night before. His Eye was everywhere; he had a Secret Police that out-Stasi'd the Stasi, that kept watch on everyone, even those everyones who lived in the States. (225)

Another novelty introduced by the novel is that it relies heavily on footnotessometimes occupying three-fourths of a page-which contrast sharply with the informality and jovial tone of the text. Through these, the author fills in the blanks for "those of you who missed your mandatory two seconds of Dominican history" (2). Through these footnotes the reader is introduced to factual Dominican history, although based on individual stories rather than official records. The footnotes expose the reader to many unknown crimes committed by Trujillo, through the guise of the narrator's voice. 
Also, the author claims, these footnotes are meant to maintain an objectivity of the historical facts. ${ }^{65}$

Some critics have pointed out the magical realist features in the novel: the talking mongoose, the man without a face, the fukú or curse that befalls the family, etc. Using fukú as a trope, the author combines elements from reality and fantasy to maintain both an objective view and to make room for the unexplained; to accommodate both magic and realism. In addition, Díaz makes frequent references to science fiction, role-playing games, video games, modern music, comic books, and anime movies, and to many hidden codes for the uninitiated.

The novel also addresses the theme of the immigrant struggle and how its main character has to face the challenges as an Afro-Latino boy whose working-class barrio does not afford him many opportunities. Díaz challenges the notion of the American Dream in the failure of his main character to "make it" in America, particularly for those of darker skin, a detail about Oscar that the author wants to emphasize. Oscar finds himself in the position of many Afro-Dominicans of defending their ethnicity when taken for blacks: “'You're not Dominican.’ And he said, over and over again, 'But I am. Soy Dominicano. Dominicano soy”” (49). He claims his Dominican heritage but he is also a foreigner on the island, thus experiencing a double marginalization.

At the end, Oscar eventually falls in love with the wrong woman (the girlfriend of a top-rank Dominican captain) and sacrifices himself for love by ignoring the imminent danger of getting killed at the orders of his rival, thus succumbing to the fukú. Although

\footnotetext{
${ }^{65}$ Through the footnotes, the narrator also criticizes U.S. intervention on the island, and how U.S. support allowed Trujillo to commit so much violence, including the massacre of thousands of Haitians, which in turn contributed to the negrophobia and to favor a Taíno inheritance.
} 
a personal story, it can also be read as a metaphor of the Dominican Republic in general. The curse may be extended to all its people, even those who emigrate. Regardless of its interpretation, Díaz aptly combines the history of a nation with a personal story including the oft-avoided topic of Dominican blackness.

\subsection{CODESWITCHING IN THE BRIEF WONDROUS LIFE OF OSCAR WAO}

Selecting this novel as the representative of Dominican American literature for this dissertation was an easy choice given its large readership and its distinction of having received the Pulitzer Prize in 2008. A minority author (and foreign born) is not the usual recipient of this award, a fact that merits a closer look. Additionally, what makes this recognition even more surprising is that the award went to a novel that most Anglo monolingual Americans would have trouble reading due to its extensive codeswitching. Since this is the latest publication among novels studied in this dissertation, a possible argument that can be raised is that codeswitching is being used increasingly in Latino literature as the number of Spanish speakers in the country grows, and as this type of literature makes its way into mainstream literature. The following sections will determine whether that is actually the case.

The total number of Spanish switches in the novel is approximately 1,120 (the breakdown of which is provided in the following section) in a novel that is 340 pages long. Not only is the number of switches larger than in the other three novels studied in this dissertation, but the switches themselves are also more radical. ${ }^{66}$ By radical, I mean that the author does not apologize for the use of Spanish, which may obstruct meaning at

\footnotetext{
${ }^{66}$ Number of Spanish switches/tokens in each novel studied in this dissertation: Bless Me Ultima: 477, When I was Puerto Rican: 770; Dreaming in Cuban: 404, The Brief Wondrous Life of Oscar Wao: 996.
} 
times, and is not always justified-he does not seem to be concerned about the difficulties that the English monolingual reader may encounter. On the contrary, he writes confidently and unapologetically, and he is oblivious of the language switches he performs.

This novel stands in sharp contrast to those studied in previous chapters in which the authors try to "cushion" or to soften the use of Spanish by employing strategies that would allow them to codeswitch without obstructing meaning, such as indirect/direct glossing, contextualized switches, “easy Spanish”, sets of repeated words, cognates, etc. In those novels, for the most part, Spanish is innocuous and plays a merely decorative and/or ethnic role. The novel has little dialogue or direct speech; therefore, most of the switches are performed by its narrator, Yunior. This fact is also indicative of the audacious use of codeswitching. In previous novels studied in this dissertation, it was observed how the codeswitched segments were transferred to the characters as a way of justifying its use.

Codeswitching is by no means a new element in literature, as we have observed in previous chapters, but The Brief Wondrous Life of Oscar Wao is certainly the first novel to use it so radically. ${ }^{67}$ Novels that have experimented with codeswitching before have always remained in the realm of ethnic literature. Díaz managed to attain national attention and bypass publishers’ censors of ethnic features that “do not sell well.” He has

\footnotetext{
${ }^{67}$ There have been other bilingual narratives published in which the authors alternate between English and Spanish almost equally (Susana Chavez-Silverman’s Killer Crónicas, Giannina Braschi’s Yo-Yo Boing!), that are clearly directed to a bilingual readership and are usually published by academic or minority presses. The works studied in this dissertation are not classified as bilingual. Their "matrix" language is English and their "embedded" language is Spanish.
} 
often been asked to explain the intention behind his codeswitching, to which he has responded:

For me allowing the Spanish to exist in my text without the benefit of italics or quotations marks a very important political move. Spanish is not a minority language. Not in this hemisphere, not in the United States, not in the world inside my head. So why treat it like one? Why 'other' it? Why de-normalize it? By keeping Spanish as normative in a predominantly English text, I wanted to remind readers of the mutability of languages. And to mark how steadily English is transforming Spanish and Spanish is transforming English. (quoted in Ch'ien 204)

The use of codeswitching as a political move-not just an aesthetic or literary one-is one of the tenets of this dissertation, but not all authors admit it publicly or are able to do so. In previous chapters dealing with codeswitching in other novels, Spanish switches largely responded to the need to introduce cultural elements, to which the monolingual English reader may be more open and tolerant. However, as claimed by Eugenia Casielles-Suárez in her study of codeswitching in the Brief Wondrous Life of Oscar Wao,

Díaz’s use of Spanish ... goes beyond gratifying the bilingual reader and approaches radical bilingualism. . . Rather than include whole paragraphs in Spanish, which a monolingual reader could simply skip or offer a kind of code alternation. . . the quantity and quality of the Spanish words and phrases which are constantly inserted in English sentences create hybrid 
phrases with the result that rather than alternating with English, Spanish become part of English. (477)

It is only logical to ask what audience does Díaz have in mind that can access his prose, which at first seems to be a bilingual one, but more than catering to a bilingual audience, I claim that he wishes to challenge the prescriptive approach to writing in the hegemonic language. It is the boldest political move that any writer has attempted, but what is even more significant is that he managed to do so and still enter U.S. mainstream literary outlets. Once again, his challenging attitude can be perceived from his comments regarding his linguistic choices:

When does a loan word become an English word? Is "hacienda” a word in Spanish or English? You know what I'm saying? The point is that I'm pushing the dates on a lot of these words. I decided I don’t need a hundred years for the Oxford English Dictionary to tell me that it is okay to adopt this or that word as part of our normal vocabulary. (quoted in Casielles 204)

So, he seems to be saying that these words will eventually enter the English language, which is not likely to happen. More than borrowing words he is challenging standard English, and its hegemonic status: The more subversive and unorthodox, the greater the impact. I agree with Casielles in her view that "rather than portraying naturally occurring code switches, it seems that Diaz is more interested in flouting the rules in order to create powerful, disjunctive linguistic hybrids” (482), which she calls “language violence” more than language alternation: "Spanish does not so much alternate with English, but ‘invades’ English” (Casielles 485). 
As we will see below, Diaz's use of Spanish indeed does not correspond to actual codeswitching, and it is rather a heavy borrowing of lexical items, and when he does attempt to codeswitch he breaks the basic rules under which it is allowed, thus challenging not imitating real life speech. I also argue that Díaz, in addition to challenging the English language—or the writing of it—he is challenging all his readers, whether monolingual or bilingual. A close reading reveals that even the bilingual reader is left in the dark when he uses Spanish switches that are either specific to the Dominican Republic or the Caribbean, high register words, some even specific sociolectal words, some intellectual and some even made-up words that belong to his own fictive world. He has admitted to such an intention:

What attracts the average person is the otherness of the language- the Spanish. They weren't being drawn to the intellectual language. I just felt there were a number of registers in there-there was Dominican Spanish, general Spanish which is like a Spanish drawn from growing up with a bunch of Latinos, so it's not specific to Dominican-ness, then there's the various Englishes. I just found it really weird that the other language everyone kept focusing on was the homogenized Spanish. . . . I always thought I have a number of readers, I knew that I would have that from the beginning. I was going to have a black readership because one of the people who was reading my work and who I was writing to was AfAm [African American], and I knew I was going to have a Latino readership, and I knew that there was going to be a readership that only read English. 
So it was good that there was going to be unintelligibility for each group. (quoted in Ch'ien 202)

Thus, what may appear as advanced territory for Spanish, is actually a writing style that an author like Díaz can afford to do. Codeswitching is only one of the many resources he is using to make the reader work as he/she reads. However, what stands out is the presence of Spanish. This is not his first work in which he codeswitches; he has successfully experimented with it before in previous works. He may just have taken it up a notch and built it into his already acquired linguistic and symbolic capital.

Below, I provide some examples of Díaz’s radical language, including codeswitching, which I have classified in the following categories:

1. Uncushioned Spanish or codeswitching: Use of hundreds of Spanish words that are not familiar to the monolingual English reader (not cognates or easy Spanish words). Some examples are: "a personaje so outlandish," "with the chanclas and the correa, and her stupid bata," "I was a fea," "without a speck of vergüenza," “una maldita borracha,” "tú eres guapa,” "gordo asqueroso,” and “what a tertulia it was.”

2. Hispanization of English words, grammar, and pronunciation: Use of English words as they would be pronounced by the Spanish or Dominican speaker or the adoption of Spanish grammar using English words: "Yunior the movie is finis," "What did you know about Nueba Yol," "My hermanita she called Beli," "Eighteen months she worked," "where in coñado do you think...,", "what in carajo else could it be?” 
3. Non-lexical borrowings: Borrowing of elements such as adverbs, verbs, adjectives: "No be a baby," "Your own fucking neighbors could acabar con you...," “at tal-and-tal," "that was my big puta moment," "the family’s resident metéselo expert,” “you ven acá,” “would you stop jodiéndome!”

4. Intrasentential and intersentential switching: Complete Spanish phrases: "Ese muchacho está bueno." "Yo soy prieta, Yuni she said, pero no soy bruta," "La única haitiana aquí eres tú, mi amor, she retorted,” “A culo que jalaba más que una junta de buey.”

5. Non-standard and Caribbean Spanish: These are terms that a native speaker of Spanish could have trouble understanding: jabao, güey, jojote, coñazo, parcha, zafa, enamorao, urikáan, dique, tetúa, rípio, popola, plepla, ojas, guanga, toto, toyo, concho, galletazo, cuco, ciguapa, parigüayo, popola, yolas, cursi-ness, chulo, comparona, klerín, guaraguao, ojas, guangas, toto, peledeísta, rayano, lambesacos, toyo.

6. Specialized terms: These are terms that would be unknown for the nonspecialized reader: gaijin, Oyá-souls, dalit, Kimota, ringwraiths, homunculi, Mithra, lingam, scromfed, do-lo, bonhomie, caracaracol, chooch, katana, baká, kaiju, maenad, perejiling, theremin, grimoire, restavek, monsterglove, hibakusha, flensed, geas, plinth, otakuness, adamantine, anthracite, badmash, orchidaceous, sclera, manga-eyes, ectomorphic, gaijin, ectomorphic, Nathan, alizé, bonewalls of the macroverse, dalit, kimota, melnibonian, ringwraiths, homunculi, cerulean, lingam, scromfed, do-lo, caracaracol, palaver, chooch, louche, katana, baká, 
funtoosh, kaiju, chabine, maenad, theremin, grimoire, restavek, monsterglove, hibakusha, RPGs, high-G planet, zygomatic arch, bailey, triffids, plinth.

7. Intellectual references to science fiction, films, comics, books, television, writers, characters, etc.: Galactus, Fantastic Four, Stan Lee, Jack Kirby, Derek Walcott, Sauron, Arawn, Darkseid, Mobuto, Omega Effect, Morgoth, Toto, Captain Trips, General Urko, Dejah Thoris, Shazam, Herculoids, Space Ghost, Chaka, Mighty Isis, Chincha, Ill Will, The Eyes of Mingus, Tom Swift, Ultraman, Lovecraft, Wells, Burroughs, Howard, Alexander, Herbert, Asimov, Bova, Heinlein, E.E. "Doc” Smith, Stapledon, Chakobsa, Slan, Dorsai, Lensman, Run Run Shaw, Danny Dunn, Dr. Who, Blake’s 7, Veritech, Zentraedi, Tolkien, Margaret Weis, Tracy Hickman, Raistlin, Wyndham and Christopher and Gamma World, DM, SS-N-17, Daniel Clowes, Beto Hernández, Morlock, Robert Durán, Frank Miller, Alan Moore, Zardoz, Virus, New Order, Clay’s Ark, Sinéad, Manhunter, Dune, PsiWorld, Gary Gygax, Robotech Macross, Alan Moore, Akira, Hellen Keller, Hija de Liborio, Siouxsie and the Banshees, Big Blue Marble, Bear Mountain, Smiths, Sisters of Mercy, The Fountainhead, Minas Tirith, Mordor, Sycorax, Jean Pierre Aumont, Ahab, Anacaona, Casanova Wave, Eyes of Atlantis, Jack Kirby, Uatu the Watcher, DarkZoner, X-Men, Brotherhood of Evil Mutants, Teen Titans, Deathstroke, Foreman and Ali, Morrison and Crouch, Kim Novak, Shiva, 4d10, Strom Thurmond, Gormenghast, Noh, Maris, Marichal, Arbenz, Morgul Lords, Guacanagarí, Rat Pack, Shelob, Source Wall, John Woo, Galadriel, Lothlorien, Mother Abigail, Gondoli, Apokolips and New Genesis, Biggie Smalls, Sindarin, Queen of the Demonweb Pits, the Beyonder, 
Unus the Untouchable, Awilda, This Island Earth, Appleseed, Project A, Master Killer in Shaolin Temple, La Jablesse, Jedi, Beelzebub, Lou Reed, SDF-1, d10s, Samuel Delany, Mellon, Goa, Van Allen belt, Salusa Secundus, Ceti Alpha Six, Tattoine, Star Blazers, Captain Harlock, Innsmouth, Nanoo-Nanoo, Harold Lauder, Sandman, Eighball, Solomon Grondy, Gorilla Glod, Gollum, Gotterdammerung, Aslan.

The above are merely examples to illustrate that the difficulty of reading Díaz's novel does not lie exclusively in the excessive Spanish switches but in the specialized language he employs mainly around the world of science fiction movies and comics (the largest category). Needless to say, Díaz's codeswitching does not respond to or obey the rules of codeswitching, but rather, he seems to be creating a language of his own and creating switches without mirroring codeswitching as it occurs in real life. Díaz may have given us the clue in an interview when he said: "When I learned English in the States, this was a violent enterprise. And by forcing Spanish back on English, forcing it to deal with the language it tried to exterminate in me, I've tried to represent a mirror-image of that violence on the page. Call it my revenge on English” (quoted in Ch’ien 209-10).

4.8 TYPOLOGY AND CLASSIFICATION OF CODESWITCHING IN THE BRIEF AND WONDROUS LIFE OF OSCAR WAO

In order to appreciate the full scope of the language alternation in The Brief Wondrous Life of Oscar Wao, the following is a breakdown of the categories of speech in which these switches occur:

1. References to people/entities: hijo/a, abuelo/a, mamá, papá, tío/tía, puto/a, moreno/a, mami, papi, El Jefe, parigüayo, güey, chilenos, argentinos, cubano/a, 
dominicano/a/s, venezolanos, haitiano/a, chinos, muchacho/a, muchachita, bruja, viejito, morenito, madre, padre, gringo/a, caballero, señorita, dentista, criada, hombres, princesa, zapatero, hermanita, mujer, mujerón, compañero, señora, fulano, taxista, capitán, cobrador, chica, madrina, ahijada, diablo, palomo, novio/a/s, doctora, exnovio, americano, presidente, quisqueyanos, cibaeño, cuco, yanquis, bebé, guitarrista, niño, moncadistas, trujillista, comunista, bailarina, amigo, cibaeño, zángana, prieta, ladroncitos, asesina, cocolos, lesbiana, maricón, anciano, sanmarcorisano, diosa, maestra, mesera, esposa, quisqueyanos, prieto/a, amigo, zapatero, india.

2. Culinary terms: yuca, chicharrón de pollo, pastelitos, sancocho, pan de agua, arroz con habichuelas, plátano, achiote, nata, dulce de coco, perejil, [h]ojas de mammon, salchicha, natas, caldo de pollo, biscocho [sic], marisco, mamajuana, bacalao, pollos, guanábana, pescado frito.

3. Ethnographic terms: ciguapa, paja de arroz, fukú, trujillato, merengue, salsa, bachatero, parigüayo, jíbara, machete, colmado, colmadero, cacique, campesino/a, guagua, azabache, bodega, batey, braceros, pana, jabao, yola, boricua, piñata, chacabana, jiringonza, boleros, chancletas, pulpería, bemba, bochinche, cuco, zafa, jojote, güey, galletazo, morena, enamorao, urikán, bochinche, cuero, pulpos, greca, chanclas, novelas, boleros, patria, morir-vivir, concho, motels, morena, zángana.

4. Locations: Nueba Yol, Nueva York, parque central, Calle El Sol, Foro Popular, Mirador Norte, La Capital, zona colonial, moteles, ingenios, colonias, barrios, 
malecones, colegio, casa, campos, El Pozo, callejón, supermercado, parque, infierno, México, sur, villa, Palacio, factoría.

5. Terms of address/endearment: mi amor, mami, papi, tío, tía, abuelo, abuela, hijo bello, la pobrecita, negrita, flaquita, mi hijo precioso, mi monita, doña, negra bella, mi negrita, guapa, mi’ja, gordita, querido.

6. Religious terms: Jesú Cristo, Dios mío, todopoderoso, que Dios te bendiga, bendición, Dios santísimo, Semana Santa.

7. Swear words/insults: puta, coño, pendeja, hija de tu maldita madre, muchacha del diablo, hijos de puta, maldito, benditos, bellaco, maricón, carajo, carajito, chivato, cara de culo, vieja, no me jodas, hija de la gran puta, bruto, desgraciado, hijo de la porra, jodido, ande el Diablo, maldita ciguapa, pendeja, gordo asqueroso, coñazo, puerca, figurín de mierda, culo, zángana, maldito, infelices, culo, figurín de mierda.

8. Interjections, expressions, tags, and exclamations: oye, déjame, no me toques, caramba, tú verás, qué muchacha tan fea, lo siento, ven acá, adiós, váyanse, no más, pa’fuera, pórtate como un muchacho normal, qué hombre, ese muchacho está bueno, fuá, dique, jamás, amor de pendejo, la clase alta, cabeza dura, ladronazo, mujerón, cuerpazo, pechonalidad, tal-and-tal, pendejada, ay sí, imagínate, no me toques, ande el diablo!, qué hombre.

9. Miscellaneous lexical items: perrito, hombre, paliza, guapa, pelo, fea, buenmoso [sic], vergüenza, amor, loco/a, nada, correa, bata, blanquito, tesoro, exigente, página en blanco, pequeña, grande, tranquilidad, flacas, escuela, versos, canciones, número uno, número dos, socorro, tetas, democracia, tertulia, helados, 
esponja, ciclón, bravo, cristiano, cultos, hambre, fuego, cobrador, cristiano, taxista, rabo, sucesos, mujer, sindicatos, besos, ojos, blancos, aparato, feria, rolos, sinvergüencería, casa, belleza, oro, gordo, ladrones, presidente, burro, infierno, patio, motos, gente, elegante, paquetes, cadenas, sacrificio, milagro, promesa, caballo, femenino, fulano, callejón, vecinos, brutos, tarea, pulpo, cómodo, cigarro, imbecil [sic], brillante, delincuencia, malcriada, muda, sucio/a, matador, ciegos, escopeta, rabia, puntos, guitarrista, coraje, fea, cochinos, clavo, alguien, capaz, páginas, animal, lobo, rueda, candela, cuerpo, burbuja, abrazo, Reconquista, jueguito, culto, buey.

The purpose of the above classification is also to observe the categories to which each switch belongs in order to determine the level of difficulty they may pose to the monolingual reader. As in previous chapters, I have distinguished between switches that correspond to core borrowings versus cultural borrowings, understanding that cultural borrowings (i.e., words for which there might not be an exact equivalent in English) are better tolerated by the reader than core borrowings (i.e., words for which there is an English equivalent). Of the classifications above, only culinary and ethnographic terms would fully correspond to cultural borrowings. Thus, I can conclude that most of the switches in the novel correspond to core borrowings, for which equivalent English expressions are available, and therefore their use is not "justified" for communication purposes, but requires a different interpretation.

\subsection{PARTIAL FINDINGS}

I have sought to show how markedly different Díaz’s codeswitching is from the previous authors studied in this dissertation, based on the particular conditions that have 
shaped the Dominican immigration experience and that have come to define their diasporic identity. I have labeled Díaz's codeswitching radical or bold and have pointed out the difficulties it would pose for the Anglo monolingual reader. Still, Díaz managed not only to get this and other works published, but also to win a Pulitzer-among many other awards. In today's world in which publishers have the last word on who and what gets published, it is remarkable how Díaz managed to do so. As suggested by Burrows in her dissertation Beyond the Comfort Zone: Monolingual Ideologies, Bilingual U.S. Latino Texts:

The industry tends to choose texts that have a niche market and that meet reader expectations. Since sales constitute the highest priority, mainstream presses are likely to choose minority-authored books that are less concerned with reflecting truths about how people really live, think, and feel and more with what monolingual English-speaking people want to read and believe about minorities. (9)

Hence, she goes on, “only the most accessible and well-glossed” (9) types of texts make their way into mainstream presses. Therefore, it seems reasonable to assume that at the time of this writing there appears to be more tolerance to codeswiching or to the presence of Spanish in U.S. literature. We may be witnessing a change of attitudes, at least among intellectual circles and consumers of literature, toward a more inclusive literary canon that is now beginning to open its doors to ethnic writers. However, I do not claim that Díaz is advancing the presence of Spanish: he is actually taking advantage of the ubiquity of Spanish to forward his own political (i.e. Afro-Dominican) agenda. The expanded use of Spanish in literature and other media is a secondary result. 
However, this does not mean that we will see radical codeswitching happening every day or that it has become a new trend. For instance, the Pulitzer has not been awarded to a minority author since Díaz in 2008. Also, at the time of this writing, the New York Times Summer Reading List for 2015, which has become the ultimate guide on what Americans read, does not include a single minority author. ${ }^{68}$ Thus, my claim is that rather than—or in addition to-a higher tolerance for the presense of Spanish, what allowed Díaz to enter mainstream consciousness with his novel was the symbolic and linguistic capital he had earned for himself. Díaz is indeed an immigrant, but he is also a successful university professor at M.I.T. (he attended Rutgers and Cornell). He managed to overcome the adversities of his childhood and made it to the top in academia. This is what has allowed him to earn his linguistic capital (in terms of Bourdieu). Only with such linguistic capital could he have managed to do what Ch’ien claims:

Junot Díaz invests language with the power to influence political and social vision. He forcefully incorporates Spanish into his mainly English texts, showing concretely the linguistic violence that Spanish inflicts on English and vice versa. Instead of contorting English to fit Spanish, he demonstrates the inadequacy of English by substitution rather than metonymy or metaphor. He makes Spanglish an American language. (22)

My claim regarding Díaz’s use of codeswitching is anchored in the theories of linguist Monica Heller, in the sense that "language practices are inherently political insofar as they are among the ways individuals have at their disposal of gaining access to

\footnotetext{
${ }^{68}$ All authors featured in the New York Times Summer Reading List for 2015 are Caucasian. http://www.nytimes.com/2015/05/22/books/cool-beach-books-for-hot-summer-days.html?ref=books
} 
the production, distribution and consumption of symbolic and material resources, that is, insofar as language forms part of processes of power” (Codeswitching and Politics 161). Díaz has the power to allocate value to codeswitching insofar as he can maintain his position as a representative of his community.

Of course, linguistic capital by itself would not have been enough; his novel also has the literary merits for such a recognition. On the issue of linguistic capital, Pierre Bourdieu, who coined the term, postulates: "Linguistic capital is power over the mechanisms of linguistic price formation, the power to make the laws of price formation operate to one's advantage and to extract the specific surplus value” (Sociology 80). He goes on to add that "a competence has value only so long as it has a market;" competence here refers to Díaz's codeswitching and market is the readership willing to read his book. The following comment by Díaz regarding his choice of code corroborates that he does possess linguistic capital and is aware of it: “After this many years you just don’t give a fuck. It's like I don't care. And I'm writing a book that in its structure reflects the I-don'tcareness” (Interview Díaz). How many writers can afford to say that?

Despite his own personal success story, his novel poignantly presents the struggles of the immigrant and the story of a country under a tyrant, which, when combined, turned into a winning formula. Many English monolingual readers (as the sales figures show) have taken up the challenge to read Díaz’s novel as an intellectual exercise.

Those readers who do take up the challenge of reading this novel will be enriched by the experience of entering the world of Oscar Wao, which can only be told by another Dominican. Thus, Díaz not only has the authority (social capital) to narrate the story 
about the Dominican Republic and life in the Diaspora, but also to convince readers to accept such a tall order. He has said: "I wanted everybody at one moment to feel kind of like an immigrant in this book. There would be one language chain that you might not get. And that it was okay. It might provoke in you a reaction to want to know-and that's good, because it'll make you go look, and read other books and start conversations... (Interview). Thus, incomprehensibility is the name of the game. Díaz seems to be asking readers to look for meaning beyond the actual words-whether it is the codeswitching, the intellectual or "nerd" language, or the specialized terms that the reader cannot access.

His codeswitching, rather than being off-putting, is actually an attractive feature, an additional intellectual exercise for the reader. Díaz becomes a linguistic entrepreneur by promoting language change. He codeswitches because he can. Codeswitching is a luxury not available to every writer.

Whether he does it intentionally or not, by challenging the monolingual, he also caters to the bilingual and displaces the language of the majority, thus building linguistic capital for future writers. It remains to be seen whether he can continue to draw on his linguistic resources and what the future holds for other Latino writers yet to come. 


\section{CONCLUSIONS}

This study set out to establish the role of codeswitching in Latino literature, in order to determine whether what is observed at the surface level, that is, on the page, has more profound implications beyond that of a decorative role, and whether the particular conditions of each author and his or her community have any bearing on how this linguistic strategy is used. To accomplish this goal, four novels by different Latino authors written between 1972 and 2007 were selected with the aim of providing a broadly diverse, as well as a diachronic view of how Latino authors employ codeswitching strategically. For each novel, quantitative and linguistic findings were analyzed in each chapter in light of sociolinguistic, cultural, and social theories in order to obtain a more overarching understanding of the role of codeswitching. These data are in addition to the research conducted on the literary, linguistic, and historic conditions of the community to which each author belongs. It was expected that these findings, when combined, would give us an insight into whether there was a progressive use of codeswitching, that could be interpreted as an advancement of a Latino agenda. Establishing whether this is the case is important to help us understand whether literature has a role in expanding the cultural space into which ethnic minorities are allowed to operate. This study is at the intersection of the fields of sociolinguistics, literature, and cultural studies. Its findings are expected to shed light on the use of language for socio-political purposes.

Until 1960, there were only a handful of publications that were labeled as Latino literature. At this writing, fifty-five years later, there might be a few more Latino titles at the bookstore, but they are generally found in the ethnic literature corner. Occasionally, a Latino author makes it into mainstream literature. Despite this underrepresentation in the 
bookstore shelves relative to the Latino population in the United States, Latinos are writing much more than they were 50 years ago and continue to fight for inclusion in the American literary canon.

When Latinos do write, they often employ a hybrid language known as codeswitching, mixing English and Spanish. There is a myriad definitions for codeswitching, ranging from morphosyntactic descriptions, with a structural focus, to more sociolinguistic explanations that take cultural and social approaches. One of the latter defines codeswitching as "a strategy used to establish, cross or destroy group boundaries; to create, evoke or change interpersonal relations” (Gal Code Choice 245). Even though there are no official definitions for written codeswitching, I argue that written and oral codeswitching may be equally motivated but each with a different application. This research found that codeswitching, when used in literature, may perform two distinct roles: one at the immediate level of the text—usually a decorative and ethnic role with some literary justification—and another much wider role intended to challenge literary conventions. The analysis of the works revealed that some authors may employ just one role, while others employ both. There are several factors that influence this choice, including the author's linguistic capital and degree of assimilation to the host culture, the period in which she or he writes, and the evolving conditions surrounding the Latino community to which the author belongs.

Codeswitching cannot be solely understood as the alternation between two languages, but as the alternation between a hegemonic language supported by the state and a minority language, with the corresponding implications of this asymmetrical relation of power. Pierre Bourdieu writes that "Linguists are right in saying that all 
languages are linguistically equal; they are wrong in thinking they are socially equal” (The Economics 652). The negative value of using oral codeswitching is well documented. Needless to say, written codeswitching is doubly frowned upon (due to the permanence of the written word) by purists of both languages. Still, many Latino authors have paid no heed to such views and continue to write against the grain. Thus, in Latino literature, codeswitching may serve-in addition to its literary and decorative role—-to inscribe difference and to make a political act of reclamation, thus making English "the other" language. This is possible provided that the author has earned enough symbolic capital to afford this challenge to the literary and linguistic establishment. As posited by Monica Heller: "Conventional language practices represent relatively stable relations of power, while violations can be seen as forms of resistance” (The Politics 12). But, as this study has found, not all codeswitching is equally combative and aggressive.

Not all codeswitching is created equal. Borrowing the concepts proposed by theorists Reed Way Dasenbrock and Lourdes Torres, I have identified a continuum in the level of codeswitching that ranges from "accommodating" the switches in order to make them accessible, to using a "radical" codeswitching, which shuts out the English monolingual reader. Making them accessible to the English monolingual reader means employing strategies that may give the impression that there is a high presence of Spanish whereas, in reality, it has been "cushioned" by providing direct translation or explanation, contextual or indirect glossing, simple Spanish, empty words, cognates, sets of repeated words, and other redundancies or reiterations of meaning. For each novel, I have also dissected all Spanish switches by category in order to distinguish between ethnic switches and core switches (following Myers-Scotton's terminology). I have defined ethnic 
switches as more tolerable by the English monolingual reader, as these perform a role that may be justified by the context, such as those describing cultural elements, terms of endearment, food, songs, sayings, prayers, interjections, etc., which for the most part do not obstruct meaning and are understood as inherent to the setting of the novel. Conversely, core switches represent a more defiant attitude on behalf of the author, as these are switches that do have an equivalent term in English and may thus seem unjustified to the English monolingual reader. These may be everyday words not particularly related to a cultural context. Based on this analysis I have defined whether a particular author's codeswitching is either accommodating or radical.

Additionally, given that writing is a more premeditated activity than speaking, an important tenet of this study is that codeswitching is a deliberate choice made by the authors, that is, they choose to make codeswitching salient in their writing. This is in line with Carol Myers-Scotton’s claim that “language users are rational actors ... supporting the premise that speakers make choices from an opportunity set (i.e. their linguistic repertories) to achieve certain goals important to them as individuals (Codes and Consequences 7). Such goals may be individual and/or general (i.e., for authors themselves or for their community), but there are also risks involved in the choice to codeswitch. This resource, however, is only available to those who have earned enough linguistic and symbolic capital to avail themselves of it. Bourdieu claims that "Linguistic forms have no power in themselves; they only reflect the power of the groups they index" (quoted in Gal, Language 353). This is because ethnic groups have specific structural positions of power or subordination in their local communities (or marketplace, in Bourdieu's terms). For some authors, codeswitching is an act of resistance to the 
domination of the hegemonic language. For others, it is the flavor of the day. Heller posits that: "Dominant groups rely on norms on language choice to maintain symbolic domination while subordinate groups may use codeswitching to resist or redefine the value of symbolic resources in the linguistic marketplace” (quoted in Nilep 13).

This study adheres to the following principles: (1) that language may perform a role beyond communication; (2) that there is a continuum from word borrowing to fullfledged codeswitching; (3) that codeswitching cannot be analyzed without first understanding and taking into account the social, cultural, literary, historical, and political contexts, and thus it is not a static practice; and (4) that codeswitching is a deliberate strategy exploited in varying degrees and with different goals. The first two principles have been amply studied and accepted in the realm of sociolinguistics. I have addressed the other two for each novel in the previous chapters. I have also clearly outlined the implications of using codeswitching in literature by positing the symbolic and political value of this writing strategy. I believe that the amount and degree of codeswitching bear meaning, which can give us clues as to the political positioning of each author. The authors chosen represent four of the largest Latino minorities in the United States, and while they cannot speak for everyone, the research conducted on each particular community supports my findings.

I began this study by looking at the literary works produced by Chicanos, which were the first Latino community to fight for inclusion in the literary world and also the first to introduce codeswitching in literature. The Chicano Movement was born in the 1960s as an offspring of the Civil Rights Movement. This gave way to Chicano literature, which was used, along with other cultural productions, as a combative element for the 
advancement of a Chicano agenda. In Chapter One, I provided an overview of Chicano literature by closely analyzing one of its most prominent works, Rudolfo Anaya's Bless Me Ultima (1972), in which Anaya occasionally and assertively uses codeswitching for what became a nationwide audience. His prose still catered to the English monolingual, despite the large number of language switches, for only seldom did they obscure meaning. Some of the strategies used by the author to give his novel the appearance of heavy codeswitching - in addition to both direct and indirect contextual glossinginclude repeated sets of words and easily identifiable Spanish expressions. I concluded that Anaya's use of codeswitching was enough to add Spanish—or rather Chicanoflavor to the narrative, by employing Spanish switches whenever possible but within certain categories that still made the text accessible to the English monolingual reader. However, it is important to be reminded that this was 1972, when the Latino population did not reach ten million (compared to fifty-five million at the time of this writing) and at a time when codeswitching had very seldom been employed in literary texts.

My findings indicate that the literature produced during the Chicano Movement was one of resistance—both in subject matter and language—-disguised under the label of ethnic literature. Bless Me Ultima falls on the "accommodating” end of the spectrum, but considering its timing, it represented a strong political stance. However, Chicano literature lost momentum and although it continues to be written, it no longer exhibits the same rebellious nature. Anaya, for instance, has continued to write, but his more recent works reveal a more assimilated view. Aztlán is no longer the only space to write about. That is not to say that the feelings of alienation and otherness have disappeared, but rather that the commercial forces of publishing houses seem to have prevailed. The 
importance of the Chicano movement is paramount to Latino letters as it has been the most political and influential movement from among all the Latino communities in the United States.

The Chicano movement was followed by the Nuyorican movement, which produced similar cultural and literary results. For this reason, I chose to study a literary work written by a Nuyorican but at a later time-Esmeralda Santiago's When I was Puerto Rican (1994) — in order to appreciate what changes had taken place in Latino literature twenty years later.

Esmeralda Santiago did not find the same favorable conditions as the authors writing at the height of the Chicano or Nuyorican movements in the 1960s and 70s. At the time of her writing, the momentum for both movements had abated, and challenging the status quo probably meant not getting published. Hence, Santiago's approach to codeswitching is more conservative, not in quantitative but in qualitative terms. In fact, of the works studied in this research hers employs the highest number of switches, but these are of rather innocuous nature, falling on the "accommodating" end of the spectrum. She uses codeswitching to season her memoir with Puerto Rican colors and flavors, and always resorting to compensating strategies so as not to obstruct meaning for the English monolingual reader. Besides, her memoir is a story of assimilation and success. Challenging the English language would not seem to match the theme of her novel. She does indeed address the issues that are common to all Latino literature, such as a divided identity, feelings of otherness, the struggles of learning English, among others, but in the end her story is successful, and her tone is conciliatory. I argue that codeswitching needs 
to match the theme as well as the political positioning of the author. The more assimilated the author is, the less aggressively codeswitching is employed.

Additionally, when applying Bourdieu’s marketplace analogy, we find that at the time of her writing, Santiago did not possess linguistic or symbolic capital that she could exploit, given that the momentum of the Nuyorican movement had subsided. There are fewer instances of bold codeswitching or core borrowings than in Anaya's novel despite the larger number of switches overall. I argue that Santiago had to submit to the rules of the marketplace that were in effect at the time, and therefore had to write using the standard and expected code: in a language that could be understood by all, while employing codeswitching only as a stock literary device (i.e., as a decorative or ethnic element and for the purpose of characterization). To go against this would have meant commercial suicide, as it could be said that the license to codeswitch had already expired for Nuyoricans.

Later works by Santiago, such as The Turkish Lover (2004) and Conquistadora (2011) distance her even more from the immigrant experience, and she no longer addresses topics that would require or justify codeswitching. This is further evidence that codeswitching is not only thematically bound but also responds to the current social circumstances affecting the authors and their respective communities.

The study of Cuban-American literature confirms my findings that codeswitching does not perform the same role in every Latino work of fiction. In Cristina García’s Dreaming in Cuban (1992), codeswitching is solely used as a literary and decorative element. As opposed to other Latino literature, Cuban-American literature is less concerned with fighting for inclusion or feelings of discrimination or alienation-to 
mention just two of the more frequent topics found in other Latino literature. Rather, Cuban-American literary topics often revolve around the condition of exile, historical memory, and nostalgia for the lost country. This leads me to conclude that codeswitching is not part of the arsenal of Cuban-American writers, beyond an instrumental use. Cuban Americans, because of their more favorable conditions for immigrating to the United States, find that their predicament is what they—or their parents—left behind in Cuba. That is not to say that Cuban Americans are indifferent or unmoved by the plight of other communities or that they do not experience the same feelings themselves, but these may be secondary. Hence, codeswitching tends to perform a more literary and accessory role, one connected to the narrated events that contribute to the verisimilitude of the story. It is seldom used as a sign of rebellion. Their plight is a different one, and it is manifested in how they use codeswitching, or in the absence thereof.

Since their condition of exile seems to be the primary source of their literature rather than feelings of otherness, there is usually less rebellion or combativeness in their language. Their potential ally in setting their country free from the tyranny of dictatorship is the country that has welcomed them with open arms. This relationship with the host country is very different from that of other ethnic communities, who may feel ignored or even unwanted by hegemonic society. Once again, we witness how the conditions of the community to which the author belongs have implications for how codeswitching is employed.

A very different situation was found in Junot Díaz's The Brief Wondrous Life of Oscar Wao (2007). In Chapter Four, I established how the experience of Dominican immigrants differs from that of other immigrants due to their particular racial condition. 
On the one hand, Dominicans in the United States experience a double discrimination for being immigrants and for their skin color. At the same time, those who have witnessed the racial affirmation of African Americans in the United States may have come to terms - or are in the process of coming to terms - with their skin color, which would allow Dominican Americans to share in the social gains of Blacks since the Civil Rights Movement.

As such, Junot Díaz seems to have overcome any feelings of self-discrimination and to have adopted a Black identity—judging from the topics he addresses in his works and his self-proclaimed Blackness. Thus, he is able to reap the benefits of self-affirmation and act as an advocate for other Black Dominicans. Vested with that "power," he set out to write a novel largely inaccessible to the English monolingual reader —challenging the English-only status quo_-but still managing to sell well. Only a writer with symbolic capital could achieve this feat. His symbolic capital derives from his Blackness (which he has used to his advantage), the closely-knit Dominican-American community to which he belongs, and his academic achievements, which have earned him respect and admiration in his community and beyond.

I have summarized how codeswitching is used by each author and have explained how each use differs based on the authors' individual circumstances, the time of writing, the community they represent, and the relationship of each author's home country with the United States, all of which, I claim, have a bearing on the mode, extent, and degree of codeswitching adopted by each author, thus challenging the notion of a monolithic Latino ethnicity. 
Based on these findings, I can summarize the use of codeswitching in Latino literature as follows. (1) It depends on the relationship of each community with the host country and the immigrant's experience. (2) The author's symbolic and linguistic capital determines the quantity and the quality of codeswitching. (3) Codeswitching will vary depending on the time the writing takes place and the political conditions that surround the community to which the author belongs. (4) Written codeswitching does not mirror oral codeswitching. (5) Written codeswitching is not a static practice. (6) Written codeswitching may be solely literary (a decorative or ethnic role) or literary and political. (7) Written codeswitching does not represent any gains in status for the Latino community. A greater presence or tolerance of Spanish in literature does not mean its prestige is on the rise.

Whether codeswitching is viewed by Anglos as a decorative element or as an obstruction to reading will depend on how accessible it has been made on the page, based on the cushioning techniques employed. Very little of the codeswitching studied in the four novels responds to actual codeswitching as it actually takes place in oral exchanges, which is evidence of its intentionality and artificiality. Thus, we must look for its symbolic value rather than for its role in communicating or mirroring real life speech.

U.S. mainstream literature has opened up to include some Latino authors who occasionally make it to the Best-Sellers lists and enter the reading lists of different literary outlets; however, for the most part, Latino works remain on the shelves of Ethnic Writing. It may seem as if there has been a progressive escalation in the use of codeswitching in Latino literature, for example if we compare the first author studied from 1972, to the latest one from 2007, but this does not tell us anything about future 
trends. It is possible that by seeing the positive reception that authors like Junot Díaz have had, future Latino authors may be encouraged to engage more in codeswitching. However, it would still be tied to the symbolic capital they may possess at the time, and to the social struggles of their community.

Literature, like other art forms, is often used as a combative element and a form of denunciation and resistance, as well as a claim for the inclusion of minorities. Latino literature is no exception. It has performed such a role successfully at certain times in history, such as around the time of the Civil Rights Movement, with both the Chicano and Nuyorican communities. However, such gains were not extended to every Latino community. Nevertheless, through the use of codeswitching, Latino literature has occasionally managed to enter the mainstream. Radical codeswitching has become recognized as a mark of “engaged” Latino literature.

As a community, Latinos may at times benefit from this brand of literature, whenever all the necessary conditions align and produce a winning formula for a novel that happens to cross over into the closely held U.S. literary canon. Such sporadic instances may serve to raise awareness and contribute to the empowerment of the Latino community, even if no significant gains may be accounted for at this time. 


\section{BIBLIOGRAPHY}

Acosta-Belén, Edna. "Beyond Island Boundaries: Ethnicity, Gender and Cultural Revitalization in Nuyorican Literature.” Callaloo, Vol. 15, No. 4 (Autumn, 1992): 979-998.

Acuña, Rodolfo. Occupied America: A History of Chicanos. New York: Harper \& Row, 1988.

Alicea, Marisa. “The Latino Immigration Experience: The Case of Mexicanos, Puertorriqueños, and Cubanos." In Handbook of Hispanic Cultures in the United States: Sociology. Eds. Nicolás Kanellos and Claudia Esteva-Fabregat. Houston, Texas: Arte Público Press, 1994. 35-56.

Algarín, Miguel, and Piñero, Miguel. Eds. Nuyorican Poetry: An Anthology of Puerto Rican Words and Feelings. New York: William Morrow, 1975.

Álvarez-Borland, Isabel. Cuban-American Literature of Exile: From Person to Persona. Charlottesville, Virginia: University Press of Virginia, 1998.

--- and Bosch, Lynette. Cuban-American Literature and Art: Negotiating Identities. Albany: State University of New York Press, 2009.

Anaya, Rudolfo A. Bless Me, Ultima. New York: Warner Books, 1994.

Anzaldúa, Gloria. Borderlands/La Frontera: The New Mestiza. San Francisco: Spinters/Aunt Lute Books, 1987.

Aparicio, Ana. Dominican-Americans and the Politics of Empowerment. Gainesville: University Press of Florida, 2006.

Aparicio, Frances R. "From Ethnicity to Multiculturalism: The Historical Development of Puerto Rican Literature in the United States.” In Handbook of Hispanic Cultures in the United States: Literature and Art. Ed. Francisco Lomelí. Houston: Arte Público Press, 1993. 19-39.

Arteaga, Alfred. An Other Tongue: Nation and Ethnicity in the Linguistic Borderlands. Durham: Duke University Press, 1994.

Ashcroft, Bill. “Chicano Transnation.” In Imagined Transnationalism: U.S. Latino/a Literature, Culture, and Identity. Eds. Concannon, Kevin, Francisco A. Lomelí, and Marc Priewe. New York: Palgrave Macmillan, 2009.

Bailey, Benjamin. "Language Alternation as a Resources For Identity Negotiations Among Dominican American Bilinguals.” In Style and Social Identities: Alternative Approaches to Linguistic Heterogeneity. Ed. Auer, Peter. Berlin, Germany: Mouton de Gruyter, 2007. 29-55. 
---. "Language and negotiation of ethnic/racial identity among Dominican Americans." Language in Society, 29.4 (2000): 555-82.

Bebout, Lee. Mythohistorical Interventions: The Chicano Movement and Its Legacies. Minneapolis: University of Minnesota Press, 2011.

Bourdieu, Pierre. "The Economics of Linguistic Exchanges.” Social Science Information, 16 (6) (1977): 645-668.

--- and John B. Thompson. Language and Symbolic Power. Cambridge: Polity, 1991.

----. Sociology in Question. London: Sage Publications, 1993.

Bruce-Novoa, Juan. Retrospace: Collected Essays on Chicano Literature, Theory, and History. Houston: Arte Público Press, 1990.

---. “Dialogical Strategies, Monological Goals: Chicano Literature.” In An Other Tongue: Nation and Ethnicity in the Linguistic Borderlands. Ed. Alfred Arteaga. Durham: Duke University Press, 1994. 225-246.

Burrows, Sonja S. "Beyond the Comfort Zone: Monolingual Ideologies, Bilingual U.S. Latino Texts.” Diss. U. of Oregon, 2010.

Callahan, Laura. Spanish/English Codeswitching in a Written Corpus. Amsterdam: John Benjamins Pub, 2004.

Camayd-Freixas, Erik. US Immigration Reform and Its Global Impact: Lessons from the Postville Raid. New York: Palgrave MacMillan, 2013.

Caminero-Santangelo, Marta. On Latinidad: U.S. Latino Literature and the Construction of Ethnicity. Gainesville: University Press of Florida, 2007.

Casielles-Suárez, Eugenia. "Radical Code-Switching in the Brief Wondrous Life of Oscar Wao.” Bulletin of Hispanic Studies 90.4 (2013): 475-487.

Ch’ien, Evelyn Nien-Ming. Weird English. Cambridge, MA: Harvard University Press, 2004.

Cocco-DeFilippis, Daisy. Desde La Diáspora: Selección Bilingüe de Ensayos = A Diaspora Position: A Bilingual Selection of Essays. New York: Ediciones Alcance, 2003.

Coonrod Martínez, Elizabeth. "Between the Tenements and the Island: DominicanAmerican Literature.” In Companion to U.S. Latino Literature. Eds. Carlota Caulfield and Darien Davis. Suffolk. UK: Boydell \& Brewer, 2007. 101-119. 
Cortina, Rodolfo. "History and Development of Cuban American Literature: A Survey." In Handbook of Hispanic Cultures in the United States: Literature and Art. Ed. Francisco Lomelí. Houston, Texas: Arte Público Press, 1993. 40-61.

Coulmas, Florian. The Handbook of Sociolinguistics. Oxford, UK: Blackwell Publishers, 1998.

Díaz, Junot. “Interview with Junot Díaz.” Other Voices 36. Web del sol, 2002. Web. 26 June 2015.

---. The Brief Wondrous Life of Oscar Wao. New York: Riverhead Books. 2007.

Duany, Jorge. Un Pueblo Disperso: Dimensiones Sociales y Culturales de la Diáspora Cubana. Valencia, España: Advana Vieja. 2014.

Duke, Dos Santos M. I. and De La Fuente P. Sabine R. Ulibarrí: Critical Essays. Albuquerque, N.M: University of New Mexico Press, 1995.

Epple, Juan Armando. “'Hispanic Exile in the United States.” In Hispanic Cultures in the United States: Literature and Art. Ed. Francisco Lomelí. Houston, Texas: Arte Público Press, 1993. 333-59.

Falcon, L. M. and Gilbarg, D. "Mexicans, Puerto Ricans, and Cubans in the Labor Market: An Historical Overview." In Handbook of Hispanic Cultures in the United States: Sociology. Eds. Kanellos and F.M. Padilla. Houston, Texas: Arte Público Press. 1994. 57-79.

Fanon, Frantz. The Wretched of the Earth. New York: Grove Press, 1963.

Flores, Juan. Divided Borders: Essays on Puerto Rican Identity. Houston, Texas: Arte Público Press, 1993.

---. From Bomba to Hip-Hop: Puerto Rican Culture and Latino Identity. New York: Columbia University Press, 2000.

---. "Puerto Rican Literature in the United States: Stages and Perspectives.” In Recovering the U.S. Hispanic Literary Heritage. Volume 1. Ed. Ramón Gutiérrez and Genaro Padilla. Houston: Arte Público Press, 1993.

Franco, Jean. Introduction. Divided Borders: Essays on Puerto Rican Identity. Ed. Juan Flores. Houston, Texas: Arte Público Press, 1993.

Gal, Susan. “The Political Economy of Code Choice.” In Codeswitching: Anthropological and Sociolinguistic Perspectives. Ed. Monica Heller. Berlin: Mouton de Gruyter, 1988. 245-264. 
---. Language and Political Economy. Annual Review of Anthropology, 18 (1989): 345367.

García, Cristina. Dreaming in Cuban. New York: Knopf, 1992.

García, Cristina. “A Conversation with Cristina García.” Interview by Scott Shibuya Brown. Monkey Hunting. New York: Random, 1992.

García, María C. Havana USA: Cuban Exiles and Cuban Americans in South Florida, 1959-1994. Berkeley: University of California Press, 1996.

Garrett, R S. Puerto Rico's Political Status and the 2012 Plebiscite: Background and Key Questions. Washington, DC: Congressional Research Service, Library of Congress, 2012.

Gonzales, Rodolfo. “I am Joaquín.” In Herencia: The Anthology of Hispanic Literature of the United States. Ed. Kanellos, Nicolás, M. K. Dworkin, and Alejandra Balestra. Oxford: Oxford University Press, 2002. 195.

González, Juan. Harvest of Empire: A History of Latinos in America. New York: Viking, 2000.

Gracia, Jorge J. E., Lynette M. F. Bosch, and Isabel Álvarez-Borland. Identity, Memory, and Diaspora: Voices of Cuban-American Artists, Writers, and Philosophers. Albany: State University of New York Press, 2008.

Gross, Steven. "Intentionality and the markedness model in literary codeswitching." Journal of Pragmatics, Volume 32, Issue 9 (August 2000): 1283-1303.

Gumperz, John J. Discourse Strategies. Cambridgeshire: Cambridge University Press, 1982.

Gutiérrez, Franklin. "Literatura dominicana de la diaspora: otro costado de las letras dominicanas”. Caribe: Revista de Cultura y Literatura 13.1 (2010): 63-82.

Hall, Stuart. "Cultural Identity and Diaspora.” In Colonial Discourse and Post-colonial Theory: A Reader. Ed. Patrick Williams and Laura Chrisman. London: Havester Wheatsheaf, 1994. 392-401.

Haslhofer, Iris. Resistance and Social Criticism in Chicano Literature: As Represented in J. Villarreal, O.Z Acosta, R. Anaya, A. Islas. Saarbrücken: VDM, 2009.

Heller, Monica. "The politics of codeswitching and language choice”. Journal of Multilingual and Multicultural Development, v13 n1-2 (1992): 123-42.

---. “Code-Switching and the Politics of Language.” In One Speaker, Two languages. Ed. L. Milroy and P. Muysken. Cambridge: Cambridge University Press, 1995. 158-174. 
Hospital, Carolina. The Child of Exile: A Poetry Memoir. Houston, Tex: Arte Público Press, 2004.

Itzigsohn, José and Carlos Dore-Cabral. "Competing Identities? Race, Ethnicity and Panethnicity Among Dominicans in the United States." Sociological Forum. 15.2 (2000): 225-247.

Jonsson, Carla. "Code-switching in Chicano Theater: Power, Identity and Style in Three Plays by Cherríe Moraga.” Diss. Umeå universitet, 2005.

Kanellos, Nicolás, M. K. Dworkin, and Alejandra Balestra. Herencia: The Anthology of Hispanic Literature of the United States. Oxford: Oxford University Press, 2002.

Keller, Gary D. "The Literary Stratagems Available to the Bilingual Chicano Writer.” In The Identification and Analysis of Chicano Literature. Eds. García, Lomelí, Ortiz. New York: Bilingual, 1979. 263-316.

---. "Using Bilingual Techniques for Literary Effect.” Chicano Studies: A MultiDisciplinary Approach. New York: Teachers College Press, 1984. 171-190.

Kevane, Bridget and Juanita Heredia. Eds. Latina Self-Portraits: Interviews with Contemporary Women Writers. Alburqueque: University of New Mexico Press, 2000.

Laviera, Tato. La Carreta Made a U-Turn. Houston: Arte Público Press, 1992.

Leal, Luis. "Chicano Literary History: Origin and Development," JSRI Occasional Paper \#8, East Lansing, Michigan: The Julian Samora Research Institute, Michigan State University, 1996.

Lipski, John M. "Linguistic Aspects of Spanish-English Language Switching.” Special Studies 25. Tempe: Arizona State University, Center for Latin American Studies, 1985.

---. "Spanish-English Language Switching in Speech and Literature: Theories and Models”: The Bilingual Review/La revista bilingüe 9.3 (1982): 191-212.

Lomelí, Francisco A. "Contemporary Chicano Literature, 1959-1990: From Oblivion to Affirmation to the Forefront." In Handbook of Hispanic Cultures in the United States: Literature and Art. Eds. Lomelí, Francisco A., Nicolás Kanellos, and Fabregat C. Esteva. Houston, TX: Arte Público Press, 1993. 86-108.

López, Dennis. “Good-Bye Revolution—Hello Cultural Mystique: Quinto Sol Publications and Chicano Literature Nationalism.” MELUS: Multi-Ethnic Literature of the U.S. Vol. 35, No. 3, (Fall 2010): 183-210. 
López, Iraida H. ““...And There Is Only My Imagination Where Our History Should Be’: An Interview with Cristina García.” Bridges to Cuba/Puentes a Cuba. Ann Arbor, MI: U. of Michigan P., 1995. 102-114.

Luis, William. Dance between Two Cultures: Latino Caribbean Literature Written in the United States. Nashville: Vanderbilt University Press, 1997.

McClennen, Sophia A. The Dialectics of Exile: Nation, Time, Language, and Space in Hispanic Literatures. West Lafayette, Indiana: Purdue University Press, 2004.

Melville, Margarita B. "Hispanic Ethnicity, Race and Class.” In Handbook of Hispanic Cultures in the United States: Anthropology. Eds. Weaver Thomas, Nicolás Kanellos, and Fabregat C. Esteva. Houston, Texas: Arte Público Press, 1994. 85106.

Mendieta-Lombrado Eva and Cintron Zaida A. "Marked and Unmarked Choices of Code Switching in Bilingual Poetry” Hispania, Vol. 78, No. 3 (Sep., 1995): 565-72.

Mendoza-Denton, Norma. "Sociolinguistics and Linguistic Anthropology of U.S. Latinos” Annual Review of Anthropology. Volume 28 (1999): 375-95.

Montes-Alcalá, Cecilia. Two Languages, One Pen: Socio-pragmatic Functions in Written Spanish-English Code-Switching. Ann Arbor, Mich: UMI Dissertation Services, 2001.

Myers-Scotton, Carol. Contact Linguistics. Bilingual Encounters and Grammatical Outcomes. Oxford: Oxford University Press, 2002.

---. Social Motivations for Codeswitching: Evidence from Africa. Oxford: Clarendon Press, 1993.

---. "Self-enhancing Codeswitching as Interactional Power.” Language \& Communication, 8.3 (1988): 199-211.

Nilep, Chad. “'Code-switching’ in Socio-cultural Linguistics.” Colorado Research in Linguistics. Volume 19. 2006.

Oboler, Suzanne. Ethnic Labels, Latino Lives: Identity and the Politics of (re)presentation in the United States. Minneapolis: University of Minnesota Press, 1995.

Ochoa Fernández, María Luisa. "Mapping Hyphenation in Cuban-American Literature.” St. John's University Humanities Review. Volume 8.1. (Fall 2009): 13-26.

O’Reilly Herrera, Andrea. “Women and the Revolution in Cristina García’s Dreaming in Cuban”. Modern Language Studies. Vol. 27, No. 3/4 (Autumn - Winter, 1997): 69-91. 
Otheguy, Ricardo, García, Ofelia, and Roca, Ana. “Speaking in Cuban” In New Immigrants in the United States: Readings for Second Language Educators. Eds. Sandra McKay, and Sau-ling C. Wong. Cambridge, U.K: Cambridge University Press, 2000. 165-88.

Pérez-Firmat, Gustavo. “¿Existe una literatura cubano-americana?” Interview by José Plats Sariol. Aurora Boreal. January 12, 2014. Web. 10 Aug. 2014.

$<$ www.gustavoperezfirmat.com/gpf_interviews.php>.

---. “The Spell Of The Hyphen.” In Cuban American Literature and Art: Negotiating Identities. Eds. I. Álvarez-Borland and L.F. Bosch. Albany, NY: State U. of New York, 2009. 15-30.

---. Tongue Ties: Logo-eroticism in Anglo-Hispanic Literature. New York: Palgrave Macmillan, 2003.

---. “Trascender el exilio: la literatura cubano-american, hoy.” In Memorias recobradas. Ed. Ambrosio Fornet. Santa Clara: Editorial Capiro, 2000. 18-24.

---. “Triple Crown.” In A Century of Cuban Writers in Florida: Selected Prose and Poetry. Sarasota, Florida: Pineapple Press. 1996. 127.

Pérez, Rosario V. Hispanic Caribbean Literature of Migration: Narratives of Displacement. New York: Palgrave Macmillan, 2010.

Poplack, Shana. "Sometimes I'll start a sentence in Spanish Y TERMINO EN ESPAÑOL: Toward a typology of code-switching.” Linguistics 18 (7/8) (1980): 581-618.

Poyo, Gerald E. and Díaz-Miranda Mariano. "Cubans in the United States.” In Handbook of Hispanic Cultures in the United States: History. Eds. Weaver Thomas, Nicolás Kanellos, and Fabregat C. Esteva. Houston, Texas: Arte Público Press, 1994. 30220.

Ricourt, Milagros. Dominicans in New York City: Power from the Margins. New York: Routledge, 2002.

Rivero, Eliana. "Writing in Cuban, Living as Other: Cuban American Women Writers Getting It Right.” In Cuban-American Literature and Art. Negotiating Identities. Eds. Isabel Álvarez- Bordland and Lynette M.F. Bosch. Albany: State University of New York Press, 2009. 109-25.

---. “From Immigrants to Ethnics”. In Breaking Boundaries. Eds. A. Horno-Delgado [et al.]. Amherst: The University of Massachusetts Press, 1989. 189-200.

Rudin, Ernst. Tender Accents of Sound: Spanish in the Chicano Novel in English. Tempe, Arizona: Bilingual Press, 1996. 
Said, Edward W. Culture and Imperialism. London: Vintage. 1994.

Sánchez-González, Lisa. Boricua Literature: A Literary History of the Puerto Rican Diaspora. New York: New York University Press, 2001.

Santiago, Esmeralda. When I Was Puerto Rican. New York: Vintage Books, 1994.

---. “When I was Puerto Rican Title Question.” Online video clip. YouTube, 21 Nov. 2012. Web. 15 Apr. 2014.

Sollors, Werner. The Invention of Ethnicity. New York: Oxford University Press, 1988.

Soto-Crespo, Ramón E. Mainland Passage: The Cultural Anomaly of Puerto Rico. Minneapolis: University of Minnesota Press, 2009.

Sprouse, Keith Alan. "Between Bilingüe and Nilingüe: Language and the Translation of Identity in Esmeralda Santiago's Memoirs.” American Studies in Scandinavia 32:1 (2000): 107-16.

Stavans, Ilan. The Hispanic Condition: The Power of a People. New York: Rayo, 2001.

Thomas, Piri. Down These Mean Streets. New York: Knopf, 1967.

Tonn, Horst. “Bless Me, Ultima: Fictional Response to Times of Transition”. In Rudolfo Anaya. Focus on Criticism. Ed. César González. La Jolla: Lalo Press. 1990. 1-13.

Toribio, Almeida, Jacqueline. "Nosotros Somos Dominicanos: Language And SelfDefinition Among Dominicans.” Research on Spanish in the United States: Linguistic Issues and Challenges. Somerville, MA: Cascadilla, 2000. 252-70.

----. "Language Variation and the Linguistic Enactment of Identity Among Dominicans.” Linguistics. 38.6 (2000): 1133-1159.

Torres-Padilla José L. “When “I” became ethnic.” In Writing Off the Hyphen: New Perspectives on the Literature of the Puerto Rican Diaspora. Eds. J. TorresPadilla and C. H. Rivera. Seattle: University of Washington Press. 2008. 81-104.

Torres-Saillant, Silvio. Introduction to Dominican Blackness. New York, N.Y: CUNY Dominican Studies Institute, City College of New York, 1999.

---, and Ramona Hernández. The Dominican Americans. Westport, Conn: Greenwood Press, 1998.

---. “Dominican-American Literature”. The Routledge Companion to Latino/a Literature. Eds. Suzanne Bost and Frances R. Aparicio. New York: Routledge, 2013. 423-35. 
Wardhaugh, Ronald. An Introduction to Sociolinguistics. Oxford: Blackwell, 2002. 
VITA

MARIL YN ZELEDÓN

1998

B.A. Languages

Universidad Pedagógica Nacional

Bogotá, Colombia

2006

Certificate of Translation and Interpretation

Florida International University

Miami, Florida

2008

M.A. Lingusitics

Florida International University

Miami, Florida

2012

Doctoral Candidate in Spanish

Florida International University

Miami, Florida

- Teaching Assistant, Department of Modern Languages, Florida International University (2009-2015). Courses taught:

o SPN 4802 - Contrastive Syntax*

o SPT 3800 - Foundations of Translation*

o SPT 4820 - Computer-Aided Translation*

o SPT 4808 - Technical Translation*

o $\quad$ SPT 4807 - Business Translation*

o SPN 1130 - Spanish I

o SPN 1131 - Spanish II

o ENC 1101 - English Composition

* Courses developed and taught

- Research Assistant, Department of English, Florida International University (2006-2008)

- Adjunct Instructor, Florida International University (2008-2009) 